Algebraic and Graphic

Methods for Evaluating

Discordant Lead-Isotope

Ages

GEOLOGIGAL SURVEY PROFESSIONALPAPER 414-E

Prepared on behalf of the U.S.

Atomic Energy Commission 


\section{Algebraic and Graphic}

Methods for Evaluating

\section{Discordant Lead-Isotope}

\section{Ages}

By L. R. STIEFF, T. W. STERN, and R. N. EICHER

SHORTER CONTRIBUTIONS TO GENERAL GEOLOGY

GEOLOGICAL SURVEY PROFESSIONAL PAPER 414-E

Algebraic and graphic procedures for the calculation of a concordant age from discordant $\mathrm{Pb}^{206} / \mathrm{U}^{238}$, $\mathrm{Pb}^{207} / \mathrm{U}^{235}$, and $\mathrm{Pb}^{207} / \mathrm{Pb}^{206}$ age data using one to three samples. Prepared on behalf of the U.S. Atomic Energy Commission

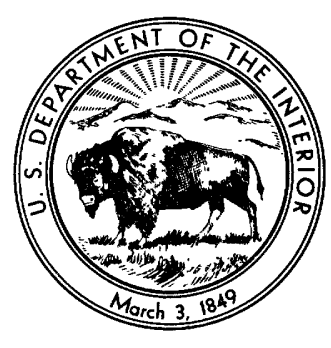




\section{UNITED STATES DEPARTMENT OF THE INTERIOR \\ STEWART L. UDALL, Secretary \\ GEOLOGICAL SURVEY \\ Thomas B. Nolan, Director}

For sale by the Superintendent of Documents, U.S. Government Printing Office Washington 25, D.C. 


\section{CONTENTS}

Abstract

Introduction

Previous work

Graphic methods.

Algebraic methods

Method based on expansion of $e^{x}$

Calculation of concordant ages

One sample $\ldots$

Radiogenic $\mathrm{Pb}^{207} / \mathrm{Pb}^{206}$ ratio given

Common $\mathrm{Pb}^{207} / \mathrm{Pb}^{206}$ ratio given

Two samples.

Amount of contaminating radiogenic lead and its $\mathrm{Pb}^{207} / \mathrm{Pb}^{206}$ ratio unknown

Amount of contaminating common lead and its $\mathrm{Pb}^{207} / \mathrm{Pb}^{206}$ ratio unknown

Amount of contaminating radiogenic and common lead and the $\mathrm{Pb}^{207} / \mathrm{Pb}^{206} \mathrm{ratio}$ unknown

Three samples_...

Amount and $\mathrm{Pb}^{207} / \mathrm{Pb}^{206}$ ratios of contaminating common and radiogenic lead unknown

General equations....

References cited

\section{ILLUSTRATIONS}

FIgURE 1. Ratios of the number of atoms of $\mathrm{Pb}^{207}$ to $\mathrm{Pb}^{204}, N_{207} / N_{204}$, plotted against the ratios of the number of atoms of $\mathrm{Pb}^{206}$ to $\mathrm{Pb}^{204}, N_{206} / N_{204} \ldots$

2. Ratios of the number of atoms of radiogenic $\mathrm{Pb}^{207}$ to $\mathrm{U}^{235}, N_{207} / N_{235}$, plotted against the ratios of the number of atoms of radiogenic $\mathrm{Pb}^{206}$ to $\mathrm{U}^{238}, \mathrm{~N}_{206} / N_{238}$

3. Ratios of the total number of atoms of $\mathrm{Pb}^{207}$ to $\mathrm{U}^{235},{ }^{t} N_{207} / N_{235}$, plotted against the ratio of the total number of atoms of $\mathrm{Pb}^{206}$ to $\mathrm{U}^{238},{ }^{t} N_{206} / N_{238}$

4. Normalized difference ratios for two uranium-bearing samples contaminated by the same common lead, and which were altered or contaminated by an older radiogenic lead.

\section{TABLES}

TABLE 1. Letter symbols used in evaluating discordant lead-isotope ages.

2. Factors for use with equations of the second degree

3-8. Computed concordant ages obtained-

3. From equation 12

4. From equation 17

From equation 22

From equation 26

7. From equation 35

From equation 39 



\title{
ALGEBRAIC AND GRAPHIC METHODS FOR EVALUATING DISCORDANT LEAD-ISOTOPE AGES
}

\author{
By L. R. Stieff, T. W. Stern, and R. N. Eicher
}

\begin{abstract}
The calculated lead-isotope ages of many uranium-bearing minerals yield the following discordant age sequence: $\mathrm{Pb}^{206} /$ $\mathrm{U}^{238}<\mathrm{Pb}^{207} / \mathrm{U}^{235}<<\mathrm{Pb}^{207} / \mathrm{Pb}^{206}$. In the literature these and the reverse discordant lead-isotope age sequences are usually attributed to loss or gain of lead or uranium or an intermediate uranium daughter product. An alternative interpretation, generally not stressed, is that this failure of the lead-uranium and lead-lead ages to agree may also be a consequence of the deposition of an older generation of radiogenic $\mathrm{Pb}^{207}$ and $\mathrm{Pb}^{206}$ at the time of formation of the uranium-bearing mineral. Also, the calculated lead-isotope ages of many uranium- and thoriumbearing minerals yield $\mathrm{Pb}^{208} / \mathrm{Th}^{232}$ ages which are less than the lead-uranium and lead-lead ages obtained on the same sample. The usefulness of the $\mathrm{Pb}^{208} / \mathrm{Th}^{232}$ age has been reduced because of the difficulties encountered in evaluating these age discrepancies.

Graphic solutions for the discordant lead-uranium age problem
\end{abstract} that are available in the literature have been amplified and extended to cover corrections for common lead without using either $\mathrm{Pb}^{204}$ or $\mathrm{Pb}^{208}$ as the common-lead index. Where isotope studies have been made on two or three samples of the same age and from the same deposit or formation, a new graphical procedure using the index isotope is presented that will yield concordant ages corrected for both lead loss and original radiogenic lead. These concordant ages may be obtained without knowledge of either the amounts or the isotopic compositions of the contaminating common lead, the $\mathrm{Pb}^{207} / \mathrm{Pb}^{206}$ ratio of original radiogenic lead, or the extent of past or recent alteration if original radiogenic lead is not present.

A new set of age equations has also been developed which permit algebraic solutions of the problems of original radiogenic lead and lead loss that are equivalent to the solutions obtained graphically. The derivation of these equations may also be considered as proof of the graphical constructions. A table of factors is provided in order that either exact lead-loss or original radiogenic lead solutions may be obtained from the age equations expanded only to the second degree. The general form of these new age equations is also given for programing on computing machines. The latter equations give both the concordant ages corrected for original radiogenic lead and for loss of lead. Both the graphic and algebraic solutions are applicable to the discordant thorium-uranium age problem.

The algebraic and graphic treatments of discordant leadisotope ages define both the type and minimum number of samples necessary for adequate mathematical analysis of the problem. This mathematical treatment also makes it clear that discordant lead-isotope age data alone cannot provide the basis for the choice of an age corrected for loss of lead or old radio- genic lead. The most reasonable age can be selected only after careful consideration of independent geochronologic data as well as field, stratigraphic, and paleontologic evidence, and the petrographic and paragenetic relations.

\section{INTRODUCTION}

Uranium-bearing minerals that give lead-uranium and lead-lead ages that are essentially in agreement, that is, concordant, generally are considered to have had a relatively simple geologic history and to have been unaltered since their deposition. The concordant ages obtained on such materials are, therefore, assumed to approach closely the actual age of the minerals. Many uranium-bearing samples, particularly uranium ores, give the following discordant age sequences: $\mathrm{Pb}^{206} / \mathrm{U}^{238}<\mathrm{Pb}^{207} / \mathrm{U}^{235}<<\mathrm{Pb}^{207} / \mathrm{Pb}^{206}$ or, less frequently, $\mathrm{Pb}^{207} / \mathrm{Pb}^{206}<<\mathrm{Pb}^{207} / \mathrm{U}^{235}<\mathrm{Pb}^{206} / \mathrm{U}^{238}$. In an effort to evaluate a discordant age sequence, therefore, the data are adjusted in one of several ways, either numerically or graphically, until the lead-uranium and lead-lead ages are in agreement. This is done in the belief that one of the recalculated concordant ages will more nearly approach the true age of the mineral. Thus, the criterion of concordance underlies the mathematical analysis of the observed age discrepancy and requires assumptions concerning the different processes which could have produced the age discordancies.

Unfortunately, the first discordant age sequence may be explained equally well by the continuous selective loss of one or more radioactive daughter products, by loss of radiogenic lead or additions of uranium at one time in the history of the minerals, or by initial contamination by relatively small amounts of an older generation of radiogenic lead. The reverse age sequence can be interpreted as evidence for loss of uranium, addition of lead, or initial contamination by relatively large amounts of an older radiogenic lead. Accidental concordance may occur either as a result of contamination by large amounts of an older generation of radiogenic lead, or as a result of processes of leaching and alteration in which compensating amounts of lead and uranium have been added or removed. 
The evaluation of discordant lead-isotope age data may be separated into two operations. The first operation, with which this report is concerned, is mechanical in nature and involves the calculation of the different possible concordant ages corresponding to the various processes assumed to have produced the discordant ages. Present methods for making concordant numerical solutions of discordant lead-isotope age data are both tedious and difficult. Existing graphic solutions also have their limitations. This report includes a brief review of the literature on the graphical procedures used in the analysis of discordant age data and presents a new and more generalized graphical treatment of this problem. In addition, a new set of algebraic equations equivalent to these new graphic solutions is included. These equations permit relatively simple numerical calculation of the different and equally probable concordant ages. The letter symbols used throughout the report in presenting and analyzing the discordant age data are listed in table 1.

TABLE 1.-Letter symbols used in evaluating discordant lead-isotope ages

\begin{tabular}{|c|c|}
\hline Symbol & Explanation \\
\hline & Number of atoms of $\mathrm{Pb}^{206}, \mathrm{U}^{238}$, and so on \\
\hline$R^{*}$ & $\begin{array}{l}\text { Ratio of the number of atoms of radiogenic } \\
\mathrm{Pb}^{207} \text { to radiogenic } \mathrm{Pb}^{208}\end{array}$ \\
\hline$R^{c}$ - & $\begin{array}{l}\text { Ratio of the number of atoms of } \mathrm{Pb}^{207} \text { to } \mathrm{Pb}^{206} \\
\text { in common lead }\end{array}$ \\
\hline$R_{-}$ & $\begin{array}{l}\text { Present-day ratio of the number of atoms of } \\
\mathrm{U}^{235} \text { to } \mathrm{U}^{238}, 0.007262\end{array}$ \\
\hline$t_{m-}$ & $\begin{array}{l}\text { Corrected concordant age of mineral. See } \\
\text { equation } 3\end{array}$ \\
\hline & Decay constant \\
\hline & Age \\
\hline & $\begin{array}{l}\text { Number of atoms of daughter products } \\
\text { Number of atoms of parent }\end{array}$ \\
\hline & $\begin{array}{l}\text { Difference between two-term expansion of } \\
e^{\lambda t_{1}} \text { and the actual value of } e^{\lambda t_{1}} \text { for a partic- } \\
\text { ular value of } t_{1} \text {, used for the } \mathrm{U}^{238} \text { series }\end{array}$ \\
\hline$f_{2-\ldots-1}$ & $\begin{array}{l}\text { Difference between two-term expansion of } \\
e^{\lambda t_{2}} \text { and the actual value of } e^{\lambda} t_{2} \text { for a partic- } \\
\text { ular value of } t_{2} \text {, used for the } U^{235} \text { series }\end{array}$ \\
\hline$N_{6-}$ & $\begin{array}{l}\text { Number proportional to the total number of } \\
\text { radiogenic } \mathrm{Pb}^{206} \text { atoms }\end{array}$ \\
\hline$N_{6} * \ldots$ & $\begin{array}{l}\text { Number proportional to the number of original } \\
\text { radiogenic } \mathrm{Pb}^{206} \text { atoms }\end{array}$ \\
\hline & $N^{t h}$ power \\
\hline & $\begin{array}{l}\text { Number proportional to the total number of } \\
\mathrm{Pb}^{206} \text { atoms present }\end{array}$ \\
\hline & Ratio of ${ }^{t} N_{7}$ to $N_{5}$ \\
\hline & Ratio of ${ }^{t} N_{6}$ to $N_{8}$ \\
\hline$R_{5 a-}$ & $\begin{array}{l}\text { Ratio of the number of radiogenic } \mathrm{Pb}^{207} \text { atoms, } \\
N_{7 a} \text {, to the number of } \mathrm{U}^{235} \text { atoms, } N_{5 a} \text {, now } \\
\text { present in sample } A\end{array}$ \\
\hline
\end{tabular}

It is evident, however, that in the first operation no amount of mathematical manipulation of the discordant age data will, in itself, provide the basis for the choice of the most probable age. The choice of one of the equally possible recalculated concordant ages can be made only on the basis of additional evidence. The second operation, therefore, consists of testing the validity of these recalculated concordant ages in terms of the geologic history of the area; the geologic age relation of the enclosing rock; the petrographic, paragenetic, and mineralogic data on the uranium-bearing minerals being studied; the probable sources of the uranium and contaminating lead; the isotopic composition of lead in the associated nonradioactive minerals; and other independent age measurements which are considered to be reliable. In the event that available geologic evidence is equivocal, either the alternative concordant age solutions should be presented as equally possible or, following a clear statement of the investigator's own prejudice, a preference stated for one of the concordant ages.

General papers on the interpretation of discordant lead-isotope ages have been published by Kulp and others (1954), Ahrens (1955a, b), Wetherill (1956), Stieff and Stern (1956), Kulp and Eckelmann (1957), Aldrich and Wetherill (1958), and Stieff and Stern (1961). Explanations of discordant isotopic age data using the radon-loss hypothesis have been published by Wickman (1942), Robinson (1955), Louw and Strelow (1955), Giletti and Kulp (1955), and Greenhalgh and Jeffery (1959). Interpretations of discordant age sequences using the lead-loss hypothesis have been published by Collins and others (1954), Eckelmann and Kulp (1956), and Gerling (1958). Horne and Davidson (1955) have suggested a hypothesis based on multiple periods of uranium deposition to explain the age anomalies found for a single specimen of uraninite concentrate from the Witwatersrand. Tilton (1960) has proposed continuous diffusion of lead as an explanation for discordant lead-isotope ages. Attempts to interpret the discrepancies between the lead-uranium and lead-lead ages on the basis of contamination by an older generation of radiogenic lead have been made by Stieff and others (1953), Tugarinov (1954), and more recently by Horne (1957 a, b).

This work was part of a program conducted by the U.S. Geological Survey on behalf of the Division of Research, U.S. Atomic Energy Commission.

\section{PREVIOUS WORK GRAPHIC METHODS}

Perhaps the simplest graphical treatment of the regularity in lead-isotope data was suggested by Houtermans (1946, 1947). In an analysis of the natural variation in isotopic composition of common lead he plotted the atom or mole ratios of $\mathrm{Pb}^{207} / \mathrm{Pb}^{204}$ $\left(N_{207} / N_{204}\right)$ against similar ratios of $\mathrm{Pb}^{206} / \mathrm{Pb}^{204}$ $\left(N_{206} / N_{204}\right)$. (See fig. 1A.) In graphs of this type or 


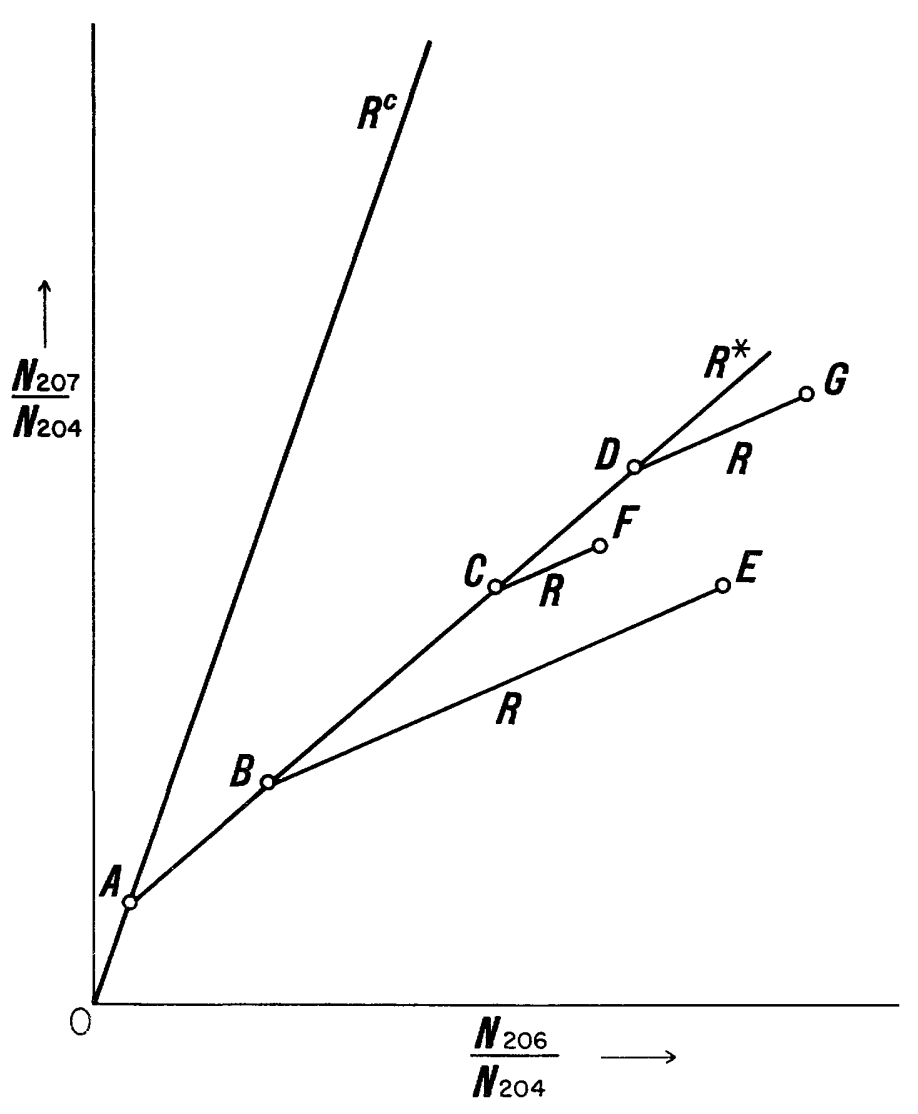

A

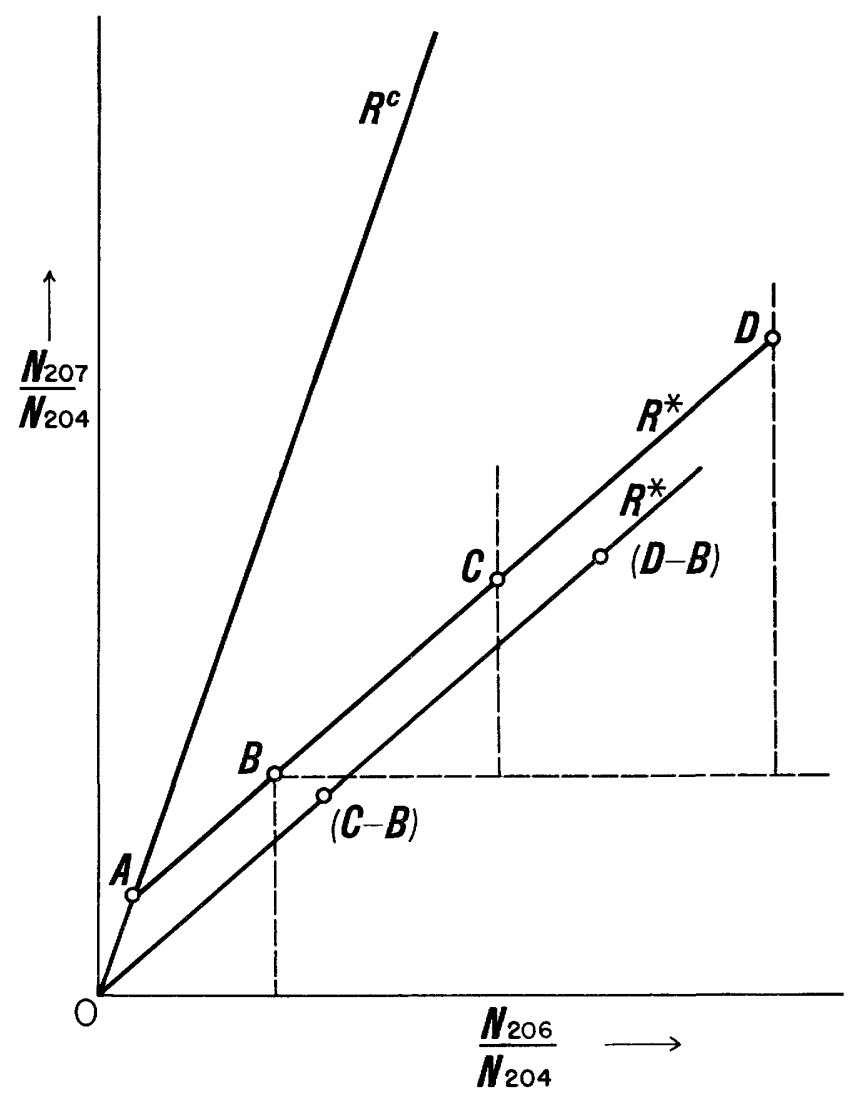

$B$

Figdre 1.-Ratios of the number of atoms of $\mathrm{Pb}^{207}$ to $\mathrm{Pb}^{204}, N_{207} / N_{204}$, plotted against the ratios of the number of atoms of $\mathrm{Pb} 206$ to $\mathrm{Pb} 204, N_{206} / N_{204}$. $A$, Two and three component lead mixtures. $B$, Two component lead mixtures and their difference plots.

in graphs of $\mathrm{Pb}^{207} / \mathrm{Pb}^{208}$ versus $\mathrm{Pb}^{206} / \mathrm{Pb}^{208}$ (where thorium has not contributed radiogenic $\mathrm{Pb}^{208}$ ), the mixture of a single common lead, $A$, having uniform $N_{207} / N_{204}$ and $N_{206} / N_{204}$ ratios, with varying amounts (points $B, C$, and $D$ ) of a single radiogenic lead of uniform $\mathrm{Pb}^{207} / \mathrm{Pb}^{206}$ ratio, $R^{*}$, will lie on a straight line. These straight lines were called isochrones by Houtermans and the slope of the isochrones passing through these points is the $\mathrm{Pb}^{207} \mathrm{~Pb}^{206}$ ratio of the added radiogenic lead.

It is apparent from figure 1 that, if isotopic data are available for at least two radiogenically enriched samples, such as $B$ and $C$, resulting from the mixture of only two components, $R^{c}$ and $R^{*}$, the $\mathrm{Pb}^{207} / \mathrm{Pb}^{206}$ ratio of the added radiogenic lead, $R^{*}$, may be obtained from the slope of the line passing through $B$ and $C$. Knowledge of the isotopic composition of the contaminating common lead, $A$, is not necessary. If the two components consist of the radiogenic lead produced by uranium-bearing minerals and its contaminating common lead, it follows that the slope of the line passing through the plotted points of the two samples will give the $\mathrm{Pb}^{207} / \mathrm{Pb}^{206}$ age of the samples. The quantitative amounts of lead and uranium do not appear in these graphs; therefore, this age is independent of either recent loss or gain of lead or uranium. It is assumed, however, that isotopic fractionation of $\mathrm{Pb}^{206}$ and $\mathrm{Pb}^{207}$ does not occur as a result of the chemical processes of alteration.

Figure $1 A$ shows that the addition of varying amounts of a third radiogenic component whose $\mathrm{Pb}^{207} / \mathrm{Pb}^{206}$ ratio, $R$, will give points $E, F$, and $G$, for which no simple linear relation can be derived. The graphical presentation of the three component mixtures $\left(R^{c}, R^{*}\right.$, and $R$ ) is typical of all discordant age sequences not produced by recent gain or loss of lead or uranium. The absence of any systematic relations between three or more samples, each of which contains a mixture of three different leads, suggests that additional data, perhaps the quantitative amounts of lead and uranium in the sample, may be required before a unique solution can be obtained.

In figure $1 B$, the differences between the coordinates for samples $(C$ minus $B)$ and $(D$ minus $B$ ) are plotted. These difference points for the two component mixtures, $R^{c}$ and $R^{*}$, must also lie on a straight line passing through the origin. The slope of this line, $R^{*}$, is equal to the slope of the line passing through the original 
points $B, C$, and $D$. This analytical relation is mentioned here to simplify the presentation of some of the graphical procedures which follow.

Ahrens (1955b) noted the linear relations that are obtained in plots of the ratios of radiogenic $N_{207} / N_{235}$ against radiogenic $N_{206} / N_{233}$ among related samples giving discordant age sequences. Wetherill (1956) developed Ahrens' suggestion into a rigorous graphical analysis of discordant lead-uranium ages resulting from multiple episodes of lead-uranium fractionation. The mathematical proofs of the properties of these ratio plots presented by Wetherill are not easy to follow, whereas the discussion of the concordia plots by Russell and Ahrens (1957) is quite brief. A relatively simple proof has been presented by Stieff and Stern (1961).

Finally, to Ahrens' plot of the mole ratios of $N_{207} / N_{235}$ versus $N_{206} / N_{238}$ Wetherill added a curve which he called concordia. (See fig. 2A.) Within this graph the coordinates of all points may be given by a $\mathrm{Pb}^{207} /$ $\mathrm{U}^{235}$ and a $\mathrm{Pb}^{206} / \mathrm{U}^{238}$ age equivalent to the two ratios, $N_{207} / N_{235}$ and $N_{208} / N_{233}$. The curve, concordia, is the locus of all points having equal $\mathrm{Pb}^{207} / \mathrm{U}^{235}$ and $\mathrm{Pb} b^{206} / \mathrm{U}^{238}$ ages. Thus, a plot of the $N_{207} / N_{235}$ and $N / 206 N_{238}$ ratios of any sample falling on this curve is, by definition, concordant, that is, the $\mathrm{Pb}^{206} / \mathrm{U}^{238}$ age $=\mathrm{Pb}^{207} / \mathrm{U}^{235}$ age $=$ the $\mathrm{Pb}^{207} / \mathrm{Pb}^{206}$ age. Conversely, any point not lying on this curve must represent a discordant age sequence. It should be stressed that before it is possible to use a graph of this type, it is first necessary to make a correction for the contaminating common lead because the values $N_{207}$ and $N_{206}$ represent only the radiogenic remainders. In those age calculations in which the common lead corrections are significant but have been incorrectly made, a discordant age sequence will result that is indistinguishable from those produced by the other causes already mentioned.

\section{ALGEBRAIC METHODS}

To the author's knowledge, only one published algebraic solution has been proposed for the originalradiogenic-lead problem. The lead-uranium isotope age equations originally derived by Keevil (1939),

and

$$
t_{(\mathrm{yrg})}=1.515 \times 10^{10} \log \left(\frac{1.15 \mathrm{~Pb}^{206}}{\mathrm{U}^{238}}+1\right)
$$

$$
t_{(\mathrm{yrg})}=2.37 \times 10^{9} \log \left(\frac{158 \mathrm{~Pb}^{207}}{\mathrm{U}^{238}}+1\right)
$$

were modified by Tugarinov (1954) to include corrections for original radiogenic lead. The suggested modifications took the form of the following system of equations:

$$
\begin{aligned}
& 15.15 \times 10^{9} \log \left[\frac{1.158\left(\mathrm{~Pb}^{206}-x \mathrm{~Pb}^{200^{*}}\right)}{\mathrm{U}}+1\right] \\
& =2.37 \times 10^{9} \log \left[\frac{159.6\left(\mathrm{~Pb}^{207}-x \mathrm{~Pb}^{207^{*}}\right)}{\mathrm{U}}+1\right]=t_{m}
\end{aligned}
$$

where $\mathrm{Pb}^{206 *}$ and $\mathrm{Pb}^{207 *}$ are the percent abundances of the original radiogenic lead, $x$ is the percentage of the occluded original radiogenic lead in the uraniumbearing material, and $t_{m}$ is the corrected concordant age of the mineral.

Tugarinov's age equations, because of their log form, cannot be solved for $x$, the amount of original radiogenic lead present. In addition, it is necessary to know independently the $\mathrm{Pb}^{207} / \mathrm{Pb}^{206}$ ratio of the original radiogenic lead. Given $\mathrm{Pb}^{206 *}$ and $\mathrm{Pb}^{207 *}$, repeated substitutions of different values for $x$ must be made until a value of $x$ is found which will make the $\mathrm{Pb}{ }^{206} / \mathrm{U}^{238}$ age equal to the $\mathrm{Pb}^{207} / \mathrm{U}^{235}$ age. The $\mathrm{Pb}^{207} / \mathrm{Pb}^{206}$ age corrected for the same amounts of original radiogenic lead will then be in agreement with the two leaduranium ages.

\section{METHOD BASED ON EXPANSION OF $e^{x}$}

Although it is not difficult to obtain an approximately concordant age from discordant isotopic leaduranium data by the graphical methods discussed above, there are geologic problems for which the exact algebraic solutions may be preferred. Furthermore, as Aldrich and Wetherill (1958) have noted, "*** the algebraic expressions involved are frequently so complex that it is difficult to visualize the physical processes [Wetherill (1956) and Wickman (1955)]." Finally, practical algebraic solutions provide an incentive to improve the measurement of the physical decay constants used in age calculations, the analytical techniques, and sampling methods in order that we may derive all of the useful geologic information that is available in a comprehensive lead-isotope age study. For these reasons, a set of algebraic expressions have been derived which are exact equivalents of the graphical procedures described by Stieff and Stern (1961). In these equations the role of the possible geologic processes can be visualized and it is possible to obtain as exact a concordant age solution as is required by the specific geologic problem.

An alternative approach to Tugarinov's algebraic solution of the problem of original radiogenic lead may be developed by using a series expansion of the exponential term in the general age equation where:

$$
e^{\lambda \imath}=N_{d} / N_{p}+1
$$

and where $N_{d}$ and $N_{p}$ represent the number of atoms of 
daughter product, $D$, and radioactive parent, $P$, respectively; $\lambda$ represents the decay constant in reciprocal years times $10^{-10}$, and $t$, the age, in $10^{10}$ years equivalent to the atom ratio $N_{d} / N_{p}$. The value $e^{\lambda t}$ may be approximated as closely as desired by the following series

$$
e^{\lambda t}=1+\lambda t+\frac{(\lambda t)^{2}}{2 !}+\frac{(\lambda t)^{3}}{3 !} \ldots+\frac{(\lambda t)^{n}}{n !} .
$$

Substituting this series for $e^{\lambda t}$, the age equation 4 may be written in the form

$$
\lambda t+\frac{(\lambda t)^{2}}{2 !}+\frac{(\lambda t)^{3}}{3 !} \ldots+\frac{(\lambda t)^{n}}{n !}=N_{d} / N_{p}
$$

For values of $t$ that are less than 250 million years, equation 5 may be carried only to the second term without introducing serious errors. As $t$ increases, however, it is necessary either to include a larger number of terms in the expansion of $e^{\lambda t}$ and to work with equations of higher degree than two or to include an additional factor, $f_{1}$ or $f_{2}$, which may be obtained from table 2 .

$$
N_{d} / N_{p}=\frac{(\lambda t)^{2}}{2}+\lambda t+f_{(1,2)}
$$

This factor $f_{(1,2)}$ represents, for a number of values of $t_{1}$, the difference between the two-term expansion of $e^{\lambda t_{1}}$ for the $\mathrm{U}^{238}$ series, $f_{1}$, and for the $\mathrm{U}^{235}$ series, $f_{2}$, and the actual value of $e^{\lambda t_{1}}$ for the particular value of $t_{1}$. The decision to use equation 5 or 6 will be determined by the requirements of the specific geologic age problem, and by the section of the geologic time scale involved in the age calculations.

In the use of the second order equations, the selection of the initial age, $t_{1}$, can be guided by the extent and type of discordant age sequences obtained in the trial age calculations. To calculate the age corrected for old radiogenic lead, the initial age $t_{1}$ and the corresponding values of $f_{1}$ and $f_{2}$ from the table of factors are chosen so that $t_{1}$ is less than or equal to the trial $\mathrm{Pb}^{206} / \mathrm{U}^{238}$ age. A selection of $t_{1}$ equal to or greater than the $\mathrm{Pb}^{207} / \mathrm{Pb}^{206}$ trial age will yield calculated ages corrected for loss or gain of lead or uranium. Should the nature of the geologic problem require a further refinement in the first calculated age, a second choice of $t_{1}$ based on the first calculated age, $t$, can be made. With experience in the initial choice of $t_{1}$, it has been found that two age calculations will usually suffice

\begin{tabular}{|c|c|c|c|c|c|}
\hline$\underset{\text { years) }}{\stackrel{t_{1}}{t_{1}}}$ & $\begin{array}{c}\text { U283 series } \\
f_{1}\end{array}$ & $\begin{array}{c}U^{236} \text { series } \\
f_{2}\end{array}$ & $\underset{\text { (millions of }}{t_{1}}$ & $\begin{array}{c}\text { U238 series } \\
f_{1}\end{array}$ & $\begin{array}{c}\text { U236 series } \\
f_{2}\end{array}$ \\
\hline $\begin{array}{r}0 \\
20 \\
40 \\
60 \\
80\end{array}$ & $\begin{array}{r}0.00000 \\
.00000 \\
.00000 \\
.00000 \\
.0000_{0}\end{array}$ & $\begin{array}{r}0.0000_{0} \\
.0000_{0} \\
.0000_{1} \\
.0000_{3} \\
.0000_{8}\end{array}$ & $\begin{array}{l}900 \\
910 \\
920 \\
930 \\
940\end{array}$ & $\begin{array}{r}0.0004_{0} \\
.00047 \\
.00049 \\
.00050 \\
.00052\end{array}$ & $\begin{array}{r}0.1410_{2} \\
.14619 \\
.1514_{8} \\
.1569_{1} \\
.1624_{8}\end{array}$ \\
\hline $\begin{array}{l}100 \\
120 \\
140 \\
160 \\
180\end{array}$ & $\begin{array}{l}.0000_{0} \\
.00000_{0} \\
.00000_{0} \\
.00000_{0} \\
.0000_{0}\end{array}$ & $\begin{array}{l}.0001_{6} \\
.00027 \\
.0004_{3} \\
.00066_{5} \\
.0009_{3}\end{array}$ & $\begin{array}{l}950 \\
960 \\
970 \\
980 \\
990\end{array}$ & $\begin{array}{l}.0005_{4} \\
.0005_{6} \\
.0005_{7} \\
.0005_{9} \\
.0006_{1}\end{array}$ & $\begin{array}{l}.16819 \\
.1740_{4} \\
.1800_{4} \\
.18619 \\
.1924_{9}\end{array}$ \\
\hline $\begin{array}{l}200 \\
210 \\
220 \\
230 \\
240\end{array}$ & $\begin{array}{l}.0000_{0} \\
.00000_{1} \\
.0000_{1} \\
.00000_{1} \\
.0000_{1}\end{array}$ & $\begin{array}{l}.0012_{8} \\
.00144_{9} \\
.0017_{2} \\
.0019_{7} \\
.0022_{4}\end{array}$ & $\begin{array}{l}1000 \\
1010 \\
1020 \\
1030 \\
1040\end{array}$ & $\begin{array}{l}.0006_{3} \\
.0006_{5} \\
.0006_{7} \\
.0006_{9} \\
.0007_{1}\end{array}$ & $\begin{array}{l}.1989_{3} \\
.20554 \\
.2123_{1} \\
.21923 \\
.2263_{2}\end{array}$ \\
\hline $\begin{array}{l}250 \\
260 \\
270 \\
280 \\
290\end{array}$ & $\begin{array}{l}.0000_{1} \\
.00000_{1} \\
.0000_{1} \\
.00000_{1} \\
.0000_{1}\end{array}$ & $\begin{array}{l}.0025_{4} \\
.00288_{7} \\
.0032_{2} \\
.0036_{0} \\
.0040_{1}\end{array}$ & $\begin{array}{l}1050 \\
1060 \\
1070 \\
1080 \\
1090\end{array}$ & $\begin{array}{l}.0007_{3} \\
.0007_{5} \\
.0007_{7} \\
.0008_{0} \\
.0008_{2}\end{array}$ & $\begin{array}{l}.2335_{7} \\
.24209_{9} \\
.2485_{8} \\
.2563_{4} \\
.2642_{3}\end{array}$ \\
\hline $\begin{array}{l}300 \\
310 \\
320 \\
330 \\
340\end{array}$ & $\begin{array}{l}.0000_{2} \\
.00002_{2} \\
.0000_{2} \\
.00000_{2} \\
.0000_{2}\end{array}$ & $\begin{array}{l}.0044_{5} \\
.0049_{2} \\
.0054_{3} \\
.0059_{7} \\
.0064_{4}\end{array}$ & $\begin{array}{l}1100 \\
1110 \\
1120 \\
1130 \\
1140\end{array}$ & $\begin{array}{l}.0008_{4} \\
.0008_{6} \\
.0008_{9} \\
.0009_{1} \\
.0009_{3}\end{array}$ & $\begin{array}{l}.27239 \\
.28069 \\
.28918 \\
.29784 \\
.30670\end{array}$ \\
\hline $\begin{array}{l}350 \\
360 \\
370 \\
380 \\
390\end{array}$ & $\begin{array}{l}.0000_{3} \\
.00000_{3} \\
.00003_{3} \\
.00000_{3} \\
.0000_{4}\end{array}$ & $\begin{array}{l}.0071_{6} \\
.0078_{1} \\
.0085_{0} \\
.0092_{4} \\
.0100_{1}\end{array}$ & $\begin{array}{l}1150 \\
1160 \\
1170 \\
1180 \\
1190\end{array}$ & $\begin{array}{l}.0009_{6} \\
.0009_{9} \\
.0010_{2} \\
.0010_{4} \\
.0010_{7}\end{array}$ & $\begin{array}{l}.3157_{4} \\
.3429 \\
.3344_{3} \\
.340_{7} \\
.3539_{2}\end{array}$ \\
\hline $\begin{array}{l}400 \\
410 \\
420 \\
430 \\
440\end{array}$ & $\begin{array}{c}.0000_{4} \\
.00000_{4} \\
.0000_{5} \\
.00000_{5} \\
.0000_{5}\end{array}$ & $\begin{array}{r}.0108_{3} \\
.0116_{9} \\
.0126_{0} \\
.0135_{8} \\
.0145_{8}\end{array}$ & $\begin{array}{l}1200 \\
1210 \\
1220 \\
1230 \\
1240\end{array}$ & $\begin{array}{l}.0011_{0} \\
.0011_{2} \\
.0011_{5} \\
.0011_{8} \\
.0012_{1}\end{array}$ & $\begin{array}{l}.3639_{6} \\
.37422 \\
.3846_{9} \\
.39538 \\
.4062_{8}\end{array}$ \\
\hline $\begin{array}{l}450 \\
460 \\
470 \\
480 \\
490\end{array}$ & $\begin{array}{l}.0000_{0} \\
.00000_{6} \\
.00000_{0} \\
.00007 \\
.0000_{7}\end{array}$ & $\begin{array}{l}.0156_{2} \\
.01673 \\
.0178_{8} \\
.0191_{1} \\
.02038\end{array}$ & $\begin{array}{l}1250 \\
1260 \\
1270 \\
1280 \\
1290\end{array}$ & $\begin{array}{l}.0012_{4} \\
.0012_{7} \\
.0013_{0} \\
.0013_{4} \\
.0013_{7}\end{array}$ & $\begin{array}{l}.4174_{0} \\
.4287_{6} \\
.44033 \\
.4521_{4} \\
.4641 \mathrm{~s}\end{array}$ \\
\hline $\begin{array}{l}500 \\
510 \\
520 \\
530 \\
540\end{array}$ & $\begin{array}{l}.0000_{3} \\
.00000 \\
.00009 \\
.00000_{0} \\
.0001_{0}\end{array}$ & $\begin{array}{l}.0217_{1} \\
.0231_{0} \\
.0245_{5} \\
.0260_{0} \\
.0276_{4}\end{array}$ & $\begin{array}{l}1300 \\
1320 \\
1340 \\
1360 \\
1380\end{array}$ & $\begin{array}{l}.0014_{0} \\
.0014_{7} \\
.0015_{4} \\
.0016_{0} \\
.0016_{8}\end{array}$ & $\begin{array}{l}.4764_{6} \\
.5017 \mathrm{~s} \\
.5279_{9} \\
.55552_{6} \\
.5835_{8}\end{array}$ \\
\hline $\begin{array}{l}550 \\
560 \\
570 \\
580 \\
590\end{array}$ & $\begin{array}{l}.0001_{0} \\
.0001_{1} \\
.00011_{1} \\
.0001_{2} \\
.0001_{3}\end{array}$ & $\begin{array}{l}.0292_{8} \\
.0309_{9} \\
.03276 \\
.0346_{1} \\
.0365_{3}\end{array}$ & $\begin{array}{l}1400 \\
1420 \\
1440 \\
1460 \\
1480\end{array}$ & $\begin{array}{l}.0017_{5} \\
.0018_{3} \\
.0019_{1} \\
.0020_{0} \\
.0020_{3}\end{array}$ & $\begin{array}{l}.6129_{6} \\
.64334_{4} \\
.6750_{4} \\
.7078_{1} \\
.7417_{5}\end{array}$ \\
\hline $\begin{array}{l}600 \\
610 \\
620 \\
630 \\
640\end{array}$ & $\begin{array}{l}.0001_{3} \\
.00011_{4} \\
.0001_{5} \\
.00011_{6} \\
.0001_{6}\end{array}$ & $\begin{array}{r}.0385_{2} \\
.04058 \\
.0427_{3} \\
.0449_{5} \\
.0472_{5}\end{array}$ & $\begin{array}{l}1500 \\
1520 \\
1540 \\
1560 \\
1580\end{array}$ & $\begin{array}{l}.0021_{7} \\
.0022_{6} \\
.0023_{5} \\
.0024_{4} \\
.0025_{4}\end{array}$ & $\begin{array}{l}.77690 \\
.81332 \\
.8510_{0} \\
.89000 \\
.93034\end{array}$ \\
\hline $\begin{array}{l}650 \\
660 \\
670 \\
680 \\
690\end{array}$ & $\begin{array}{l}.00017 \\
.00018 \\
.00019 \\
.00020 \\
.00020\end{array}$ & $\begin{array}{l}.04963 \\
.05210 \\
.05464 \\
.05728 \\
.0600_{1}\end{array}$ & $\begin{array}{l}1600 \\
1620 \\
1640 \\
1660 \\
1680\end{array}$ & $\begin{array}{l}.0026_{4} \\
.0027_{4} \\
.0028_{5} \\
.0029_{8} \\
.0030_{7}\end{array}$ & $\begin{array}{l}.9720_{6} \\
1.015_{2} \\
1.059_{8} \\
1.1058 \\
1.1534\end{array}$ \\
\hline $\begin{array}{l}700 \\
710 \\
720 \\
730 \\
740\end{array}$ & $\begin{array}{l}.0002_{1} \\
.00022_{2} \\
.00022_{3} \\
.0002_{4} \\
.0022_{5}\end{array}$ & $\begin{array}{l}.0628_{2} \\
.0657_{3} \\
.0687_{4} \\
.0718_{3} \\
.0750_{3}\end{array}$ & $\begin{array}{l}1700 \\
1720 \\
1740 \\
1760 \\
1780\end{array}$ & $\begin{array}{l}.0031_{8} \\
.0033_{0} \\
.0034_{1} \\
.00354 \\
.0036_{6}\end{array}$ & $\begin{array}{l}\text { 1. } 202_{6} \\
1.2533 \\
1.3057 \\
1.359_{7} \\
1.415_{5}\end{array}$ \\
\hline $\begin{array}{l}750 \\
760 \\
770 \\
780 \\
790\end{array}$ & $\begin{array}{l}.00026 \\
.00022_{7} \\
.00022_{8} \\
.00033_{1} \\
.0031_{1}\end{array}$ & $\begin{array}{l}.0783_{2} \\
.08172 \\
.0852_{2} \\
.0888_{3} \\
.09254\end{array}$ & $\begin{array}{l}1800 \\
1820 \\
1840 \\
1860 \\
1880\end{array}$ & $\begin{array}{l}.0037_{9} \\
.0039_{2} \\
.0040_{5} \\
.0041_{9} \\
.0043_{3}\end{array}$ & $\begin{array}{l}1.4730 \\
1.5323 \\
1.5935 \\
\text { 1. } 6566_{5} \\
1.7215\end{array}$ \\
\hline $\begin{array}{l}800 \\
810 \\
820 \\
830 \\
840\end{array}$ & $\begin{array}{l}.0003_{2} \\
.0003_{3} \\
.0003_{4} \\
.0003_{6} \\
.00037\end{array}$ & $\begin{array}{r}.0963_{6} \\
.10029 \\
.1043_{4} \\
.10850 \\
.11278\end{array}$ & $\begin{array}{l}1900 \\
1920 \\
1940 \\
1960 \\
1980\end{array}$ & $\begin{array}{l}.00447 \\
.00462 \\
.00477 \\
.0049_{2} \\
.0050_{3}\end{array}$ & $\begin{array}{l}1.7884 \\
1.8574 \\
1.9284 \\
2.0015 \\
2.0768\end{array}$ \\
\hline $\begin{array}{l}850 \\
860 \\
870 \\
880 \\
890\end{array}$ & $\begin{array}{l}.0003_{9} \\
.0004_{0} \\
.0004_{1} \\
.0004_{3} \\
.0004_{4}\end{array}$ & $\begin{array}{l}.1171_{7} \\
.12169 \\
.1263_{4} \\
.1311_{1} \\
.13600\end{array}$ & $\begin{array}{l}2000 \\
2020 \\
2040 \\
2060 \\
2080\end{array}$ & $\begin{array}{l}.0052_{4} \\
.0054_{0} \\
.00557 \\
.00574 \\
.0059_{1}\end{array}$ & $\begin{array}{l}2.154_{4} \\
2.234_{1} \\
2.316_{2} \\
2.4007 \\
2.4876\end{array}$ \\
\hline
\end{tabular}
for most geologic problems.
TABLE 2.-Factors for use with equations of the second degree 
TABLE 2.-Factors for use with equations of the second degree-Con.

\begin{tabular}{|c|c|c|c|c|c|}
\hline $\begin{array}{c}i_{1}^{t_{1}} \\
\text { (millions of } \\
\text { years) }\end{array}$ & $\begin{array}{c}\text { U283 series } \\
f_{1}\end{array}$ & $\begin{array}{c}\text { U23s series } \\
f_{2}\end{array}$ & $\underset{\text { (millions of }}{t_{1}}$ & $\begin{array}{c}U^{2338} \text { series } \\
f_{1}\end{array}$ & $\begin{array}{c}\text { U23s series } \\
\boldsymbol{f}_{\mathbf{2}}\end{array}$ \\
\hline $\begin{array}{l}2100 \\
2120 \\
2140 \\
2160 \\
2180\end{array}$ & $\begin{array}{r}0.0060_{8} \\
.00627 \\
.0064_{6} \\
.0066_{4} \\
.0068\end{array}$ & $\begin{array}{l}2.5769 \\
2.668_{8} \\
2.763_{3} \\
2.860_{5} \\
2.960_{3}\end{array}$ & $\begin{array}{l}2900 \\
2920 \\
2940 \\
2960 \\
2980\end{array}$ & $\begin{array}{r}0.0165_{6} \\
.0169_{2} \\
.0172_{0} \\
.0176_{6} \\
.0180_{3}\end{array}$ & $\begin{array}{r}8.971_{1} \\
9.2258 \\
9.486_{6} \\
9.753_{6} \\
10.027\end{array}$ \\
\hline $\begin{array}{l}2200 \\
2220 \\
2240 \\
2260 \\
2280\end{array}$ & $\begin{array}{l}.0070_{3} \\
.0072_{3} \\
.0074_{3} \\
.0076_{4} \\
.0078_{3}\end{array}$ & $\begin{array}{l}3.062_{9} \\
3.168_{4} \\
3.276_{7} \\
3.388_{0} \\
\text { 3. } 502_{4}\end{array}$ & $\begin{array}{l}3000 \\
3020 \\
3040 \\
3060 \\
3080\end{array}$ & $\begin{array}{c}.0184_{1} \\
.0188_{0} \\
.0191_{9} \\
.01959 \\
.0199_{9}\end{array}$ & $\begin{array}{l}10.30_{7} \\
10.59_{3} \\
10.88_{6} \\
11.188 \\
11.49_{3}\end{array}$ \\
\hline $\begin{array}{l}2300 \\
2320 \\
2340 \\
2360 \\
2380\end{array}$ & $\begin{array}{l}.0080_{6} \\
.00828_{8} \\
.0085_{1} \\
.00877_{6} \\
.00896\end{array}$ & $\begin{array}{l}3.619_{8} \\
3.740_{3} \\
3.864_{9} \\
3.991_{2} \\
4.121_{7}\end{array}$ & $\begin{array}{l}3100 \\
3120 \\
3140 \\
3160 \\
3180\end{array}$ & $\begin{array}{l}.0204_{0} \\
.0208_{1} \\
.02124 \\
.0216_{6} \\
.0220_{8}\end{array}$ & $\begin{array}{l}11.80_{8} \\
12.120 \\
12.458 \\
12.793 \\
13.139\end{array}$ \\
\hline $\begin{array}{l}2400 \\
2420 \\
2440 \\
2460 \\
2480\end{array}$ & $\begin{array}{l}.0092_{0} \\
.0094_{4} \\
.00968 \\
.0099_{8} \\
.0101_{8}\end{array}$ & $\begin{array}{l}4.255_{6} \\
4.393_{1} \\
4.534_{1} \\
4.6788 \\
4.827_{3}\end{array}$ & $\begin{array}{l}3200 \\
3220 \\
3240 \\
3260 \\
3280\end{array}$ & $\begin{array}{l}.0225_{3} \\
.02299_{3} \\
.0234_{3} \\
.02388 \\
.02434\end{array}$ & $\begin{array}{l}13.49_{2} \\
13.85_{2} \\
14.22_{1} \\
14.598 \\
14.984\end{array}$ \\
\hline $\begin{array}{l}2500 \\
2520 \\
2540 \\
2560 \\
2580\end{array}$ & $\begin{array}{l}.0104_{4} \\
.01077_{0} \\
.01097 \\
.0112_{4} \\
.0115_{1}\end{array}$ & $\begin{array}{l}4.9796 \\
5.1358 \\
5.2960 \\
5.460 \mathrm{~b} \\
5.6288\end{array}$ & $\begin{array}{l}3300 \\
3320 \\
3340 \\
3360 \\
3380\end{array}$ & $\begin{array}{l}.0248_{1} \\
.02522^{\circ} \\
.02577 \\
.0262_{5} \\
.0267_{5}\end{array}$ & $\begin{array}{l}15.378 \\
15.78_{2} \\
16.195 \\
16.617 \\
17.04_{3}\end{array}$ \\
\hline $\begin{array}{l}2600 \\
2620 \\
2640 \\
2660 \\
2680\end{array}$ & $\begin{array}{r}.0117_{9} \\
.0120_{8} \\
.0123_{6} \\
.0126_{8} \\
.01298\end{array}$ & $\begin{array}{l}5.801_{6} \\
5.978_{6} \\
6.160_{2} \\
6.346_{3} \\
6.537_{t}\end{array}$ & $\begin{array}{l}3400 \\
3420 \\
3440 \\
3460 \\
3480\end{array}$ & $\begin{array}{l}.0272_{5} \\
.0277_{6} \\
.0282_{7} \\
.0287_{9} \\
.0293_{1}\end{array}$ & $\begin{array}{l}17.49_{0} \\
17.94_{\mathrm{I}} \\
18.40_{3} \\
18.87_{4} \\
19.35_{8}\end{array}$ \\
\hline $\begin{array}{l}2700 \\
2720 \\
2740 \\
27760 \\
2780\end{array}$ & $\begin{array}{l}.0132_{6} \\
.0135_{7} \\
.0138_{8} \\
.0142_{0} \\
.0145_{2}\end{array}$ & $\begin{array}{l}6.732_{6} \\
6.932_{8} \\
7.138_{1} \\
7.3484 \\
7.5639\end{array}$ & $\begin{array}{l}3500 \\
3520 \\
3540 \\
3560 \\
3580\end{array}$ & $\begin{array}{l}.0298_{5} \\
.0303_{9} \\
.03093 \\
.0314_{9} \\
.0320_{5}\end{array}$ & $\begin{array}{l}19.848 \\
20.354 \\
20.869 \\
21.398 \\
21.934\end{array}$ \\
\hline $\begin{array}{l}2800 \\
2820 \\
2840 \\
2860 \\
2880\end{array}$ & $\begin{array}{l}.0148_{5} \\
.01518 \\
.0155_{2} \\
.0158_{6} \\
.0162_{1}\end{array}$ & $\begin{array}{l}7.784 a \\
8.0107 \\
8.2423 \\
8.4793 \\
8.7224\end{array}$ & $\begin{array}{l}3600 \\
3620 \\
3640 \\
3660 \\
3680\end{array}$ & $\begin{array}{l}.0326_{2} \\
.0331_{0} \\
.03377 \\
.03436 \\
.0349_{6}\end{array}$ & $\begin{array}{l}22.48_{4} \\
23.04_{6} \\
23.62_{1} \\
24.20_{8} \\
24.80_{8}\end{array}$ \\
\hline
\end{tabular}

\section{CALCULATION OF CONCORDANT AGES}

ONE SAMPLE

RADIOGENIC Pb ${ }^{207 / P D^{206}}$ RATIO GIVEN

If the $\mathrm{Pb}^{207} / \mathrm{Pb}^{206}$ ratio, $R^{*}$, of the radiogenic lead lost at a time, $t$, or the contaminating original radiogenic lead is assumed or is inferred from independent evidence, such as the isotopic study of the lead in associated nonradioactive sulfides, it is possible to obtain an algebraic concordant age solution for a single sample without knowledge of either the amount of contaminating radiogenic $\mathrm{Pb}^{206}$ and $\mathrm{Pb}^{207}$ present in the sample or the extent of a single past period of alteration. However, this concordant age will be valid only if the following conditions are met.

1. The initial correction for common lead has been correctly made so that the remaining $\mathrm{Pb}^{208}$ and $\mathrm{Pb}^{207}$ represent only the total radiogenic lead in the sample.

2. The sample has not selectively lost or gained radioactive daughter products since the time of mineral formation.

3. The sample has not been altered recently.

It is easiest to consider first the correction for original radiogenic lead. The solution for this problem will also yield the concordant alteration age. Writing equation 5 for the $\mathrm{Pb}^{206} / \mathrm{U}^{238}$ and $\mathrm{Pb}^{207} / \mathrm{U}^{235}$ ratios, respectively, one obtains the following:

$$
\frac{\left(\lambda_{1} t\right)^{n}}{n !} \cdots+\frac{\left(\lambda_{1} t\right)^{2}}{2 !}+\lambda_{1} t=\frac{N_{6}-N_{8} *}{N_{8}}
$$

and

$$
\frac{\left(\lambda_{2} t\right)^{n}}{n !} \cdots+\frac{\left(\lambda_{2} t\right)^{2}}{2 !}+\lambda_{2} t=\frac{N_{7}-N_{7}^{*}}{N_{5}}
$$

where

$\lambda_{1}=$ the decay constant for $\mathrm{U}^{238}, \times 10^{-10} y^{-1}$.

$\lambda_{2}=$ the decay constant for $\mathrm{U}^{235}, \times 10^{-10} y^{-1}$.

$N_{6}=$ a number proportional to the total number of radiogenic $\mathrm{Pb}^{206}$ atoms in sample $A$.

$N_{6}{ }^{*}=\mathrm{a}$ number proportional to the number of original radiogenic $\mathrm{Pb}^{208}$ atoms in sample A.

$N_{7}=$ a number proportional to the total number of radiogenic $\mathrm{Pb}^{207}$ atoms in sample $A$.

$N_{7}{ }^{*}=$ a number proportional to the number of original radiogenic $\mathrm{Pb}^{207}$ atoms in sample A.

$N_{5}=$ a number proportional to the number of $\mathrm{U}^{235}$ atoms present now in sample $A$.

$N_{8}=$ a number proportional to the number of $\mathrm{U}^{238}$ atoms present now in sample $A$. $t=$ age in years $\times 10^{10}$

Equations 7 and 8 may be written in the form,

$$
N_{6}-N_{8}\left(\frac{\left(\lambda_{1} t\right)^{n}}{n !} \cdots+\frac{\left(\lambda_{1} t\right)^{2}}{2 !}+\lambda_{1} t\right)=N_{6}^{*}
$$

and

$$
N_{7}-N_{5}\left(\frac{\left(\lambda_{2} t\right)^{n}}{n !} \cdots+\frac{\left(\lambda_{2} t\right)^{2}}{2 !}+\lambda_{2} t\right)=N_{7}^{*}
$$

Dividing equation 10 by equation 9 one gets:

$$
\frac{N_{5}}{N_{8}}\left[\frac{\frac{N_{7}}{N_{5}}-\left(\frac{\left(\lambda_{2} t\right)^{n}}{n !} \cdots+\frac{\left(\lambda_{2} t\right)^{2}}{2 !}+\lambda_{2} t\right)}{\frac{N_{6}}{N_{8}}-\left(\frac{\left(\lambda_{1} t\right)^{n}}{n !} \cdots+\frac{\left(\lambda_{1} t\right)^{2}}{2 !}+\lambda_{1} t\right)}\right]=\frac{N_{7}^{*}}{N_{6}^{*}}
$$

and substituting the ratios one obtains:

$$
R\left[\frac{R_{5}-\left(\frac{\left(\lambda_{2} t\right)^{n}}{n !} \cdots+\frac{\left(\lambda_{2} t\right)^{2}}{2 !}+\lambda_{2} t\right)}{R_{8}-\left(\frac{\left(\lambda_{1} t\right)^{n}}{n !} \cdots+\frac{\left(\lambda_{1} t\right)^{2}}{2 !}+\lambda_{1} t\right)}\right]=R^{*}
$$

where

$R^{*}=N_{7} * / N_{6} *$, the ratio of the original radiogenic lead, and where

$R=N_{5} / N_{8}=$ the present ratio of $\mathrm{U}^{235}$ to $\mathrm{U}^{238}$, a constant, $=1 / 137.7=0.007262_{1}$;

$R_{9}=N_{6} / N_{8}$ and $R_{5}=N_{7} / N_{5}$. 
Expanding equation (11) and collecting terms one obtains:

$$
\begin{aligned}
& \left(\frac{R^{*} \lambda_{1}^{n}}{n !}-\frac{R \lambda_{2}^{n}}{n !}\right) t^{n} \ldots+\left(\frac{R^{*} \lambda_{1}^{3}}{3 !}-\frac{R \lambda_{2}^{3}}{3 !}\right) t^{3} \\
& \quad+\left(\frac{R^{*} \lambda_{1}^{2}}{2 !}-\frac{R \lambda_{2}^{2}}{2 !}\right) t^{2}+\left(R^{*} \lambda_{1}-R \lambda_{2}\right) t+\left(R R_{5}-R^{*} R_{8}\right)=0
\end{aligned}
$$

If computing facilities are available, equation 12 may be easily programed to solve directly for $t$. The degree of the equation used is determined in each case by the approximate age range of the sample being dated but generally will not exceed 10 . For values of $R^{*}, R_{5}$, and $R_{8}$ that are of geologic interest, equation 12 has two positive real roots. As the degree of this equation increases, the smaller positive root rapidly approaches the concordant age, $t$ corrected for original radiogenic lead as shown in figure $2 B$. The larger positive root approaches more slowly the value $t$ as shown in figure $2 A$ and is the concordant age obtained by correcting for loss or gain of lead or uranium at some time, $t_{1}$, in the past. In the latter case, $R^{*}$ is the $\mathrm{Pb}^{207} / \mathrm{Pb}^{206}$ ratio of the radiogenic lead produced in the time interval $t$ to $t_{1}$ and lost at the time, $t_{1}$.

If computing facilities are not available, equation 12 may be taken only to the second power of $t$. As in equation 6 , when $t$ is greater than 250 million years factors $f_{1}$ and $f_{2}$ should be added for the $\mathrm{U}^{238}$ and $\mathrm{U}^{235}$ series, respectively. These factors obtained from table 2 for different values of $t_{1}$, compensate for the failure of this second degree equation to approximate closely enough the actual value of $e^{\lambda t}$ for a specific value of $t$.

Equation 12 then takes the form

$$
\begin{aligned}
\left(\frac{R^{*} \lambda_{1}^{2}}{2 !}-\frac{R \lambda_{2}^{2}}{2 !}\right) t^{2}+ & \left(R^{*} \lambda_{1}-R \lambda_{2}\right) t \\
& +\left(R R_{5}-R^{*} R_{8}+R^{*} f_{1}-R f_{2}\right)=0 .
\end{aligned}
$$

Solving for $t$,

$$
t=\frac{-b \pm \sqrt{b^{2}-4 a c}}{2 a}
$$

where $2 a=\left(R^{*} \lambda_{1}^{2}-R \lambda_{2}^{2}\right)$

$$
\begin{aligned}
& b=\left(R^{*} \lambda_{1}-R \lambda_{2}\right) \\
& c=\left(R R_{5}-R^{*} R_{8}-R f_{2}+R^{*} f_{1}\right)
\end{aligned}
$$

and where

$f_{1}=$ the factor for the $\mathrm{U}^{238}$ series depending on $t_{1}$

$f_{2}=$ the factor for the $\mathrm{U}^{235}$ series depending on $t_{1}$.

For values of $R^{*}, R_{5}$, and $R_{8}$ that are of geologic interest, equation 13 also has two positive real roots.
In using equation 13 , the smaller root can be made to approach the concordant age corrected for original radiogenic lead by selecting values of $f_{1}$ and $f_{2}$ from table 2 for $t_{1}$ that are less than the trial $\mathrm{Pb}^{206} / \mathrm{U}^{238}$ age. With even approximately correct values for $f_{1}$ and $f_{2}$, the smaller root will fall close to the actual age of the sample corrected for original radiogenic lead. The larger root, however, depending on the extent of the lead-uranium age discordancy, may depart substantially from the concordant "lead-loss age."

If it desired to calculate exactly the alteration or "lead-loss age" using equation 13 , values of $f_{1}$ and $f_{2}$ must be chosen from the table for $t_{1}$ equal to or greater than the $\mathrm{Pb}^{207} / \mathrm{Pb}^{206}$ age. Because the terms $f_{1}$ and $f_{2}$ become increasingly important as $t$ increases, it may be desirable to make a rough graphical lead-loss solution to guide the initial choice of $t_{1}$.

The departure of the first calculated age, $t$, from the exact lead-loss solution may be tested by comparing the calculated value of $R^{*}$ with the given value of $R^{*}$ (using equation 11). The first calculated value of $t$ from equation 13 along with the appropriate values of $f_{1}$ and $f_{2}$ for this calculated value of $t$ from table 2 may be substituted in equation 11. Wickman, 1939, Kulp and others (1954), Greenhalgh and Jeffery (1959), and Stieff and others (1959) have prepared tables for the calculation of lead isotope ages. If the tables by Stieff and others (1959), (hereinafter referred to as the age tables) are used, the terms $\left[f_{1}+\left(\lambda_{1} t\right)^{2} / 2+\lambda_{1} t\right]$ and $\left[f_{2}+\left(\lambda_{2} t\right)^{2} / 2+\lambda_{2} t\right]$ may be replaced by values for the $\mathrm{N}_{206} / \mathrm{N}_{238}$ and $\mathrm{N}_{207} / \mathrm{N}_{235}$ ratios for the appropriate value of $t$. If for the particular geologic problem the agreement between the calculated $R^{*}$ and the given $R^{*}$ is not satisfactory, a new $t_{1}$ is chosen and the lead-loss age is recalculated. This age calculation may be repeated until the desired degree of agreement between the calculated $R^{*}$ and the given $R^{*}$ is obtained.

\section{EXAMPLE OF CAICULATION}

An example of the use of equations 12 and 13 for the calculation of a concordant age corrected for original radiogenic lead is given below. The following isotopic data are available for a hypothetical unaltered sample of uraninite, the true age of which is 200 million years and which contains (chemical scale) $1.14_{4}$ percent $\mathrm{Pb}$ and $27.92_{3}$ percent $U$ :

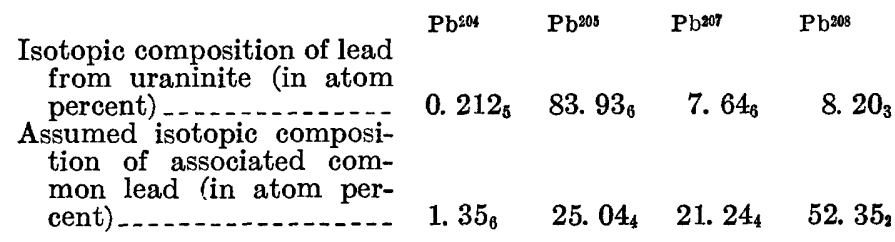
Ratio of original radiogenic lead present $=N_{7} * / N_{6} *=R^{*}=0.0718_{\text {s }}$ as found in associated nonradioactive mineral. 
Using $\mathrm{Pb}^{204}$ as the "index" of the amount of common lead present and correcting for the proportionate amounts of nonradiogenic $\mathrm{Pb}^{206}, \mathrm{~Pb}^{207}$, and $\mathrm{Pb}^{208}$, the remaining atom percent of radiogenic $\mathrm{Pb}^{206}$ and $\mathrm{Pb}^{207}$ may be obtained as follows:

\begin{tabular}{|c|c|c|c|c|}
\hline Toutonic anglysis of urani- & $\mathrm{Pb}^{204}$ & $\mathrm{~Pb}^{206}$ & $\mathrm{~Pb}^{207}$ & $\mathrm{~Pb}^{208}$ \\
\hline $\begin{array}{l}\text { Isotopic analysis of urani- } \\
\text { nite lead }\end{array}$ & $0.212_{5}$ & 83. $93_{6}$ & 7. $64_{B}$ & 8. $20_{3}$ \\
\hline $\begin{array}{l}\text { Isotopic analysis of com- } \\
\text { mon lead. }\end{array}$ & $0.212_{5}$ & 3. $92_{3}$ & 3. $32_{8}$ & 8. $20_{3}$ \\
\hline $\begin{array}{l}\text { Radiogenic lead produced } \\
\text { by uranium }\end{array}$ & 0.000 & $80.01_{3}$ & 4. $31_{8}$ & 0.000 \\
\hline
\end{tabular}

In order to use equations 12 or 13 , it is necessary to express the chemical lead and uranium data as quantities directly proportional to the number of atoms of the particular radioactive parent or radiogenic daughter isotope in the sample at the present time. For exact solutions, the quantitative lead analyses, usually reported in the chemical scale, must be corrected for the actual difference in the physical atomic weight of the radiogenic lead in the sample. In this example it is 206.27 , compared to the assumed average physical atomic weight, 207.28, used in the chemical analysis. The correction factor for this particular case is $207.28 /$ 206.27. Failure to correct the quantitative chemicallead data for the actual atomic weight of the radiogenic lead in the sample will introduce additional errors of 0.2 to 0.5 percent in the final calculated lead-uranium ages.

This corrected weight must now be multiplied by the atom-percent abundance of the radiogenic $\mathrm{Pb}^{206}$ or $\mathrm{Pb}^{207}$ in the sample after correction for common lead and divided by the atomic weight of the radiogenically enriched lead in the sample to get a quantity exactly proportional to the number of atoms present. Although it is necessary to include both Avogadro's number and the conversion factor from the chemical to the physical scales to obtain numbers of atoms, both of these terms cancel out in the ratio of the number of atoms of lead to uranium.

$$
\begin{aligned}
& N_{6}=\frac{1.14_{4} \times 207.28 \times 80.01_{3}}{206.27 \times 206.27}=0.4459_{4} \\
& N_{7}=\frac{1.14_{4} \times 207.28 \times 4.31_{8}}{206.27 \times 206.27}=0.0240_{6}
\end{aligned}
$$

$N_{7}$ may be more easily obtained by multiplying $N_{6}$ by the ratio of the radiogenic $\mathrm{Pb}^{207}$ to $\mathrm{Pb}^{206}$ remaining after correction for common lead, that is, $0.4459_{4} \times \frac{4.31_{8}}{80.01_{3}}=0.0240_{6}$.

Similarly, $N_{5}$ and $N_{s}$ may be obtained by multiplying the percent uranium (chemical scale) by the atom-per- cent abundance of the $\mathrm{U}^{235}$ or $\mathrm{U}^{238}$, and dividing by the physical atomic weight of U, 238.103.

$$
\begin{aligned}
& N_{8}=\frac{27.92_{3} \times 99.27_{9}}{238.103}=11.64_{2} \\
& N_{5}=\frac{27.92_{3} \times 0.720_{9}}{238.103}=0.08454_{6}
\end{aligned}
$$

$N_{5}$ may also be obtained by dividing $N_{8}$ by 137.7 , the atom ratio of $U^{238}$ to $U^{235}$; that is, $11.64_{2} \div 137.7$ $=0.08454_{6}$.

Expressing these analytical data as ratios of the number of atoms of radiogenic lead and uranium and using the age tables, we obtain the following ratios and discordant trial ages:

$\begin{array}{lcc} & \text { Ratio } & \text { Trial age (millions of years) } \\ N_{6} / N_{8}=R_{8}=\ldots \ldots-\ldots-1 & 0.03830_{7} & 244\left(\mathrm{~Pb}^{206} / \mathrm{U}^{238}\right) \\ N_{7} / N_{5}=R_{5}=\ldots-2845_{8} & 258\left(\mathrm{~Pb}^{207} / \mathrm{U}^{235}\right) \\ N_{7} / N_{6}=\ldots-\ldots-\ldots & .28539_{5} & 380\left(\mathrm{~Pb}^{207} / \mathrm{Pb}^{206}\right)\end{array}$

If, in the course of the evaluation of this discordant age sequence, it is now desired to test the assumption, among others, that an additional correction for original radiogenic lead should have been made; equation 12 can be used to obtain a single corrected concordant age, $t$.

As has been mentioned, equation 12 has been programed for the Geological Survey's digital computer. The values for $R_{5}, R_{8}, R^{*}$ and $R$ given for this example, when substituted in equation 12, yield two positive real roots of $t$ (in millions of years) as the degree of the equation increases from 2 to 10 (table 3 ). In this example, even the second degree equation yields a value for the smaller positive real root that closely approximates the hypothetical age of 200 million years. For such young ages, an equation of the third degree would give an age corrected for original radiogenic lead with less uncertainty than the uncertainty introduced by the experimental errors. The larger positive root converges more slowly on the "lead loss" age. An equation of the fifth degree, however, gives a geologically useful answer.

TABLE 3.-Computed concordant ages obtained from equation 12

\begin{tabular}{c|r|r}
\hline & \multicolumn{2}{|c}{ Age (millions of years) } \\
\cline { 2 - 3 } Degree of equation & $\begin{array}{c}\text { Corrected for original } \\
\text { radiogenic lead }\end{array}$ & $\begin{array}{c}\text { Corrected for loss or } \\
\text { gain of lead or uranium }\end{array}$ \\
\hline & 197.34 & 1344.5 \\
\hline 5 & 200.24 & 908.38 \\
\hline 5 & 200.39 & $860 . .77$ \\
\hline 9 & 200.40 & 853.82 \\
\hline 10 & 200.40 & 853.00 \\
& 200.40 & 852.89 \\
\hline
\end{tabular}


The decision to include the terms $R^{*} f_{1}$ and $R f_{2}$ in equation 13 is determined both by the nature of the problem and by the approximate range in age of the sample being dated. An examination of table 2 for values of $t_{1}$ in the range of 250 million years suggests that both $f_{1}$ and $f_{2}$ can be initially neglected. This decision is further supported by the fact that for this hypothetical problem, a calculated age within five percent of the actual age, and an agreement between the $\mathrm{Pb}^{208} / \mathrm{U}^{238}$ and $\mathrm{Pb}^{207} / \mathrm{U}^{235}$ ages of within one percent would be more than adequate. The ratio of the original radiogenic lead, $R^{*}$, used in equation 13 may be assumed, or, as in this example, it may be obtained from the isotopic study of the lead extracted from associated nonradioactive minerals. Substituting in 13 the values $R=1 / 137.7=0.007262_{1}, R_{5}=0.2845_{8}, R_{5}=0.03830_{7}$, and $R^{*}=0.0718_{5}$, where

$$
\begin{aligned}
2 a & =\left(R^{*} \lambda_{1}^{2}-R \lambda_{2}^{2}\right) \times 10^{-20} y^{-1} \\
& =\left(0.0718_{5} \times 2.362_{1}-0.007262_{1} \times 94.51_{0}\right) \times 10^{-20} y^{-1} \\
& =-0.5166_{2} \times 10^{-20} y^{-1} \\
b & =\left(R^{*} \lambda_{1}-R \lambda_{2}\right) \times 10^{-10} y^{-1} \\
& =\left(0.0718_{5} \times 1.536_{9}-0.007262_{1} \times 9.721_{6}\right) \times 10^{-10} y^{-1} \\
& =0.03982_{6} \times 10^{-10} y^{-1} \\
c & =\left(R R_{5}-R^{*} R_{8}\right) \\
& =\left(0.007262_{1} \times 0.2845_{8}-0.0718_{5} \times 0.03830_{7}\right) \\
& =-0.000685_{7}
\end{aligned}
$$

$t$ becomes

$$
\begin{aligned}
t & =\frac{-b \pm \sqrt{b^{2}-4 a c}}{2 a} \\
& =\left[\frac{-0.03982_{6} \pm \sqrt{.001586_{1}-.0007084_{9}}}{-0.5166_{2}}\right] \times 10^{10} y \\
& =\left[\frac{-0.03982_{6} \pm \sqrt{.0008776_{4}}}{-0.5166_{2}}\right] \times 10^{10} y \\
& =\left[\frac{-0.03982_{6} \pm .02962_{5}}{-0.5166_{2}}\right] \times 10^{10} y
\end{aligned}
$$

$t=0.0197_{4} \times 10^{10}=197 \mathrm{~m} . y$. (age corrected for old radiogenic lead)

or

$t=0.1344_{3} \times 10^{10}=1344.3 \mathrm{~m} . \mathrm{y}$. (age corrected for loss or gain of lead or uranium).

These two concordant ages are in close agreement with the solutions for equation 12 expanded to the second degree (table 3 ).

For most geologic problems falling in this age range, the value of $t=197 \mathrm{~m} . \mathrm{y}$. would be acceptable; the age would be rounded to the nearest 5 million years, that is, 195 million years. If, however, a closer approxi- mation of the true age is required, a test of the convergence of the lead-uranium and lead-lead ages may be made by first calculating $N^{*}{ }_{6}$ using equation 7 and $t=0.0197 \times 10^{10} y$. If the age tables are used, the sum of the terms $\frac{\left(\lambda_{1} t\right)^{n}}{n !} \cdots+\frac{\left(\lambda_{1} t\right)^{2}}{2 !}+\lambda_{1} t$ can be replaced with the appropriate value of $N_{206} / N_{208}$ for $t=$ $0.0197 \times 10^{10}$ years. If the age tables are not used, the term $f_{1}$ for the closest value of $t_{1}$ from table 2 must be added to the two-term expansion of $e^{\lambda_{1} t}$, that is,

$$
\left[f_{1}+\frac{\left(\lambda_{1} t\right)^{2}}{2 !}+\lambda_{1} t\right]
$$

Given the ratio $N_{7}^{*} / N_{6}^{*}=R^{*}=.0718_{5}$, when $N_{6}^{*}=$ $0.0880_{0}, N_{7}^{*}$ is found to be $0.00632_{3}$. The $\mathrm{Pb}^{206} / \mathrm{U}^{238}$, $\mathrm{Pb}^{207} / \mathrm{U}^{235}$ and $\mathrm{Pb}^{207} / \mathrm{Pb}^{206}$ ages corrected for original radiogenic $\mathrm{Pb}^{206}$ and $\mathrm{Pb}^{207}$ can be obtained now by subtracting $N_{6}^{*}$ and $N_{7}^{*}$ from the total number of atoms of $N_{6}$ and $N_{7}$, respectively. The recalculated ages are:

$$
\frac{\mathrm{Pb}^{200} / \mathrm{U}^{238}}{197 \mathrm{~m} \mathrm{y} \cdot} \quad \frac{\mathrm{Pb}^{207 / \mathrm{U}^{235}}}{196 \mathrm{~m} \cdot \mathrm{y}} \quad \frac{\mathrm{Pb}^{207} / \mathrm{Pb}^{206}}{184 \mathrm{~m} \cdot \mathrm{y}}
$$

As the $\mathrm{Pb}^{206} / \mathrm{U}^{238}$ and $\mathrm{Pb}^{207} / \mathrm{U}^{235}$ ages are nearly in agreement and because the $\mathrm{Pb}^{207} / \mathrm{Pb}^{206}$ age is less than the two lead-uranium ages, a slightly larger value is chosen for $t_{1}$, that is, $t_{1}=198 \mathrm{~m}$.y. In table 2 , it is noted that for $t_{1}=198$ m.y., $f_{1}$ is negligible and $f_{2}=0.00125$.

The value of the coefficient $c$ in equation 13 now becomes $-0.000693_{2}$, where $R f_{2}=0.0000091$, while the coefficients $a$ and $b$ in equation 13 remain unchanged. Using these coefficients in equation 13 the new age is found to be, $t=200.0$ m.y. For this value of $t$, it can be shown that the lead-uranium and lead-lead ages converge exactly:

$$
\frac{\mathrm{Pb}^{200 / \mathrm{U}^{238}}}{200 \mathrm{~m} \cdot \mathrm{y} .} \quad \frac{\mathrm{Pb}^{207} / \mathrm{U}^{235}}{200 \mathrm{~m} \cdot \mathrm{y} \cdot} \quad \frac{\mathrm{Pb}^{207} / \mathrm{Pb}^{206}}{200 \mathrm{~m} \cdot \mathrm{y}}
$$

It is thus possible, as part of the evaluation of a discordant age sequence, to calculate the single concordant age that would result from an additional correction for original radiogenic lead of known ratio. It is not necessary that the amounts of original radiogenic $\mathrm{Pb}^{206}$ and $\mathrm{Pb}^{207}$ be known. In this case, however, it is necessary that the proper common-lead correction be made, and that the sample be unaltered. This corrected age may now be compared with similar calculations on other samples from the same area or deposit. Finally, the ages obtained assuming correction for original radiogenic lead as well as losses or gains of lead and uranium must be combined with both field and other laboratory data to establish the most consistent interpretation of all the evidence, isotopic as well as geologic. 

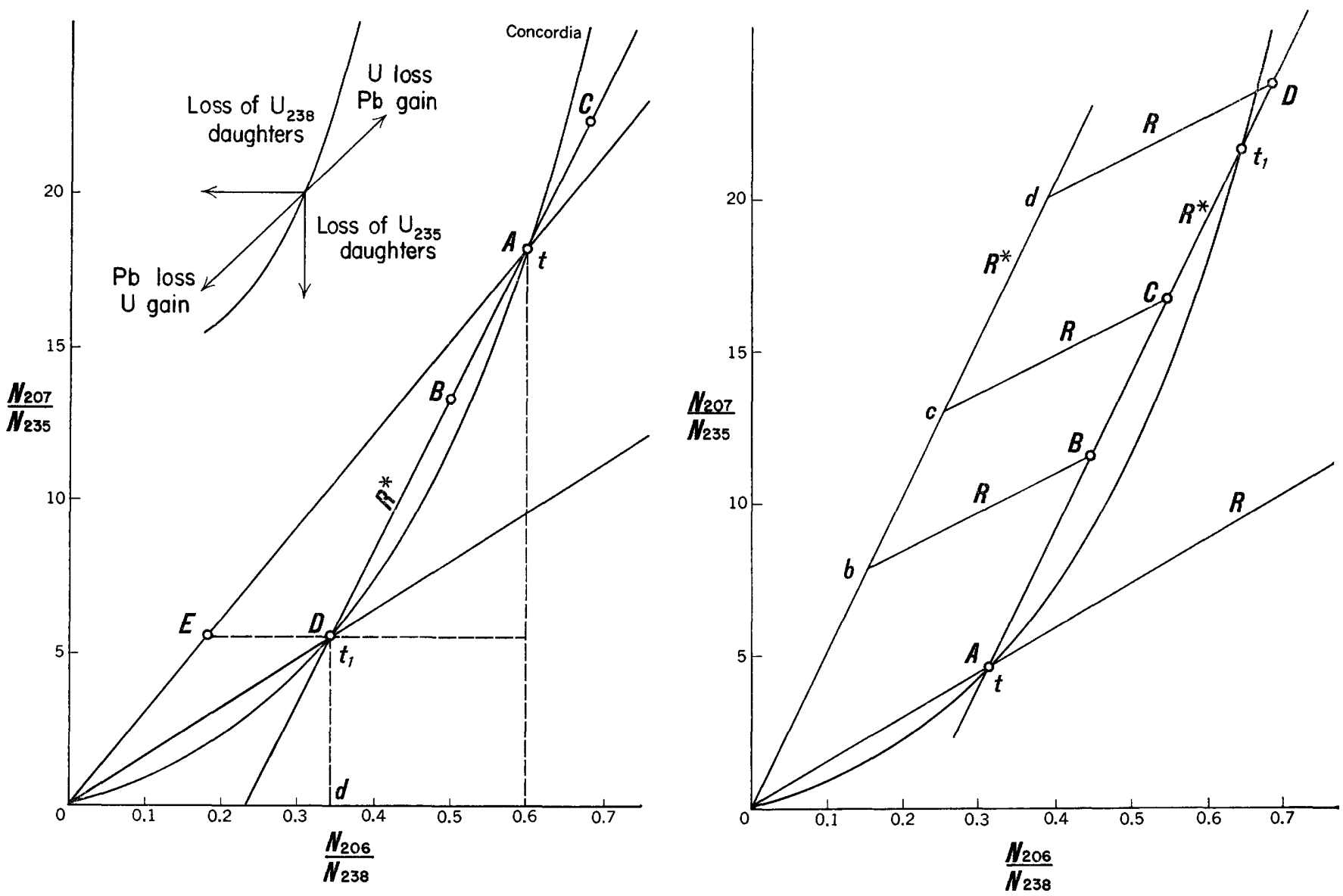

FiguRE 2.-Ratios of the number of atoms of radiogenic $\mathrm{Pb}{ }^{207}$ to $\mathrm{U}^{233}, N_{207} / N_{235}$, plotted against the ratios of the number of atoms of radiogenic $\mathrm{Pb} b^{208}$ to $\mathrm{U}^{238}, N_{298} / N_{238}$. $L_{4}$ eft, Uranium-bearing samples which lost or gained lead or uranium at a time, $t_{1}$, in the past. Right, Uranium-bearing samples contaminated with an original radiogenic lead having a $\mathrm{Pb}^{207} / \mathrm{Pb}^{208}$ ratio, $R^{*}$.

GRAPHIC SOLUTION

Figure $2 A$ is the graphic equivalent of the algebraic concordant age solution assuming a single period of past loss or gain of lead or uranium. The graphic equivalent of the correction for original radiogenic lead is shown in figure $2 B$. A detailed discussion of the concordant graphical solutions for this case as well as for the other cases in this paper have been presented by Stieff and Stern (1961).

Samples $A, B$, and $C$ (fig. $2 A$ ) are assumed to have been formed at the same time, $t$. Sample $A$ has not been altered during its history, while $B$ lost lead or gained uranium, and $C$ lost uranium or gained lead at a time, $t_{1}$, in the past. The $\mathrm{Pb}^{207} / \mathrm{Pb}^{206}$ ratio of the radiogenic lead present in $A, B$, and $C$ at the time, $t_{1}$, is given by the slope of the line, $R^{*}$, passing through the points $t$ and $t_{1}$ on the concordant age curve, times $1 / 137.7$, the ratio of the present day relative abundance of $\mathrm{U}^{235} / \mathrm{U}^{238}$. Thus, given $R^{*}$ and the discordant age data for one sample, $B$, it is possible to find the concordant unaltered age, $t$, and the time of alteration, $t_{1}$, by passing a line through the point $B$ whose slope is $R^{*} \times 137.7$, and noting the two intersections with the concordant age curve.

Samples $A, B, C$ and $D$ (fig. $2 B$ ) are also assumed to have been formed at the same time, $t$. At the time of their formation, however, $B, C$, and $D$ were contaminated with different amounts of an older radiogenic lead having a $\mathrm{Pb}^{207} / \mathrm{Pb}^{206}$ ratio, $R^{*}$. These samples would therefore, at the time of their formation, have the $N_{207} / N_{235}$ and $N_{206} / N_{238}$ ratios shown by the points $b, c$, and $d$ lying on the line of slope $R^{*} \times 137.7$, passing through the origin. If the samples have been unaltered since their formation, the $N_{207} / N_{235}$ and $N_{206} / N_{238}$ ratios will move from $b, c$, and $d$ to $B, C$, and $D$. Given, for example, $R^{*}$ and the discordant $N_{207} / N_{235}$ and $N_{206} /$ $N_{238}$ age ratios for $B$, the concordant age, $t$, corrected for original radiogenic lead can be obtained by passing a line with a slope $R^{*} \times 137.7$ through the point $B$. In this instance, $t_{1}$ would represent the maximum age of the uraniferous source material which provides the older, contaminating radiogenic lead. 


\section{COMMON Pb207/Pb206 RATIO GIVEN}

The correction of lead-isotope-age data for contaminating common lead is an important problem closely related to the problem of correcting for original radiogenic lead. In some age calculations, the corrections for common lead are so large that it is necessary to know exactly the isotopic composition of the contaminating common lead. If the exact common-lead correction is not made, it is difficult to determine whether the lead-uranium and lead-lead discrepancies are a consequence of the assumed isotopic composition of the contaminating lead, experimental errors in the determination of the index isotope $\mathrm{Pb}^{204}$ or $\mathrm{Pb}^{208}$, or other factors.

One method of correcting for common lead, as indicated on page $\mathrm{E} 8$ is the use of the $\mathrm{Pb}^{204}$ abundance (and in certain special instances, the $\mathrm{Pb}^{208}$ abundance) as an "index" of the amount of common lead present. The isotopic composition of the contaminating common lead in the radioactive mineral may be assumed to be identical with the analyzed isotopic composition of the lead in associated nonradioactive minerals, such as galena. Alternately, if such data are not available, an isotopic composition may be chosen that is presumably representative of the lead available at the time of mineral formation. In either case, it is necessary to have very precise isotopic data on the abundance of the "index" isotope $\left(\mathrm{Pb}^{204}\right.$ or $\left.\mathrm{Pb}^{208}\right)$ used in the correction calculations. The role of $\mathrm{Pb}^{204}$ as the "index" is further complicated by the fact that $\mathrm{Pb}^{204}$ is the least abundant of the four isotopes and is consequently the most difficult to measure precisely in highly radiogenic samples. It would be desirable, therefore, if the common lead correction could be made without reference to either $\mathrm{Pb}^{204}$ or $\mathrm{Pb}^{208}$. For a calculation of this type to be valid, it is necessary that: (a) the sample be unaltered in any way since its formation, and (b) the sample be uncontaminated by original radiogenic lead.

An examination of equation 12 suggests an alternative solution. For ages in excess of current estimates of the age of the earth (4.5 billion years), $R^{*}$, the ratio of the radiogenic $\mathrm{Pb}^{207}$ to $\mathrm{Pb}^{206}$, rapidly approaches the value of the $\mathrm{Pb}^{207} / \mathrm{Pb}^{206}$ ratio found in common leads. If the notation used in equation 13 is now modified so that ${ }^{t} N_{6}$ and ${ }^{t} N_{7}$ are proportional to the total number of atoms of $\mathrm{Pb}^{206}$ and $\mathrm{Pb}^{207}$ in a sample, then the number of atoms of common $\mathrm{Pb}^{206}$ and $\mathrm{Pb}^{207}, N_{6}^{c}$ and $N_{7}^{c}$ will be given by the following equations:

and

$$
{ }^{t} N_{6}-N_{8}\left(\frac{\left(\lambda_{1} t\right)^{n}}{n !} \cdots+\frac{\left(\lambda_{1} t\right)^{2}}{2 !}+\lambda_{1} t\right)=N_{6}^{c}
$$

$$
{ }^{t} N_{7}-N_{5}\left(\frac{\left(\lambda_{2} t\right)^{n}}{n !} \cdots+\frac{\left(\lambda_{2} t\right)^{2}}{2 !}+\lambda_{2} t\right)=N_{7}^{c}
$$

Dividing equation 15 by equation 14 one gets,

$$
R\left[\frac{R_{5 t}-\left(\frac{\left(\lambda_{2} t\right)^{n}}{n !} \cdots+\frac{\left(\lambda_{2} t\right)^{2}}{2 !}+\lambda_{2} t\right)}{R_{8 t}-\left(\frac{\left(\lambda_{1} t\right)^{n}}{n !} \cdots+\frac{\left(\lambda_{1} t\right)^{2}}{2 !}+\lambda_{1} t\right)}\right]=\frac{N_{7}^{c}}{N_{6}^{c}}=R^{c}
$$

where $R$, a constant, $=N_{5} / N_{8}=0.00726_{2}$

$$
\begin{array}{r}
R^{c}=N_{7}^{c} / N_{6}^{c} \text {, the ratio of the number of atoms of } \\
\mathrm{Pb}^{207} \text { to } \mathrm{Pb}^{206} \text { in the common lead. } \\
R_{5 t}={ }^{t} N_{7} / N_{5} \text {, the ratio of the total number of atoms } \\
\text { of } \mathrm{Pb}^{207} \text { to the number of atoms } \\
\text { of } \mathrm{U}^{235} \text {. } \\
R_{8 t}={ }^{t} N_{6} / N_{8} \text {, the ratio of the total number of atoms } \\
\text { of } \mathrm{Pb}^{206} \text { to the number of atoms } \\
\text { of } \mathrm{U}^{238} \text {. }
\end{array}
$$

Expanding and collecting terms, equation 16 takes the form

$$
\begin{aligned}
\left(\frac{R^{c} \lambda_{1}^{n}}{n !}-\frac{R \lambda_{2}^{n}}{n !}\right) & t^{n} \ldots+\left(\frac{R^{c} \lambda_{1}^{2}}{2 !}-\frac{R \lambda_{2}^{2}}{2 !}\right) t^{2} \\
& +\left(R^{c} \lambda_{1}-R \lambda_{2}\right) t+R R_{5 t}-R^{c} R_{8 t}=0
\end{aligned}
$$

For geologically possible values of $R^{c}, R_{5 t}$, and $R_{8 t}$, equation 17 expanded to the third degree or higher has two positive real roots. The equations of odd degree also have one negative real root. The smaller positive root is the concordant age corrected for a common lead having a $\mathrm{Pb}^{207} / \mathrm{Pb}^{206}$ ratio, $R^{c}$. The larger positive root generally has values in excess of current estimates of the age of the earth; these values are geologically impossible and consequently can be neglected. The negative real root does not have any geologic significance.

If computing facilities are not available, equation 17 can be taken to the second power of $t$ and the terms $f_{1}$ and $f_{2}$ added. One then obtains

$$
R\left[\frac{R_{5 t}-\left(f_{2}+\frac{\left(\lambda_{2} t\right)^{2}}{2 !}+\lambda_{2} t\right)}{R_{8 t}-\left(f_{1}+\frac{\left(\lambda_{1} t\right)^{2}}{2 !}+\lambda_{1} t\right)}\right]=R^{c}
$$

Expanding equation 18 and solving for $t$,

$$
t=\frac{-b \pm \sqrt{b^{2}-4 a c}}{2 a}
$$

where

$$
\begin{aligned}
2 a & =\left(R^{c} \lambda_{1}^{2}-R \lambda_{2}^{2}\right) \\
b & =\left(R^{c} \lambda_{1}-R \lambda_{2}\right) \\
c & =\left(R R_{5 t}-R^{c} R_{8 t}+R f_{1}-R f_{2}\right) .
\end{aligned}
$$

Equation 19 has one positive and one negative root for geologically possible values of $R^{c}, R_{5 t}$, and $R_{8 t}$. 
With approximately correct values for $f_{1}$ and $f_{2}$ from table 2 , the calculated age, $t$, from equation 19 will closely approach the exact concordant age, $t$, for the specific value of $R^{c}$, which is the $\mathrm{Pb}^{207} \mathrm{~Pb}^{206}$ ratio of the common lead contaminant.

\section{EXAMPLE OF CALCULATION}

In the frequent cases where chemical and isotopic data are available for only one uranium-bearing mineral from a given area, and where the $\mathrm{Pb}^{207} / \mathrm{Pb}^{206}$ ratio of the contaminating common lead has been accurately determined, equations 17 and 19 can be used to calculate a concordant age that is corrected for common lead without using either $\mathrm{Pb}^{204}$ or $\mathrm{Pb}^{208}$ as the common-lead "index." In addition, the isotopic composition of the common lead required to give a concordant age may be calculated. This calculated isotopic composition may then be compared with the measured isotopic composition of lead extracted from associated nonradioactive minerals. The ages obtained by the use of equations 17 and 19 and the conventional "index" method may also be compared. This comparison requires that the quantitative data on the lead and uranium have small limits of error, the uranium-bearing mineral be fresh and unaltered, and that the $\mathrm{Pb}^{207} / \mathrm{Pb}^{206}$ ratio of the contaminating lead be known within relatively narrow limits. Failure of the two methods to agree probably indicates small errors in the isotopic analysis of the less abundant "index" isotope from either the lead extracted from the uranium-bearing material, the associated nonradioactive mineral, or both.

The following isotopic data are given for a hypothetical unaltered sample of uraninite, the true age of which is 950 million years, and which contains (chemical scale) $6.12_{37}$ percent $\mathrm{Pb}$ and $17.5_{44}$ percent $U$.

$\begin{array}{ccccc}\text { Isotopic composition of } & \mathrm{Pb}^{204} & \mathrm{~Pb}^{208} & \mathrm{~Pb}^{207} & \mathrm{~Pb}^{208} \\ \quad \begin{array}{c}\text { lead from uraninite (in } \\ \text { atom percent) }\end{array} & 0.866_{4} & 52.54_{2} & 15.98_{3} & 30.60_{8} \\ \begin{array}{c}\text { Isotopic composition of } \\ \text { associated common lead } \\ \text { (in atom percent) }\end{array} & 1.50_{9} & 23.56_{8} & 22.65_{5} & 52.26_{0}\end{array}$

The $\mathrm{Pb}^{207} / \mathrm{Pb}^{206}$ ratio of the common lead is $0.9612_{6}$.

Using $\mathrm{Pb}^{204}$ as the "index" of the amount of common lead present, the isotopic composition of the associated nonradiogenic lead, and correcting for the proportionate amounts of nonradiogenic $\mathrm{Pb}^{206}, \mathrm{~Pb}^{207}$ and $\mathrm{Pb}^{208}$, the remaining atom percent of radiogenic $\mathrm{Pb}^{206}$ and $\mathrm{Pb}^{207}$ may be obtained as follows:

\begin{tabular}{|c|c|c|c|c|}
\hline & $\mathrm{Pb}^{204}$ & $\mathrm{~Pb}^{206}$ & $\mathrm{~Pb}^{207}$ & $\mathrm{~Pb}^{208}$ \\
\hline $\begin{array}{l}\text { Isotopic analysis of urani- } \\
\text { nite lead }\end{array}$ & $0.866_{4}$ & 52. $54_{2}$ & 15. $98_{3}$ & 30. $60_{8}$ \\
\hline $\begin{array}{l}\text { Isotopic analysis of com- } \\
\text { mon lead }\end{array}$ & $0.866_{4}$ & 13. $53_{1}$ & 13. $00_{1}$ & $30.01_{0}$ \\
\hline $\begin{array}{l}\text { Radiogenic lead produced } \\
\text { by uranium and thorium. }\end{array}$ & 0.000 & $39.01_{1}$ & $2.97_{b}$ & 0. $59_{8}$ \\
\hline
\end{tabular}

The ratios and the discordant trial ages obtained from the age tables after correction for common lead are as follows:

\begin{tabular}{lll} 
& \multicolumn{1}{c}{ Ratio } & Trial age (Millions of years) \\
$N_{6} / N_{8}=R_{8}=\ldots-1.0-$ & $0.1583_{1}$ & $956\left(\mathrm{~Pb}^{206} / \mathrm{U}^{238}\right.$ age $)$ \\
$N_{7} / N_{5}=R_{5}=\ldots-1.662_{9}$ & $1008\left(\mathrm{~Pb}^{207} / \mathrm{U}^{235}\right.$ age $)$ \\
$N_{7} / N_{6}=\ldots$ & $0.0762_{8}$ & $1122\left(\mathrm{~Pb}^{207} / \mathrm{Pb}^{206}\right.$ age $)$
\end{tabular}

In this example, $R^{c}$, the $\mathrm{Pb}^{207} / \mathrm{Pb}^{206}$ ratio of the contaminating common lead, was chosen to equal the $\mathrm{Pb}^{207} / \mathrm{Pb}^{206}$ ratio of the common lead used in the trial age calculation. Substituting also the ratios $R_{5 t}, R_{8 t}$, and $R$ in equation 17 and solving the equations of the second to the tenth degree, we obtain the computed concordant ages given in table 4.

TABLE 4.-Computed concordant ages obtained from equation 17

\begin{tabular}{|c|c|c|}
\hline Degree of equation & $\begin{array}{l}\text { Age corrected for com- } \\
\text { mon lead (millions of } \\
\text { years) }\end{array}$ & $\begin{array}{l}\text { Second real root } \\
\text { (millions of years) }\end{array}$ \\
\hline 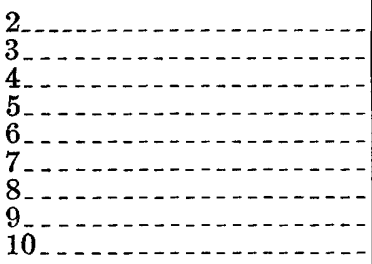 & $\begin{array}{l}945.58 \\
948.49 \\
949.79 \\
950.06 \\
950.10 \\
950.10 \\
950.10 \\
950.10 \\
950.10\end{array}$ & $\begin{array}{r}-187_{05} \\
+250_{85} \\
851_{7.7} \\
634_{6.4} \\
562_{1.3} \\
531_{6.2} \\
517_{7.6} \\
511_{4.1} \\
508_{5.7}\end{array}$ \\
\hline
\end{tabular}

The smaller, positive real root of equation 17 rapidly converges on the hypothetical age, 950 m.y., corrected for common lead. In the calculation of the trial ages, an initial error of 2 percent was deliberately introduced into the $\mathrm{Pb}^{204}$ abundance of the hypothetical common lead used in the correction. This small error in the $\mathrm{Pb}^{204}$ abundance produced in turn errors of approximately $0.6,6.0$ and 18 percent in the trial $\mathrm{Pb}^{206} / \mathrm{U}^{238}$, $\mathrm{Pb}^{207} / \mathrm{U}^{235}$ and $\mathrm{Pb}^{207} / \mathrm{Pb}^{206}$ ages, respectively. The age calculated using equation 17 did not include the index isotope and was not affected.

For equations of the third degree or higher, the larger real root is positive and converges more slowly on an age that is greater than the current estimates of the age of the earth. It should be noted that even for ages as much as 5,000 million years, equations of the tenth degree converge rapidly on the exact concordant age. This older age has no geological significance other than that a radiogenic lead with a $\mathrm{Pb}^{207} / \mathrm{Pb}^{206}$ ratio equal to 0.9612 would have been produced in the time interval between 950 and 5,110 million years ago.

In order to use equation 19 it is necessary to express the analytical data as quantities proportional to the number of atoms present. Following the procedures given on page $\mathrm{E} 8$, the analytical data take the form

$$
N_{5}=0.05311_{8}
$$




$$
\begin{aligned}
& N_{8}=7.314_{3} \\
& { }^{t} N_{6}=1.559_{6} \\
& { }^{t} N_{7}=0.4744_{1} \\
& R_{5 t}={ }^{t} N_{7} / N_{5}=8.931_{3} \\
& R_{8 t}={ }^{t} N_{6} / N_{8}=0.2132_{2} \\
& R=0.007262
\end{aligned}
$$

and the $\mathrm{Pb}^{207} / \mathrm{Pb}^{206}$ ratio of the contaminating common lead, $R^{c}$, is given as $0.9612_{6}$.

For this approximate age range, it is also necessary to include the terms $f_{1}$ and $f_{2}$. The choice of an age $t_{1}$ from table 2 may be guided by the following generalizations on discordant ages related to uncertainties introduced by common lead corrections:

1. The $\mathrm{Pb}^{206} / \mathrm{U}^{238}$ age will be affected least by a poor choice of the isotopic composition for the commonlead correction.

2. The $\mathrm{Pb}^{207} / \mathrm{U}^{235}$ and $\mathrm{Pb}^{207} / \mathrm{Pb}^{206}$ ages may lie above or below the $\mathrm{Pb}^{208} / \mathrm{U}^{238}$ age, depending on the isotopic composition of the common lead used in the correction.

3. The $\mathrm{Pb}^{207} / \mathrm{Pb}^{206}$ age will give the least satisfactory value for the actual age of the sample if the major source of error is confined to the common lead corrections.

On the basis of the trial age calculations, and using the generalizations mentioned above, values of $f_{1}$ and $f_{2}$ are chosen from table 2 for $t_{1}=950 \mathrm{~m}$.y. Substituting the values for $R_{5 t}, R_{8 t}, R^{c}$ and $R$ in equation 19 one obtains:

$$
\begin{aligned}
2 a & =\left(R^{c} \lambda_{1}^{2}-R \lambda_{2}^{2}\right) \\
& =1.584_{3} \times 10^{-20} y^{-2} \\
b & =\left(R^{c} \lambda_{1}-R \lambda_{2}\right) \\
& =1.406_{8} \times 10^{-10} y^{-1} \\
c & =\left(R R_{5 t}-R^{c} R_{8 t}+R^{c} f_{1}-R f_{2}\right) \\
& =-0.1407_{9} \\
t & =\frac{-b \pm \sqrt{b^{2}-4 a c}}{2 a} \\
t & =\frac{\left(-1.406_{8} \pm \sqrt{\left.1.9790_{8}+0.4461_{1}\right)}\right.}{1.584_{3}} \times 10^{10} y \\
t & =950 \text { m.y. }
\end{aligned}
$$

The agreement between the age, $t_{1}$, taken from table 2 , and the calculated age, $t$, obtained from equation 19 , indicates that an additional age calculation with a new value for $t_{1}$ is not necessary.
For certain geologic problems it may be useful to compare the calculated isotopic composition of the

\begin{tabular}{|c|c|c|}
\hline & Calculated & Measured \\
\hline $\begin{array}{l}\mathrm{Pb}^{204} \\
\mathrm{~Pb}^{206} \\
\mathrm{~Pb}^{207} \\
\mathrm{~Pb}^{208}\end{array}$ & $\begin{array}{l}\text { 1. } 480 \\
\text { 23. } 57_{4} \\
\text { 22. } 66_{1} \\
\text { 52. } 28_{5}\end{array}$ & $\begin{array}{l}\text { 1. } 50_{79} \\
23.56_{8} \\
22.65_{8} \\
52.26_{9}\end{array}$ \\
\hline
\end{tabular}
contaminating common lead yielding a concordant age with the measured composition of the common lead used in the trial age calculation. Quantities proportional to the number of atoms of common $\mathrm{Pb}^{206}$ and $\mathrm{Pb}^{207}, N_{6}^{c}$ and $N_{7}^{c}$, can be obtained from equation 14 and 15 , respectively. If the age tables are used, and $t=950 \mathrm{~m} . \mathrm{y} ., N_{6}^{c}$ is found to be $0.4096_{2}$ and $N_{7}^{c}$ is found to be $0.3937_{5}$. From the $\mathrm{Pb}^{208} \mathrm{~Pb}^{206}$ and $\mathrm{Pb}^{204} / \mathrm{Pb}^{208}$ ratios of the radiogenic lead, the quantities proportional to the number of atoms of $\mathrm{Pb}^{208}$ and $\mathrm{Pb}^{204}$ are found to be $0.9084_{8}$ and $0.02571_{6}$. The calculated and the measured isotopic compositions (in atom percent) used in the trial age calculation are as follows:

Isotopic composition

It does not follow from the differences in the $\mathrm{Pb}^{204}$ abundances given above that all the error must necessarily be restricted to the common lead. For the purpose of this example, the $\mathrm{Pb}^{204} / \mathrm{Pb}^{208}$ ratio of the radiogenic lead was assumed to be correct. In actual practice, however, this measurement might be more suspect than the $\mathrm{Pb}^{204} / \mathrm{Pb}^{208}$ ratio of the common-lead analysis. Under these conditions, differences in the calculated and "measured" index isotope may be used as evidence that the discordant age sequence reflects small errors in the determination of the index isotope in either the radiogenic lead, the common lead, or both.

\section{GRAPHIC SOLUTION}

The graphic equivalent of the algebraic solution of this case is shown in figure 3 , where total ${ }^{t} N_{207} / N_{235}$ versus total ${ }^{t} N_{206} / N_{238}$ is plotted instead of radiogenic $N_{207} / N_{235}$ versus radiogenic $N_{206} / N_{238}$, as was done by Ahrens (1955a, b) and Wetherill (1956). Both the concordant and the discordant ages of a sample corrected for different amounts of a common lead with a specific $\mathrm{Pb}^{207} / \mathrm{Pb}^{206}$ ratio can now be determined from this new graph. The concordant age curve still represents the locus of those points whose $N_{207} / N_{235}$ and $N_{206} / N_{238}$ ratios give the same age, $t$. In this graph, the concordant age of an unaltered sample, $A$, corrected for a common lead with a specific $\mathrm{Pb}^{207} / \mathrm{Pb}^{206}$ ratio, $R^{c}$, is obtained by passing a line whose slope is equal to $R^{c} \times 137.7$ through the point $A$, and noting the intersection of this line with the concordant age curve at the point $t$. It is 
obvious that the age, $t$, is obtained without use of either $\mathrm{Pb}^{204}$ or $\mathrm{Pb}^{208}$ as the index of the common lead present.

This concordant age solution now may be compared graphically with the ages obtained by the more conventional "index" methods of correcting for contaminating common lead, which use either $\mathrm{Pb}^{204}$ or $\mathrm{Pb}^{208}$ as the index isotope (fig. 3). First, the age is obtained from the ratio of the radiogenic $\mathrm{Pb}^{207} / \mathrm{Pb}^{206}$ using the appropriate index isotope, $\mathrm{Pb}^{204}$ or $\mathrm{Pb}^{208}$, and a common lead having the same $\mathrm{Pb}^{207} / \mathrm{Pb}^{206}$ ratio, $R^{c}$. Then, with the aid of either the nomographs or the age tables that are available, a point, $c$, is obtained on the concordant age curve whose $N_{200} / N_{238}$ or $N_{207} / N_{23 \tilde{5}}$ ratio is equivalent in age to the radiogenic $\mathrm{Pb}^{207} / \mathrm{Pb}^{206}$ ratio age just calculated. A line is now drawn from the origin to this equivalent point, $c$, on the concordant age curve. The coordinate of the intersection, $a$, of the chord, $\mathrm{O} c$, and the line passing through $A$ with the slope $R^{c} \times 137.7$, will give the corresponding $N_{207} / N_{235}$ and $N_{206} / N_{238}$ ratios that would be obtained by using the conventional index isotope method of common-lead correction. A comparison of the age equivalents of the coordinates of the intersections $a$ and $t$ may also help in a partial evaluation of the experimental errors encountered in the isotopic analysis of the generally far less abundant index isotopes.

\section{TWO SAMPLES}

AMOUNT OF CONTAMINATING RADIOGENIC LEAD AND ITS $\mathbf{P b}^{207 / P b}{ }^{208}$ RATIO UNKNOWN

From the preceding algebraic equations and from the graphic treatment (fig. $2 B$ ) it can be seen that given analytical data for two different samples, an expression for $t$ could be obtained without a knowledge of either the time and amount of alteration or amount of original radiogenic $\mathrm{Pb}^{206}$ and $\mathrm{Pb}^{207}$ present. This calculation can be made provided the two samples give different discordant ages and meet the following conditions:

1. The samples were deposited at the same time.

2. The samples were contaminated by an original radiogenic lead having the same $\mathrm{Pb}^{207} / \mathrm{Pb}^{206}$ ratio, or

3 . The samples were altered at one time in the past.

4. The initial corrections for common lead have been correctly made, so that the remaining $\mathrm{Pb}^{208}$ and $\mathrm{Pb}^{207}$ represent only the total radiogenic lead in the samples.

5. The samples have not selectively lost or gained radioactive daughter products since the time of mineral formation.

6. The samples have not been recently altered.

These assumptions require, as a general rule, that if the discordant trial $\mathrm{Pb}^{208} / \mathrm{U}^{238}$ age of sample $A$ is greater than the discordant trial $\mathrm{Pb}^{208} / \mathrm{U}^{238}$ age of sample $B$, then the trial $\mathrm{Pb}^{207} / \mathrm{Pb}^{206}$ age of sample $A$ must be equal to or greater than the trial $\mathrm{Pb}^{207} / \mathrm{Pb}^{206}$ age of sample $B$. If this condition is not met, that is, the trial $\mathrm{Pb}^{207} / \mathrm{Pb}^{206}$ age of $A$ is less than $B$ while the trial $\mathrm{Pb}^{206} / \mathrm{U}^{238}$ age of $A$ is greater than $B$, then the equations presented in this and in the following cases will probably yield one negative value of $t$. Such a pair of discordant ages may be interpreted as a failure of the two samples to fulfill one or more of the assumptions listed above.

Following the notation used in developing equation 11, expressions may be written for samples $A$ and $B$ : For sample $A$,

$$
R\left[\frac{R_{5 a}-\left(\frac{\left(\lambda_{2} t\right)^{n}}{n !} \cdots+\frac{\left(\lambda_{2} t\right)^{2}}{2 !}+\lambda_{2} t\right)}{R_{8 a}-\left(\frac{\left(\lambda_{1} t\right)^{n}}{n !} \cdots+\frac{\left(\lambda_{1} t\right)^{2}}{2 !}+\lambda_{1} t\right)}\right]=R_{a}^{*}
$$

and for"sample $B$

$$
R\left[\frac{R_{5 b}-\left(\frac{\left(\lambda_{2} t\right)^{n}}{n !} \cdots+\frac{\left(\lambda_{2} t\right)^{2}}{2 !}+\lambda_{2} t\right)}{R_{8 b}-\left(\frac{\left(\lambda_{1} t\right)^{n}}{n !} \cdots+\frac{\left(\lambda_{1} t\right)^{2}}{2 !}+\lambda_{1} t\right)}\right]=R_{b}^{*}
$$

where $R_{5 a}=$ the ratio of the number of radiogenic $\mathrm{Pb}^{207}$ atoms, $N_{7 a}$, to the number of $\mathrm{U}^{235}$ atoms, $N_{5 b}$, now present in sample $A$.

$\mathrm{R}_{8 a}=$ the ratio of the number of radiogenic $\mathrm{Pb}^{206}$ atoms, $N_{6 a}$, to the number of $\mathrm{U}^{238}$ atoms, $N_{8 a}$, now present in sample $A$.

$R_{5 b}=$ the ratio of the number of radiogenic $\mathrm{Pb}^{207}$ atoms, $N_{7 b}$, to the number of $\mathrm{U}^{235}$ atoms, $N_{5 b}$, now present in sample $B$.

$\mathrm{R}_{8 b}=$ the ratio of the number of radiogenic $\mathrm{Pb}^{206}$ atoms, $N_{6 b}$, to the number of $\mathrm{U}^{238}$ atoms, $N_{8 b}$, now present in sample $B$.

$\lambda_{1}=$ the decay constant for $\mathrm{U}^{238}$.

$\lambda_{2}=$ the decay constant for $\mathrm{U}^{235}$.

$R_{a}^{*}, R_{b}^{*}=$ the unknown ratio of the number of atoms of original radiogenic $\mathrm{Pb}^{207}$ to $\mathrm{Pb}^{206}$, that is, $N_{7 a}^{*} / N_{6 a}^{*}=N_{7 b}^{*} / N_{6 b}^{*}$.

$R=N_{5 a} / N_{8 a}=N_{5 b} / N_{8 b}=0.007262$

Accepting assumptions (1) to (6) above, equation 20 is equated to equation 21 . Expanding and collecting terms, the equation takes the form

$$
\begin{aligned}
& {\left[\frac{\lambda_{2}^{n}}{n !}\left(R_{8 a}-R_{8 b}\right)+\frac{\lambda_{1}^{n}}{n !}\left(R_{5 b}-R_{5 a}\right)\right] t^{n} \ldots } \\
+ & {\left[\frac{\lambda_{2}^{2}}{2 !}\left(R_{8 a}-R_{8 b}\right)+\frac{\lambda_{1}^{2}}{2 !}\left(R_{5 b}-R_{5 a}\right)\right] t^{2} } \\
+ & {\left[\lambda_{2}\left(R_{8 a}-R_{8 b}\right)+\lambda_{1}\left(R_{5 b}-R_{5 a}\right)\right] t } \\
+ & R_{5 a} R_{8 b}-R_{5 b} R_{8 a}=0 .
\end{aligned}
$$


If computing facilities are not available, equation 22 may be taken to the second degree and the terms $f_{1}$ and $f_{2}$ added.

$$
\begin{aligned}
& {\left[\frac{\lambda_{2}^{2}}{2 !}\left(R_{8 a}-R_{8 b}\right)+\frac{\lambda_{1}^{2}}{2 !}\left(R_{5 b}-R_{5 a}\right)\right] t^{2} } \\
+ & {\left[\lambda_{2}\left(R_{8 a}-R_{8 b}\right)+\lambda_{1}\left(R_{5 b}-R_{5 a}\right)\right] t } \\
+ & R_{5 a} R_{8 b}-R_{5 b} R_{8 a}+f_{2}\left(R_{8 a}-R_{8 b}\right)+f_{1}\left(R_{5 b}-R_{5 a}\right)=0
\end{aligned}
$$

Solving for $t$,

$$
t=\frac{-b \pm \sqrt{b^{2}-4 a c}}{2 a}
$$

where $2 a=\left[\lambda_{1}^{2}\left(R_{5 b}-R_{5 a}\right)+\lambda_{2}^{2}\left(R_{8 a}-R_{8 b}\right)\right]$

$$
\begin{aligned}
& b=\left[\lambda_{1}\left(R_{5 b}-R_{5 a}\right)+\lambda_{2}\left(R_{8 a}-R_{8 b}\right)\right] \\
& c=\left[R_{5 a} R_{8 b}-R_{5 b} R_{8 a}+f_{2}\left(R_{8 a}-R_{8 b}\right)+f_{1}\left(R_{5 b}-R_{5 a}\right)\right] .
\end{aligned}
$$

For geologically possible values of $R_{5 a}, R_{8 a}, R_{5 b}$, and $R_{8 b}$; and with assumptions " 1 " through " 4 ", given above, fulfilled; equations 22 and 23 have two positive real roots. Analogous to equations 12 and 13, the two positive roots of these equations approach the concordant ages corrected for original radiogenic lead, loss of lead, or gain of uranium.

\section{EXAMPLE OF CALCULATION}

Equations 22 and 23 may be applied to two hypothetical, unaltered 500-million-year-old uraninite samples from the same deposit. Following the procedure used on page $\mathrm{E} 8$, the chemical and isotopic data for these two samples, $A$ and $B$, are expressed after correction for common lead as follows:

$$
\begin{array}{lc}
\quad \text { Sample A } & \text { Sample } \mathrm{B} \\
N_{8 a}=17.75_{6} & N_{8 b}=14.43_{5} \\
N_{5 a}=0.1289_{4} & N_{5 b}=0.1048_{5} \\
N_{6 a}=1.736_{4} & N_{6 b}=1.654_{6} \\
N_{7 a}=0.1133_{7} & N_{7 b}=0.1171_{0} \\
& \lambda_{1}=1.53_{69} \times 10^{-10} \mathrm{y}^{-1} \\
& \lambda_{2}=\mathbf{9 . 7 2} \times 12_{16} \times 10^{-10} \mathrm{y}^{-1}
\end{array}
$$

The lead-uranium and lead-lead ratios and trial leaduranium and lead-lead ages of samples $A$ and $B$ using the age tables corrected only for original common lead are:

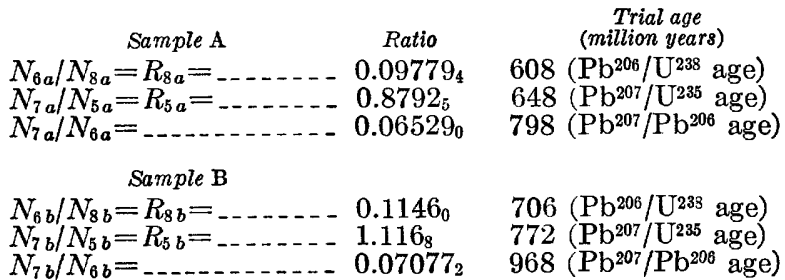

Substituting the values for $R_{5 a}, R_{8 a}, R_{5 b}$ and $R_{8 b}$ in equation 22 and solving the equations of the second to the tenth degree, the ages given in table 5 are obtained. It can be seen that in the age range of 500 million years, ages corrected for original radiogenic lead will fall within 0.1 percent of the exact concordant age when an equation of the fourth degree is used. The "lead-loss" age for the fourth-degree equation will, in contrast, be within 3.7 percent of the exact concordant "lead-loss" age. An equation of the sixth degree would be required to reduce the difference between the computed and exact "lead-loss" age to less than 0.1 percent. For most geologic problems falling within this age range, the two concordant ages obtained from a fifth- or sixth-degree equation would be more than adequate.

TABLE 5.-Computed concordant ages obtained from equation $2 \mathcal{Q}$

\begin{tabular}{c|r|r}
\hline & \multicolumn{2}{|c}{ Age (millions of years) } \\
\cline { 2 - 3 } & $\begin{array}{c}\text { Degree of equation } \\
\text { Corrected for original } \\
\text { radiogenic lead }\end{array}$ & $\begin{array}{c}\text { Corrected for loss or } \\
\text { gain of lead or uranium }\end{array}$ \\
\hline & 477.09 & $345_{0.2}$ \\
\hline 5 & 496.72 & $164_{5.8}$ \\
\hline 7 & 499.64 & $144_{1.2}$ \\
\hline 9 & 499.93 & $140_{0.9}$ \\
\hline 10 & 499.95 & $139_{2.7}$ \\
\hline & 499.96 & $139_{1.1}$ \\
\hline
\end{tabular}

In order to use equation 23 , it is first necessary to examine the values of $f_{1}$ and $f_{2}$ in table 2 for a time, $t_{1}$, of around 600 million years. This examination suggests that the terms including both $f_{1}$ and $f_{2}$ should be used in the calculation. As an age including an additional correction for original radiogenic lead must necessarily be less than the lowest $\mathrm{Pb}^{208} / \mathrm{U}^{238}$ age in the group of samples corrected only for common lead, initial values for $f_{1}$ and $f_{2}$ equivalent to an age of $t_{1}=550 \mathrm{~m}$.y. are chosen for the calculation. Substituting the following in equation 23 ,

$$
\begin{array}{lll}
R_{5 a}=0.8792_{5} & R_{5 b}=1.116_{8} & f_{1}=0.0001_{0} \\
R_{8 a}=0.09779_{4} & R_{8 b}=0.1146_{0} & f_{2}=0.0292_{8}
\end{array}
$$

where

$$
\begin{aligned}
2 a & =\lambda_{1}^{2}\left(R_{5 b}-R_{5 a}\right)+\lambda_{2}^{2}\left(R_{8 a}-R_{8 b}\right) \\
& =\left[2.36_{21}\left(0.2375_{5}\right)+94.51_{0}\left(-0.0168_{1}\right)\right] \times 10^{-20} y^{-1} \\
& =-1.027_{58} \times 10^{-20} y^{-2} \\
b & =\lambda_{1}\left(R_{5 b}-R_{5 a}\right)+\lambda_{2}\left(R_{8 a}-R_{8 b}\right) \\
& =\left[1.53_{69}\left(0.2375_{5}+9.72_{16}\left(0.0168_{1}\right)\right] \times 10^{-10} y^{-1}\right. \\
& =0.2016_{7} \times 10^{-10} y^{-1} \\
c & =\left[R_{5 a} R_{8 b}-R_{5 b} R_{8 a}+f_{1}\left(R_{5 b}-R_{5 a}\right)+f_{2}\left(R_{8 a}-R_{8 b}\right)\right] \\
& =\left[0.1007_{62}+-0.1092_{16}+0.0000_{24}-0.0004_{92}\right] \\
& =-0.0089_{22}
\end{aligned}
$$


$t$ becomes,

$$
\begin{aligned}
t & =\frac{-b \pm \sqrt{b^{2}-4 a c}}{2 a} \\
& =\left[\frac{-0.2016_{7} \pm \sqrt{\left(.2016_{7}\right)^{2}-2 \times-1.027_{58} \times-0.0089_{22}}}{-1.027_{58}}\right] 10^{10} \mathrm{y} \\
& =\left[\frac{-0.2016_{7} \pm \sqrt{0.0223_{55}}}{-1.0275_{8}}\right] \times 10^{10} \mathrm{y} \\
& =\frac{-0.2016+0.1494_{5}}{-1.027_{58}}=0.0508_{2} \times 10^{10} \mathrm{y} \\
& =508 \mathrm{~m} . \mathrm{y} .
\end{aligned}
$$

From the fact that the calculated age, $t=508 \mathrm{~m} . \mathrm{y}$., included values from table 2 of $f_{1}$ and $f_{2}$ for $t_{1}=550 \mathrm{~m}$.y., it is obvious that a recalculation of $t$ using values of $f_{1}$ and $f_{2}$ for $t$ slightly less than $508 \mathrm{~m}$.y. would be better. There is, however, an exceedingly sensitive test of the departure of the age, $t=508$ m.y., from the exact solution of equation 23. This test consists of comparing the calculated ratios of the original radiogenic leads in samples $A$ and $B$ ( $R_{a}^{*}$ and $R_{b}^{*}$,) using equations 20 and 21 and $t=0.0508 \times 10^{10} y$. As a first approximation, the values of $f_{1}$ and $f_{2}$ in equations 20 and 21 may be chosen from table 2 for $t_{1}=510$ m.y. A simpler procedure is to substitute the ratios $N_{6} / N_{8}$ and $N_{7} / N_{5}$ obtained from the age table for $t=508 \mathrm{~m}$.y. for the terms $\left[f_{1}+\frac{\left(\lambda_{1} t\right)^{2}}{2 !}+\lambda_{1} t\right]$ and $\left[f_{2}+\frac{\left(\lambda_{2} t\right)^{2}}{2}+\lambda_{2} t\right]$ in equation 20 and 21 . Using the age tables, $R_{a}^{*}$ and $R_{b}^{*}$ are, respectively, 0.1051 , and 0.1040 .

If the geologic requirements of the age problem are not stringent, and the disagreement between $R_{a}^{*}$ and $R_{b}^{*}$ is acceptable, the calculated age may be rounded down to the nearest five million years and reported as $t=505$ m.y. If, however, further refinements are required by the nature of the geologic problem, $t$ may be recalculated using equation 23. The values of $f_{1}$ and $f_{2}$, $0.0000_{79}$ and $0.0224_{05}$, for $t_{1}=505 \mathrm{~m} . y$. , are obtained from table 2 by linear extrapolation. The recalculated age of samples $A$ and $B$ using equation 23 then becomes, $t=500.06$ m.y.

A test of this calculated age at $t=501$ m.y., using equations 20 and 21 gives for $R_{a}^{*}$ and $R_{b}^{*}$ respectively, $0.1029_{7}$ and $0.1028_{1}$. The condition $R_{a}^{*}=R_{b}^{*}=0.1026_{6}$ occurs at $t=500$ m.y. For almost any conceivable problem, this very close agreement between $R_{a}^{*}$ and $R_{b}^{*}$ would be more than adequate. As the second recalculated age is still less than the age $t_{1}$ used in choosing $f_{1}$ and $f_{2}$, the final age for samples $A$ and $B$ would now be rounded down to the nearest $5 \mathrm{~m} . y$. and reported as, $t=500$ m.y.
In areas where detailed age studies are being made on a suite of uranium ores, isotopic data may also have been obtained for the lead in the associated nonradioactive minerals. If the lead in these associated minerals is abnormally enriched in $\mathrm{Pb}^{206}$ and $\mathrm{Pb}^{207}$ relative to $\mathrm{Pb}^{204}$, the $\mathrm{Pb}^{207} / \mathrm{Pb}^{206}$ ratio of this radiogenically enriched lead may now be compared with the calculated ratio of the original radiogenic lead, $R^{*}$, required to produce concordant lead-uranium and lead-lead ages in any particular pair of ore samples. Agreement between the calculated ratio of the required original radiogenic lead and the measured $\mathrm{Pb}^{207} / \mathrm{Pb}^{206}$ ratio of the radiogenic lead in the associated nonradioactive minerals, could be used as convincing evidence in the evaluation of a discordant age pattern in terms of the presence of original radiogenic lead. Evidence of alteration, conversely, could be used to support a "lead-loss" type of evaluation.

The complexity of most geologic age problems as well as an awareness of the experimental uncertainties usually suggest the desirability of studying, where possible, more than two samples from the same area. Similarities in the calculated concordant ages and the $R^{*}$ obtained from two or more pairs would not only support the interpretation of the discordant age data in terms of a specific process, but also further limit alternative interpretations.

\section{GRAPHIC SOLUTION}

The graphic equivalent of the algebraic concordant age solution for two samples is shown in figure $2 B$. The concordant age corrected for the presence of an older generation of radiogenic lead can be obtained by passing a line through the two points, $B$ and $C$, and noting the intersection, $t$, with the concordant age curve having the smallest $N_{206} / N_{238}$ and $N_{207} / N_{235}$ ratios. The slope of this straight line divided by 137.7 will equal $R^{*}$, the $\mathrm{Pb}^{207} / \mathrm{Pb}^{206}$ ratio of the older radiogenic lead. The intersection giving the higher age value, $t_{1}$, corresponds to the age obtained after correcting for the gain or losses of lead or uranium as previously described. This graph makes it clear, as do the equations, that the two concordant age solutions $t$ and $t_{1}$ are mathematically equally acceptable. The choice of either $t$ or $t_{1}$ as the most probable concordant age for both $B$ and $C$ must be based on other evidence.

\section{AMOUNT OF CONTAMINATING COMMON LEAD AND TTS} Pb $^{207 / P b} 200$ RATIO UNKNOWN

Following the arguments used in the previous example and the notation used in the correction for common lead, a concordant age, based on the following assumptions, can be found for a pair of samples giving different discordant trial ages.

1. The samples were deposited at the same time. 
2. The samples were contaminated only by a common lead having the same $\mathrm{Pb}^{207} / \mathrm{Pb}^{206}$ ratio.

3. The samples have not been altered since deposition.

Sample $A$, equation 16 , takes the form,

$$
R\left[\frac{R_{5 t a}-\left(\frac{\left(\lambda_{2} t\right)^{n}}{n !} \cdots+\frac{\left(\lambda_{2} t\right)^{2}}{2 !}+\lambda_{2} t\right)}{R_{8 t a}-\left(\frac{\left(\lambda_{1} t\right)^{n}}{n !} \cdots+\frac{\left(\lambda_{1} t\right)^{2}}{2 !}+\lambda_{1} t\right)}\right]=N_{7 a}^{c} / N_{6 a}^{c}=R_{a}^{c},
$$

and sample $B$.

$$
R\left[\frac{R_{5 t b}-\left(\frac{\left(\lambda_{2} t\right)^{n}}{n !} \ldots+\frac{\left(\lambda_{2} t\right)^{2}}{2 !}+\lambda_{2} t\right)}{R_{8 t b}-\left(\frac{\left(\lambda_{1} t\right)^{n}}{n !} \ldots+\frac{\left(\lambda_{1} t\right)^{2}}{2 !}+\lambda_{1} t\right)}\right]=N_{7 b}^{c} / N_{6 b}^{c}=R_{b}^{c} .
$$

where $N_{7 a}^{c} / N_{6 a}^{c}=R_{a}^{c}$, the ratio of the number of atoms of $\mathrm{Pb}^{207}$ to $\mathrm{Pb}^{206}$ in the contaminating common lead (sample $A$ ).

$N_{7 b}^{c} / N_{6 b}^{c}=R_{b}^{c}$, the ratio of the number of atoms of $\mathrm{Pb}^{207}$ to $\mathrm{Pb}^{206}$ in the contaminating common lead (sample $B$ ).

$R_{5 t a}=$ the ratio of the total number of atoms of $\mathrm{Pb}^{207},{ }^{t} N_{7 a}$, to the number of $\mathrm{U}^{235}$ atoms, $N_{5 a}$, now present in sample $A$.

$R_{8 t a}=$ the ratio of the total number of atoms of $\mathrm{Pb}^{206},{ }^{t} N_{6 a}$, to the number of $\mathrm{U}^{238}$ atoms, $N_{\delta a}$, now present in sample $A$.

$R_{5 t b}=$ the ratio of the total number of atoms of $\mathrm{Pb}^{207},{ }^{i} N_{7 b}$, to the number of $\mathrm{U}^{235}$ atoms, $N_{5 b}$, now present in sample $B$.

$R_{8 t b}=$ the ratio of the total number of atoms of $\mathrm{Pb}^{206},{ }^{t} N_{6 b}$, to the number of $\mathrm{U}^{238}$ atoms, $N_{8 b}$, now present in sample $B$.

Equating equations 24 and 25, (assumption 2) clearing and collecting terms,

$$
\begin{aligned}
& {\left[\frac{\lambda_{1}^{n}}{n !}\left(R_{5 t b}-R_{5 t a}\right)+\frac{\lambda_{2}^{n}}{n !}\left(R_{8 t a}-R_{8 t b}\right)\right] t^{n} \ldots } \\
+ & {\left[\frac{\lambda_{1}^{2}}{2 !}\left(R_{5 t b}-R_{5 t a}\right)+\frac{\lambda_{2}^{2}}{2 !}\left(R_{8 t a}-R_{8 t b}\right)\right] t^{2} } \\
+ & {\left[\lambda_{1}\left(R_{5 t b}-R_{5 t a}\right)+\lambda_{2}\left(R_{8 t a}-R_{8 t b}\right)\right] t } \\
+ & R_{5 t a} R_{8 t b}-R_{5 t b} R_{8 t a}=0 .
\end{aligned}
$$

If computing facilities are not available, equation 26 may be expanded to the second degree and the terms $f_{1}$ and $f_{2}$ added. Solving this equation for $t$ one obtains:

$$
t=\frac{-b \pm \sqrt{b^{2}-4 a c}}{2 a}
$$

where

$$
\begin{aligned}
2 a & =\lambda_{1}^{2}\left(R_{5 t b}-R_{5 t a}\right)+\lambda_{2}^{2}\left(R_{8 t a}-R_{8 t b}\right) \\
b & =\lambda_{1}\left(R_{5 t b}-R_{5 t a}\right)+\lambda_{2}\left(R_{8 t a}-R_{8 t b}\right) \\
c & =R_{5 t a} R_{8 t b}-R_{5 t b} R_{8 t a}+f_{1}\left(R_{5 t b}-R_{5 t a}\right)+f_{2}\left(R_{8 t a}-R_{8 t b}\right) .
\end{aligned}
$$

For geologically possible values of $R_{5 t a}, R_{8 t a}, R_{5 t b}$, and $R_{8 t b}$ fulfilling assumption 1,2 , and 3 equations of degree 3 or greater, equation 26 has two positive, real roots. The smaller root, as was the case for equation 17, approaches the concordant age corrected for a common lead whose $\mathrm{Pb}^{207} / \mathrm{Pb}^{206}$ ratio, $R^{c}$, is given by equation 24 or 25 . Equation 27 has one positive and

\begin{tabular}{|c|c|c|c|c|c|c|}
\hline \multirow{2}{*}{ Sample } & \multicolumn{4}{|c|}{ Isotopic composition (in atom percent) } & \multicolumn{2}{|c|}{$\begin{array}{l}\text { Uranium and lead } \\
\text { content (chemical } \\
\text { scale) }\end{array}$} \\
\hline & $\mathrm{Pb}^{204}$ & $\mathrm{~Pb}^{206}$ & $\mathrm{~Pb}^{207}$ & $\mathrm{~Pb}^{20 \mathrm{z}}$ & $\underset{U}{\text { Percent }}$ & $\begin{array}{l}\text { Percent } \\
\text { Pb }\end{array}$ \\
\hline $\begin{array}{l}A_{\ldots} \\
B_{\ldots}\end{array}$ & $\begin{array}{l}0.866_{4} \\
0.652_{3}\end{array}$ & $\begin{array}{l}\text { 52. } 54_{2} \\
62.64_{7}\end{array}$ & $\begin{array}{l}\text { 15. } 98_{3} \\
13.65_{4}\end{array}$ & $\begin{array}{l}\text { 30. } 60_{8} \\
23.04_{7}\end{array}$ & $\begin{array}{l}\text { 17. } 5_{44} \\
30.7_{53}\end{array}$ & $\begin{array}{l}\text { 6. } 12_{37} \\
\text { 7. } 94_{47}\end{array}$ \\
\hline
\end{tabular}
one negative root. The positive root for approximately correct values of $f_{1}$ and $f_{2}$ approaches the smaller root of equation 26 .

\section{EXAMPLE OF CALCULATION}

An example of the use of equation 26 in the correction for common lead is given below. The following isotopic and chemical data are given for two hypothetical, unaltered 950-million-year-old uraninite samples, $A$ and $B$ from a single deposit.

Assuming an isotopic composition for the common lead contamination in samples $A$ and $B$ to be in atom percent,

$$
\frac{\mathrm{Pb}^{204}}{1.485_{2}} \quad \frac{\mathrm{Pb}^{208}}{23.76_{4}} \quad \frac{\mathrm{Pb}^{207}}{22.27_{8}} \quad \frac{\mathrm{Pb}^{208}}{52.47_{3}}
$$

the following discordant trial age sequences are obtained using the age tables and $\mathrm{Pb}^{201}$ as the index isotope:

$$
\begin{aligned}
& \text { Sample } A \ldots \ldots \quad \frac{\mathrm{Pb}^{200 / \mathrm{U} 238}}{948 \mathrm{~m} . \mathrm{y} .} \quad \frac{\mathrm{Pb}^{207 / \mathrm{U}^{235}}}{1,010 \mathrm{~m} . \mathrm{y} .} \quad \frac{\mathrm{Pb}^{207} / \mathrm{Pb}^{208}}{1,148 \mathrm{~m} . \mathrm{y} .} \\
& \text { Sample } B_{-. . . .-} 950 \text { m.y. } \quad 984 \text { m.y. } \quad 1,064 \text { m.y. }
\end{aligned}
$$

These discordant trial ages may be compared with the concordant ages obtained from equation 26 given in table 6 . The smaller root of equation 26 converges on the concordant age corrected for common lead even though the isotopic composition of the contaminating common lead does not appear in the calculation. The similarity of the trial $\mathrm{Pb}^{206} / \mathrm{U}^{238}$ age to the concordant age corrected for common lead might be used as one 
argument that the discordant trial age sequence was the result of an incorrect assumption as to the isotopic composition of the contaminating common lead.

TABLE 6.-Computed concordant ages obtained from equation 26

\begin{tabular}{c|c|c}
\hline Degree of equation & $\begin{array}{c}\text { Concordant age cor- } \\
\text { rected for common lead } \\
\text { (millions of years) }\end{array}$ & $\begin{array}{c}\text { Second real root } \\
\text { (millions of years) }\end{array}$ \\
\hline & 945.42 & \\
\hline 5 & 948.33 & $250_{66 .}$ \\
\hline 5 & 949.63 & $851_{5.4}$ \\
\hline 5 & 949.90 & $634_{5.1}$ \\
\hline 10 & 949.94 & $562_{0.4}$ \\
\hline
\end{tabular}

Using the generalizations given on page $\mathrm{E} 8$ as a guide in the evaluation of the discordant trial ages of samples $A$ and $B$, an initial choice of $t_{1}=950 \mathrm{~m}$.y., corresponding to the $\mathrm{Pb}^{206} / \mathrm{U}^{208}$ age, is made in selecting the constants $f_{1}$ and $f_{2}$ from table 2. Following the procedure given on page E8, the chemical and isotopic data for samples $A$ and $B$ are expressed below as quantities proportional to the total number of atoms of lead and uranium in the sample at the time of analysis, and as ratios of the total number of atoms of $\mathrm{Pb}^{206}$ and $\mathrm{Pb}^{207}$ to $\mathrm{U}^{238}$ and $\mathrm{U}^{235}$.

$$
\begin{aligned}
& \begin{array}{c}
\text { Sample } \mathrm{A} \\
N_{5 a}=0.05311_{8}
\end{array} \\
& N_{8 a}=7.314_{3} \\
& { }^{\imath} N_{6 a}=1.559_{6} \\
& { }^{t} N_{7 a}=0.4744_{1} \\
& R_{5 t a}=\frac{0.4744_{0}}{0.05312_{1}}=8.931_{4} \\
& R_{5 t b}=\frac{0.5266_{5}}{0.09310_{8}}=5.656_{4} \\
& R_{8 t a}=\frac{1.559_{5}}{7.314_{8}}=0.2132_{2} \\
& R_{8 \ell b}=\frac{2.416_{4}}{12.82_{2}}=0.1884_{7} \\
& \text { for } t_{1}=950 \mathrm{~m} . \mathrm{y} \text {. } \\
& \lambda_{1}=1.53_{69} \times 10^{-10} y^{-1} \\
& f_{1}=0.0005_{4} \\
& \lambda_{2}=9.72_{16} \times 10^{-10} y-1 \\
& f_{2}=0.1681_{9} \\
& \text { Sample B } \\
& N_{\mathrm{sb}}=0.09310_{8} \\
& N_{8 b}=12.82_{1} \\
& { }^{t} N_{6 b}=2.416_{4} \\
& { }^{t} N_{7 b}=0.5266_{5}
\end{aligned}
$$

Substituting the values given above in equation 27 :

$$
t=\frac{-b \pm \sqrt{b^{2}-4 a c}}{2 a}
$$

where

$$
\begin{aligned}
2 a & =\lambda_{1}^{2}\left(R_{5 t b}-R_{5 t a}\right)+\lambda_{2}^{2}\left(R_{8 t a}-R_{8 t b}\right) \\
& =-5.396_{7} \times 10^{-20} y^{-1} \\
b & =\lambda_{1}\left(R_{5 t b}-R_{5 t a}\right)+\lambda_{2}\left(R_{8 t a}-R_{8 t b}\right) \\
& =-4.792_{2} \times 10^{-10} y^{-1}
\end{aligned}
$$

$$
\begin{aligned}
c= & R_{5 t a} R_{8 t b}-R_{5 t b} R_{8 t a}+f_{1}\left(R_{5 t b}-R_{5 t a}\right)+f_{2}\left(R_{8 t a}\right. \\
& \left.-R_{8 t b}\right) \\
= & 0.4796_{0} \\
t= & \left(\frac{4.792_{2} \pm \sqrt{\left(4.792_{2}\right)^{2}-2 \times-5.396_{7} \times 0.4796_{0}}}{-5.396_{7}}\right) \\
= & \left(\frac{4.792_{2} \pm \sqrt{28.14_{17}}}{-5.396_{7}}\right) \times 10^{10} \mathrm{y} \\
= & \left(\frac{4.792_{2}-5.304_{9}}{-5.396_{7}}\right) \times 10^{10} \mathrm{y} \\
= & 0.0950_{0} \times 10^{10} \text { years }=950 \mathrm{~m} . \mathrm{y} .
\end{aligned}
$$

The agreement between the calculated value of $t$, 950 m.y., (table 6) and the value of $t_{1}$ used in the choice of $f_{1}$ and $f_{2}$ from table 2 indicate that a recalculation of $t$ using slightly different values of $f_{1}$ and $f_{2}$ is unnecessary. The calculated values of the $\mathrm{Pb}^{207}$ / $\mathrm{Pb}^{208}$ ratios for the common lead ( $R_{a}^{c}$ and $R_{b}^{c}$ in samples $A$ and $B$ ) using $t=950 \mathrm{~m} . y$., the age tables, and equations 24 and 25 , are respectively, $0.9613_{2}$ and $0.9611_{6}$; the average calculated value is $0.9612_{5}$. The $\mathrm{Pb}^{207} / \mathrm{Pb}^{206}$ ratio used in setting up this hypothetical example was $0.9612_{7}$.

The quantity proportional to the number of atoms of common $\mathrm{Pb}^{206}$, in sample $A$ is equal to $0.4096_{4}$ and can be derived from equation 14 by substituting for $t, 0.950 \times 10^{10} \mathrm{y}$. The proportional number of atoms of common $\mathrm{Pb}^{207}$ is obtained using the ratio $N_{6 a}^{c} / N_{7 a}^{c}=$ $0.9612_{5}$, and is equal to $0.3937_{7}$. Using the $\mathrm{Pb}^{206} / \mathrm{Pb}^{204}$ and the $\mathrm{Pb}^{206} / \mathrm{Pb}^{208}$ ratios obtained from the isotopic analysis of sample $A$, quantities proportional to the total number of atoms of $\mathrm{Pb}^{204}$ and $\mathrm{Pb}^{208}$ are calculated to be $0.0257_{2}$ and $0.9085_{3}$. The actual isotopic composition used in setting up this example, the atom-percent abundances of the original common lead calculated from the number of atoms of $\mathrm{Pb}^{204}, \mathrm{~Pb}^{206}, \mathrm{~Pb}^{207}$ and $\mathrm{Pb}^{208}$, and the isotopic composition assumed to be present in the trial age calculations are given below:

Isotopic composition in atom percent

\begin{tabular}{c|r|r|r}
\hline Isotope & \multicolumn{1}{c|}{ Actual } & Calculated & \multicolumn{1}{c}{ Assumed } \\
\hline & & & \\
\hline $\mathrm{Pb}^{204}$ & $1.48_{0}$ & $1.48_{0}$ & $\begin{array}{r}1.48_{5} \\
\mathrm{~Pb}^{206}\end{array}$ \\
$\mathrm{~Pb}^{207}$ & $23.57_{4}$ & $23.57_{5}$ & $23.76_{4}$ \\
$\mathrm{~Pb}^{208}$ & $22.66_{1}$ & $22.66_{1}$ & $22.27_{8}$ \\
& $52.28_{4}$ & $52.28_{4}$ & $52.47_{3}$ \\
\hline
\end{tabular}

Thus, the ages obtained from equations 26 or 27 permit the calculation of a concordant age, $t$, without the use of either $\mathrm{Pb}^{204}$ or $\mathrm{Pb}^{208}$ as the index isotope, and without a knowledge of the isotopic composition of the contaminating common lead. Alternatively, a compar- 
ison of the ages obtained from these equations with the age obtained by using the conventional methods of common lead correction and age calculation permits an evaluation of the errors that may be introduced in the correction for common lead. If the calculated isotopic composition of the common lead necessary to bring the lead-uranium ages of samples $A$ and $B$ into agreement seems unreasonable, additional field and laboratory evidence may then be sought to determine if the disdiscordant trial age calculations were produced by experimental errors, processes of alteration, or by the presence of original radiogenic lead.

\section{GRAPHIC SOLUTION}

The graphic equivalent of the algebraic solution for the above example is shown in figure 3 , a plot of the

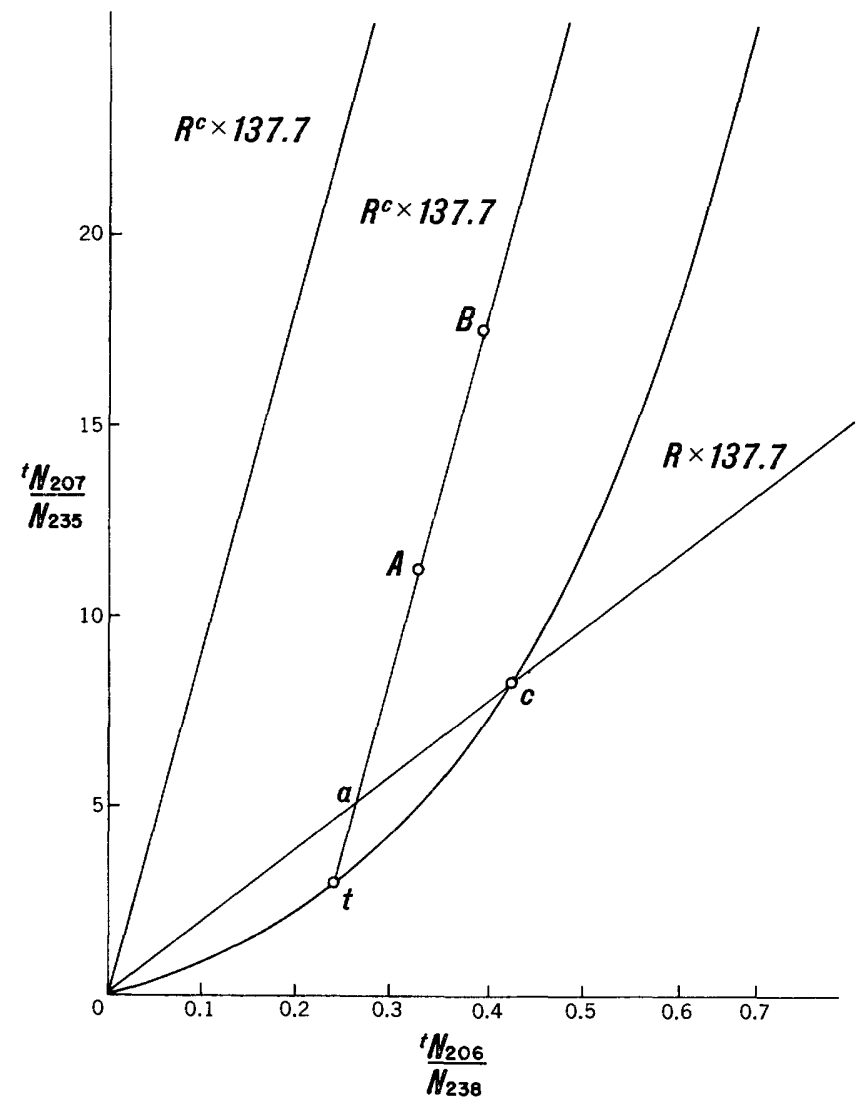

FiquRe 3.-Ratios of the total number of atoms of $\mathrm{Pb}^{207}$ to $\mathrm{U}^{235},{ }^{\prime} \mathrm{N}_{207} / N_{235}$, plotted against the ratio of the total number of atoms of $\mathrm{Pb}^{200}$ to U988, ${ }^{2} N_{200} / N_{238}$. Unal. tered uranium-bearing samples contaminated with a common lead having a $\mathrm{Pb}^{207 / \mathrm{Pb}^{208}}$ ratio, $R$ 。

ratio of the total number of atoms of $\mathrm{Pb}^{207}$ to $\mathrm{U}^{235}$, ${ }^{t} N_{207} / N_{235}$ versus the total number of atoms of $\mathrm{Pb}^{206}$ to $\mathrm{U}^{238},{ }^{t} N_{206} / \mathrm{U}_{238}$. The concordant age is obtained by passing a line through the coordinates of the points $A$ and $B$ (fig. 3 ) and observing the intersection of this line with the concordant age curve. The slope of this line divided by 137.7 will be the $\mathrm{Pb}^{207} / \mathrm{Pb}^{208}$ ratio, $R^{c}$, of the contaminating common lead which will give the same concordant age for both samples, $A$ and $B$. This ratio may now be directly compared with the experimentally determined $\mathrm{Pb}^{207} / \mathrm{Pb}^{206}$ ratio in related nonradioactive minerals, such as galena, pyrite, or feldspar. Failure of the experimentally and graphically determined $\mathrm{Pb}^{207} /$ $\mathrm{Pb}^{206}$ ratios to agree, or an abnormal graphic value for $R^{c}$, will indicate a more complex geologic history than was initially assumed. As has been mentioned, the same age can be obtained graphically from plots of $N_{207} / N_{204}$ versus $N_{206} / N_{204}$ (fig. $1 A$ ) even though the samples have been recently altered.

\section{AMOUNT OF CONTAMINATINGTRADIOGENIC AND COMMON} LEAD AND THE Pb ${ }^{207 / P b}{ }^{206}$ RATIO UNKNOWN

In the discussion of figure $1 A$ it was noted that in plots of the $\mathrm{Pb}^{207} / \mathrm{Pb}^{204}$ versus $\mathrm{Pb}^{206} / \mathrm{Pb}^{204}$ ratios (and in the case where thorium is absent, $\mathrm{Pb}^{207} / \mathrm{Pb}^{208}$ versus $\left.\mathrm{Pb}^{208} / \mathrm{Pb}^{208}\right)$, two or more different mixtures of a single common lead and a single radiogenic lead would lie on the same straight line. The slope, $R^{*}$, of this line is the $\mathrm{Pb}^{207} / \mathrm{Pb}^{206}$ ratio of the radiogenic lead, and on this line will lie the $\mathrm{Pb}^{206} / \mathrm{Pb}^{204}$ and $\mathrm{Pb}^{207} / \mathrm{Pb}^{204}$ (or the $\mathrm{Pb}^{206} / \mathrm{Pb}^{208}$ and $\mathrm{Pb}^{207} / \mathrm{Pb}^{208}$ ) ratios of the contaminating common lead. This graphical treatment and the difference plots in figure $1 B$ suggest that a useful modification may be obtained if the chemical and isotopic data for two or more samples were expressed as ratios of the total numbers of atoms of $\mathrm{Pb}^{206}, \mathrm{~Pb}^{207}$, $\mathrm{U}^{235}$, and $\mathrm{U}^{238}$ to the total number of $\mathrm{Pb}^{204}$ (or $\mathrm{Pb}^{208}$ ) atoms. Using this change in the notation of equations 11,12 , and 17 , it is possible to calculate a concordant geologic age from the discordant age data without knowledge of the amount or $\mathrm{Pb}^{207} / \mathrm{Pb}^{206}$ ratio of the contaminating common lead. In this case, however, the ratio of the contaminating radiogenic lead must be known.

For the above calculation to be valid, it would be necessary (as in the previous cases), for the two or more samples in question to yield different discordant ages and to meet conditions (1) through (4), and either (5) or (6) given below.

(1) The samples were formed at essentially the same time.

(2) The samples have not been recently altered.

(3) The samples at the time of their formation contained a common lead with the same $\mathrm{Pb}^{207} / \mathrm{Pb}^{206}$ ratio.

(4) The samples could not contain thorium if $\mathrm{Pb}^{208}$ is used as the index isotope.

(5) The samples at the time of their formation contained an original radiogenic lead with the same $\mathrm{Pb}^{207} / \mathrm{Pb}^{206}$ ratio, or 
(6) The samples were altered only once and at the same time in the history of the material.

This calculation does involve the precise determination of the abundance of the index isotope, $\mathrm{Pb}^{204}$ (or $\mathrm{Pb}^{208}$ ). The relative simplicity of this modification, however, and the many instances where it can be used to advantage compensate, in part, for this obvious shortcoming.

Following the notation used in equations 9 and 10 , one can write for sample $A$

and

$$
\left[{ }^{t} N_{6 a}-N_{8 a}\left(\frac{\left(\lambda_{1} t\right)^{n}}{n !} \ldots+\frac{\left(\lambda_{1} t\right)^{2}}{2 !}+\lambda_{1} t\right)\right]=N_{6 a}^{c *}
$$

$$
\left[{ }^{t} N_{7 a}-N_{5 a}\left(\frac{\left(\lambda_{2} t\right)^{n}}{n !} \ldots+\frac{\left(\lambda_{2} t\right)^{2}}{2 !}+\lambda_{2} t\right)\right]=N_{7 a}^{\iota *}
$$

where

$N_{6 a}^{c *}=$ a quantity proportional to the sum of the number of atoms of common and original radiogenic $\mathrm{Pb}^{206}$ in sample $A$.

$N_{7 a}^{c *}=$ a quantity proportional to the sum of the number of atoms of common and original radiogenic $\mathrm{Pb}^{207}$ in sample $A$.

If both sides of equations 28 and 29 are now divided by the index isotope, ${ }^{t} N_{\text {I } a}$, a quantity proportional to the total number of either $\mathrm{Pb}^{204}$ or $\mathrm{Pb}^{208}$ atoms in sample $A$, depending on the choice of the index isotope, one obtains the following:

$$
{ }^{\prime} N_{8 a}-{ }^{\prime} N_{8 a}\left(\frac{\left(\lambda_{1} t\right)^{n}}{n !} \ldots+\frac{\left(\lambda_{1} t\right)^{2}}{2 !}+\lambda_{1} t\right)={ }^{\prime} N_{6 a}^{c *}
$$

and

$$
{ }^{t} N_{7 a}-{ }^{\prime} N_{5 a}\left(\frac{\left(\lambda_{2} t\right)^{n}}{n !} \ldots+\frac{\left(\lambda_{2} t\right)^{2}}{2 !}+\lambda_{2} t\right)={ }^{\prime} N_{7 a}^{c *}
$$

where

$$
\begin{array}{ll}
{ }^{i} N_{6 a}={ }^{t} N_{6 a} /{ }^{t} N_{\mathrm{I} a} & { }^{i} N_{7 a}={ }^{t} N_{7 a} /{ }^{t} N_{\mathrm{I} a} \\
{ }^{\prime} N_{6 a}^{*}=N_{6 a}^{* *} /{ }^{t} N_{\mathrm{I} a} & { }^{\prime} N_{5 a}=N_{5 a} /{ }^{t} N_{\mathrm{I} a} \\
{ }^{\prime} N_{7 a}^{c *}=N_{7 a}^{\mathrm{c} *} /{ }^{t} N_{\mathrm{I} a} & { }^{\prime} N_{8 a}=N_{8 a} /{ }^{t} N_{\mathrm{I} a}
\end{array}
$$

Similarly, equations for sample $B$, expressed as ratios of the index isotope, $N^{t}{ }_{\mathrm{I} b}$, are:

and

$$
{ }^{\prime} N_{6 b}-{ }^{\prime} N_{8 b}\left(\frac{\left(\lambda_{1} t\right)^{n}}{n !} \ldots+\frac{\left(\lambda_{1} t\right)^{2}}{2 !}+\lambda_{1} t\right)={ }^{\prime} N_{6 b}^{c *}
$$

$$
{ }^{t} N_{7 b}-{ }^{\prime} N_{5 b}\left(\frac{\left(\lambda_{2} t\right)^{n}}{n !} \ldots+\frac{\left(\lambda_{2} t\right)^{2}}{2 !}+\lambda_{2} t\right)={ }^{\prime} N_{7 b}^{c *}
$$

where

$$
\begin{aligned}
{ }^{t} N_{6 b} & ={ }^{t} N_{6 b} /{ }^{t} N_{\mathrm{I} b} & & { }^{t} N_{7 b}={ }^{t} N_{7 b} /{ }^{t} N_{\mathrm{I} b} \\
{ }^{t} N_{6 b}^{c *} & =N_{8 b}^{e *} /{ }^{t} N_{\mathrm{I} b} & { }^{\prime} N_{5 b} & =N_{b b}{ }^{t} N_{\mathrm{Ib}} \\
{ }^{t} N_{7 b}^{c *} & =N_{7 b}^{c *} /{ }^{t} N_{\mathrm{I} b} & { }^{\prime} N_{8 b} & =N_{8 b} /{ }^{t} N_{\mathrm{I} b}
\end{aligned}
$$

In the graphic treatment of the isotopic data for a mixture of a common and a radiogenic lead expressed as ratios of $\mathrm{Pb}^{204}$ or $\mathrm{Pb}^{208}$ (fig. $1 B$ ), it has been mentioned that the slope of the line passing through the origin and the points $C-B$ is equal to the ratio of the added radiogenic lead, $R^{*}$. The point $C-B$ in figure $1 B$ is equivalent to a point having the coordinates $\left(' N_{7 a}^{c *}-{ }^{\prime} N_{7 b}^{c *}\right)$ and $\left({ }^{\prime} N_{6 a}^{c *}-{ }^{\prime} N_{6 b}^{c *}\right)$. Therefore, subtracting equation 33 from equation 31 and dividing by equation 32 subtracted from equation 30 one obtains:

$$
\begin{array}{r}
{\left[\frac{\left({ }^{i} N_{7 a}-{ }^{t} N_{7 b}\right)-\left({ }^{\prime} N_{5 a}-{ }^{\prime} N_{5 b}\right)\left(\frac{\left(\lambda_{2} t\right)^{n}}{n !} \ldots+\frac{\left(\lambda_{2} t\right)^{2}}{2 !}+\lambda_{2} t\right)}{\left({ }^{\prime} N_{6 a}-{ }^{i} N_{6 b}\right)-\left({ }^{\prime} N_{8 a}-{ }^{\prime} N_{8 b}\right)\left(\frac{\left(\lambda_{1} t\right)^{n}}{n !} \ldots+\frac{\left(\lambda_{1} t\right)^{2}}{2 !}+\lambda_{1} t\right)}\right]} \\
=\frac{{ }^{\prime} N_{7 a}^{c *}-{ }^{\prime} N_{7 b}^{c *}}{{ }^{c} N_{6 a}^{c *}-{ }^{\prime} N_{6 b}^{c *}}
\end{array}
$$

or

$$
R\left[\frac{{ }^{\prime} R_{5(a-b)}-\left(\frac{\left(\lambda_{2} t\right)^{n}}{n !} \ldots+\frac{\left(\lambda_{2} t\right)^{2}}{2 !}+\lambda_{2} t\right)}{{ }^{\prime} R_{8(a-b)}-\left(\frac{\left(\lambda_{1} t\right)^{n}}{n !} \ldots+\frac{\left(\lambda_{1} t\right)^{2}}{2 !}+\lambda_{1} t\right)}\right]=R^{*}
$$

where the normalized difference ratios are

$$
\begin{aligned}
& { }^{\prime} R_{5(a-b)}=\frac{{ }^{\prime} N_{7 a}-{ }^{\prime} N_{7 b}}{{ }^{\prime} N_{5 a}-{ }^{\prime} N_{5 b}} \\
& R_{8(a-b)}=\frac{{ }^{\prime} N_{6 a}-{ }^{\prime} N_{6 b}}{{ }^{\prime} N_{8 a}-{ }^{\prime} N_{8 b}}
\end{aligned}
$$

and

$$
\begin{gathered}
R=\frac{{ }^{\prime} N_{5 a}-{ }^{\prime} N_{5 b}}{N_{8 a}-N_{8 b}^{\prime}}=0.007262 \\
R^{*}=\frac{{ }^{\prime} N_{7 a}^{c *}-N_{7 b}^{c} N_{7 b}^{c *}}{{ }^{\prime c} N_{6 a}^{c *}-{ }^{\prime} N_{b b}^{c *}}=\frac{N_{7 a}^{*}}{N_{6 a}^{*}}=\frac{N_{7 b}^{*}}{N_{6 b}^{*}}
\end{gathered}
$$

and where the same index isotope $\left(\mathrm{Pb}^{204}\right.$ or $\left.\mathrm{Pb}^{208}\right)$ is used in both samples $A$ and $B$.

Clearing and collecting terms

$$
\begin{aligned}
\left(\frac{R^{*} \lambda_{1}^{n}}{n !}-\frac{R \lambda_{2}^{n}}{n !}\right)^{t^{n}} \cdots+ & \left(\frac{R^{*} \lambda_{1}^{2}}{2 !}-\frac{R \lambda_{2}^{2}}{2 !}\right)^{t^{2}}+\left(R^{*} \lambda_{1}-R \lambda_{2}\right) t \\
& +R^{\prime} R_{5(a-b)}-R^{* \prime} R_{8(a-b)}=0 .
\end{aligned}
$$

If computing facilities are not available, equation 35 may be carried only to the second power of $t$ and the terms $f_{1}$ and $f_{2}$ added. Solving this equation for $t$ one obtains,

$$
t=\frac{-b \pm \sqrt{b^{2}-4 a c}}{2 a}
$$

where

$$
\begin{aligned}
2 a & =\left(R^{*} \lambda_{1}^{2}-R \lambda_{2}^{2}\right) \\
b & =\left(R^{*} \lambda_{1}-R \lambda_{2}\right) \\
c & =\left(R^{\prime} R_{5(a-b)}-R^{* \prime} R_{8(a-b)}+R^{*} f_{1}-R f_{2}\right) .
\end{aligned}
$$


For geologically possible values of $R^{*}, R_{5(a-b) \text {, and }}$

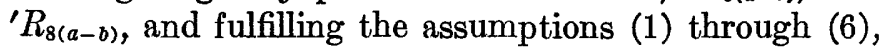
equations 35 and 36 have two positive roots. If original radiogenic lead is assumed to be responsible for the discordant trial ages obtained on sample $A$ and $B$, the smaller root will approach, as the degree of the equation increases, a concordant age corrected both for the presence of an original radiogenic lead having a $\mathrm{Pb}^{207} \mathrm{~Pb}^{206}$ ratio, $R^{*}$, and a single common lead. The isotopic composition of the common lead need not be known. If past alteration is assumed to be responsible for the discordant trial ages, the larger root will approach the concordant "lead-loss" age as the degree of the equation increases. For the latter assumption, the smaller root will approach the time in the past when the alteration took place, and $R^{*}$ will become the $\mathrm{Pb}^{207} /$ $\mathrm{Pb}^{206}$ ratio of the radiogenic lead produced by the uranium in the time interval, $\left(t-t_{1}\right)$, given by the two roots.

\section{EXAMPLE OF CALCOLATION}

An example of the use of both equations 35 and 36 in the calculation of a concordant age, $t$, corrected for unknown amounts and ratios of both a common and an original radiogenic lead are given below. In this example, the absence of $\mathrm{Th}^{232}$ in the chemical analyses suggests the use of the much more abundant isotope, $\mathrm{Pb}^{208}$, rather than $\mathrm{Pb}^{204}$ as the index of the common lead present. The isotopic and chemical data for two hypothetical unaltered 1,400-million-year-old uraninites, $A$ and $B$, from the same deposit are:

\begin{tabular}{|c|c|c|c|c|c|c|}
\hline \multirow{2}{*}{ Sample } & \multicolumn{4}{|c|}{ Isotopic composition (in atom percent) } & \multicolumn{2}{|c|}{$\begin{array}{l}\text { Uranium and lead } \\
\text { content (chemical } \\
\text { scale) }\end{array}$} \\
\hline & $\mathrm{Pb}^{204}$ & $\mathrm{~Pb}^{206}$ & $\mathrm{~Pb}^{207}$ & $\mathrm{~Pb}^{203}$ & $\underset{\mathrm{U}}{\text { Percent }}$ & $\begin{array}{l}\text { Percent } \\
\quad \text { Pb }\end{array}$ \\
\hline$A \ldots$ & $\begin{array}{l}0.210_{7} \\
0.0764_{6}\end{array}$ & $\begin{array}{l}80.69_{7} \\
87.68_{4}\end{array}$ & $\begin{array}{r}11.80_{1} \\
9.59_{45}\end{array}$ & $\begin{array}{l}\text { 7. } 28_{89} \\
2.64_{48}\end{array}$ & $\begin{array}{l}31.55_{0} \\
53.17_{1}\end{array}$ & $\begin{array}{l}\text { 9. } 743_{4} \\
\text { 13. } 41_{2}\end{array}$ \\
\hline
\end{tabular}

Assuming a common lead whose isotopic composition is $\mathrm{Pb}^{204}=1.52_{5}, \mathrm{~Pb}^{206}=22.86_{7}, \mathrm{~Pb}^{207}=22.86_{9}$, and $\mathrm{Pb}^{208}=52.75_{3}$, trial age calculations yield the following discordant results:

\begin{tabular}{|c|c|c|c|}
\hline & $\mathrm{Pb} b^{200 / \mathrm{U}} 238$ & $\mathrm{~Pb}^{207} / \mathrm{U}^{238}$ & $\mathrm{~Pb} 200 / \mathrm{Pb} 206$ \\
\hline $\begin{array}{l}\text { ample } A \\
\text { ample } B\end{array}$ & $\begin{array}{l}\text { 1,605 m.y. } \\
1,480 \text { m.y. }\end{array}$ & $\begin{array}{l}\text { 1,715 m.y. } \\
\text { 1,530 m.y. }\end{array}$ & $\begin{array}{l}1,850 \mathrm{~m} . \mathrm{y} \\
1,650 \mathrm{~m} . \mathrm{y}\end{array}$ \\
\hline
\end{tabular}

Using the data given above for samples $A$ and $B$ in equation 35 , the concordant ages were obtained for equations of the second to the tenth degree (table 7). The smaller positive roots yield concordant ages corrected for original radiogenic lead given a $\mathrm{Pb}^{207} / \mathrm{Pb}^{206}$ ratio, $R^{*}$, of $0.2500_{4}$. The larger root of the tenth$649977-63-4$ degree equation is very close to the concordant age of samples $A$ and $B$ corrected for loss or gain of lead or uranium during a single period of alteration 1,400 million years ago.

TABLE 7.-Computed concordant ages obtained from equation 35

\begin{tabular}{c|r|r}
\hline \multirow{2}{*}{ Degree of equation } & \multicolumn{2}{|c}{ Age (millions of years) } \\
\cline { 2 - 3 } & $\begin{array}{c}\text { Corrected for original } \\
\text { radiogenic lead }\end{array}$ & $\begin{array}{c}\text { Corrected for loss or } \\
\text { gain of lead or uranium }\end{array}$ \\
\hline & $126_{6.7}$ & $642_{66}$. \\
\hline 6 & $134_{4.2}$ & $464_{8.5}$ \\
\hline 5 & $138_{3.5}$ & $312_{0.1}$ \\
\hline 10 & $139_{6.3}$ & $276_{1.0}$ \\
\hline \\
\hline
\end{tabular}

Following the procedure and notation used on page $\mathrm{E} 8$, the chemical and isotopic data for samples $A$ and $B$ are expressed in terms proportional to the total number of atoms present.
Sample A

$N_{5 a}=0.09552_{6}$

$N_{8 a}=13.15_{4}$

${ }^{t} N_{6 a}=3.829$

${ }^{t} N_{7 a}=0.5600_{4}$

${ }^{t} N_{08 a}=0.3459_{1}$

$$
\begin{gathered}
\text { Sample B } \\
N_{5 b}=0.1609_{9} \\
N_{8 b}=22.16_{9} \\
{ }^{t} N_{8 b}=5.734_{0} \\
{ }^{t} N_{7 b}=.6274_{1} \\
{ }^{t} N_{08 b}=.1729_{5}
\end{gathered}
$$

In the above tabulation, ${ }^{t} N_{08 a}$ and ${ }^{t} N_{08 b}$ are proportional to the total number of $\mathrm{Pb}^{208}$ index atoms in samples $A$ and $B$ at the present time.

Expressing these data as multiples of the index isotope, $\mathrm{Pb}^{208}$, that is, ' $N_{5 a}=\frac{N_{5 a}}{{ }^{i} N_{08 a}}$, and so on, one obtains:

Sample A

$N_{5 a}=0.2761_{6}$

${ }^{\prime} N_{8 a}=38.02_{7}$

${ }^{t} N_{6 a}=11.07_{1}$

${ }^{\prime}{ }^{i} N_{7 a}=1.619_{0}$

Sample B

' $N_{5 b}=0.9308_{5}$

, $N_{8 b}=128.1_{8}$

${ }^{t} N_{6 b}=33.15$

${ }^{\prime} N_{7 b}=3.627_{7}$ and for $t_{1}=1,350 \mathrm{~m} . \mathrm{y}$.

$$
f_{1}=0.0015_{7} \quad f_{2}=0.5415_{0}
$$

where

$$
\begin{aligned}
& { }^{\prime} R_{5(a-b)}=\frac{{ }^{\prime} N_{7 a}-{ }^{\prime t} N_{7 b}}{{ }^{\prime} N_{5 a}-{ }^{\prime} N_{5 b}}=3.068_{3},\left(R^{*}=0.2500_{4}, \text { given }\right) \\
& { }^{\prime} R_{8(a-b)}=\frac{{ }^{t} N_{6 a}-{ }^{\prime} N_{6 b}}{{ }^{\prime} N_{8 a}-{ }^{\prime} N_{8 b}}=0.2449_{6},(R=0.007262)
\end{aligned}
$$

Substituting in equation 36

$$
\begin{aligned}
& 2 a=\left(R^{*} \lambda_{1}^{2}-R \lambda_{2}^{2}\right)=-0.0957_{1} \times 10^{-20} y^{-1} \\
& b=\left(R^{*} \lambda_{1}-R \lambda_{2}\right)=0.3136_{9} \times 10^{-10} y^{-1} \\
& c=\left(R^{\prime} R_{5(a-b)}-R^{* \prime} R_{8(a-b)}+R^{*} f_{1}-R f_{2}\right)=-0.04250_{4} \\
& \text { and solving for } t
\end{aligned}
$$




$$
t=\frac{-b \pm \sqrt{b^{2}-4 a c}}{2 a}
$$$$
t=\left(\frac{-0.3136_{9} \pm \sqrt{0.09840_{1}-2 \times-0.0957_{1} \times-0.04250_{4}}}{-0.0957_{1}}\right)
$$$$
t=\left(\frac{-0.3136_{9}+0.3004_{4}}{-0.0957_{1}}\right) 10^{10} y=0.1384_{4} \times 10^{10} y
$$

$$
=1,384 \mathrm{~m} . \mathrm{y} \text {. }
$$

The calculated value for $t, 1,384$, lies above the initial choice of $t_{1}, 1,350$, used to obtain $f_{1}$ and $f_{2}$ from table 2 . This fact indicates that in using table 2 , a choice for $t$ greater than 1,384 and less than 1,480 should be made for the second age calculation if, for geologic reasons, the first age calculated is not acceptable.

A very sensitive test of the departure of the value $t=1,384$ m.y. from the concordant age for samples $A$ and $B$ may be made by comparing the calculated value of $R_{(a-b)}^{*}$ using equation 34 and $t=0.1384 \times 10^{10} y$ with the observed or assumed value for $R^{*}$ used in equation 36 . The value of $R^{*}$ calculated in this way and the given $R^{*}$ are, respectively, 0.2083 and $0.2500_{4}$. For the value $t=1,400 \mathrm{~m}$.y., the calculated and given values of $R^{*}$ are, respectively, $0.2498_{5}$ and $2,500_{4}$. As can be seen, relatively small changes in $t$ will result in substantial changes in the calculated $R^{*}$.

\section{GRAPHIC SOLUTION}

The graphic equivalent of the algebraic solution for the above example is shown in figure 4.

If two unaltered samples, $A$ and $B$, containing different amounts of lead and uranium were formed at the same time and were contaminated only with a common lead of uniform $\mathrm{Pb}^{207} / \mathrm{Pb}^{206}$ ratio, $R^{c}$, the point $(A-B)$ whose coordinates are given by the normalized difference ratios

$$
\begin{gathered}
\frac{\left(N_{207} / N_{204}\right) A-\left(N_{207} / N_{204}\right) B}{\left(N_{235} / N_{204}\right) A-\left(N_{235} / N_{204}\right) B} \text { and } \\
\frac{\left(N_{206} / N_{204}\right) A-\left(N_{206} / N_{204}\right) B}{\left(N_{238} / N_{204}\right) A-\left(N_{238} / N_{204}\right) B},
\end{gathered}
$$

would lie on the concordant age curve.

The problem of the three component lead mixtures, $R^{c}, R^{*}$, and $R$ can now be considered (fig. 4). Assume that in addition to a common lead having the same $\mathrm{Pb}^{207} / \mathrm{Pb}^{206}$ ratio $R^{c}$, samples $A$ and $B$ have received different amounts of an older generation of radiogenic lead with a $\mathrm{Pb}^{207} / \mathrm{Pb}^{206}$ ratio, $R^{*}$. Then the normalized difference ratios of these two component mixtures, $R^{c}$ and $R^{*}$ (see figure $1 B$ ) would lie on a line passing through the origin whose slope is equal to $R^{*} \times 137.7$; for example, the point $(c-d)$. The amounts of radiogenic $\mathrm{Pb}^{206}$ and $\mathrm{Pb}^{207}$ produced in the time interval $0-t$ may

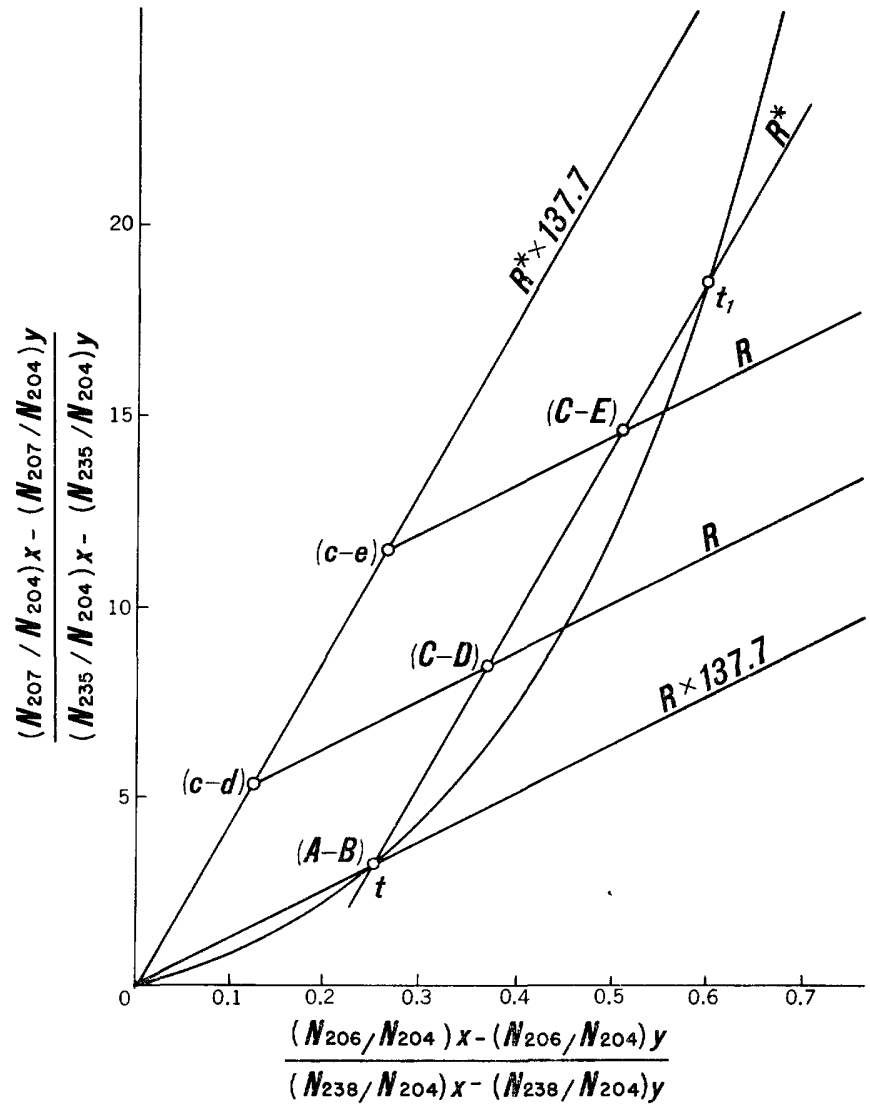

FIGURE 4.-Normalized difference ratios of $\frac{\left(N_{207} / N_{204}\right) x-\left(N_{207} / N_{204}\right) y}{\left(N_{235} / N_{204}\right) x-\left(N_{235} / N_{204}\right) y}$ plotted against $\frac{\left(N_{200} / N_{204}\right) x-\left(N_{200} / N_{204}\right) y}{\left(N_{238} / N_{204}\right) x-\left(N_{238} / N_{204}\right) y}$ for three pairs of uranium-bearing samples which were

contaminated by the same common lead and/ which, in addition, were altered at a time, $t$, in the past or contaminated by an older radiogenic lead, $R^{*}$.

now be added graphically to the point $(c-d)$ by passing a line through the point $(c-d)$ with the slope, $R$, and of a length equal to that of the line segment from the origin to the point $(A-B)$. The coordinates of the point $(C-D)$ thus represent the discordant ages that are obtained when the normalized difference ratios are plotted for a pair of samples each containing three component lead mixtures.

\section{THREF SAMPLES}

AMOUNT AND Pb207/Pb 206 RATIOS OF CONTAMINATING COMMON AND RADIOGENIC LEAD UNKNOWN

From the argument presented above it is clear that if isotopic and chemical data are available for three samples fulfilling the conditions set forth, for the two sample cases it would be possible to calculate a concordant age without knowledge of either the amounts or isotopic ratios of the contaminating common and original radiogenic lead. Using equation 34, the following equations can be written for the two pairs of samples ( $A$ and $B$, and $A$ and $C$ ) where the isotopic and quantitative lead and uranium data are expressed 
as normalized difference ratios of the number of atoms of lead and uranium to the number of atoms of the index isotope, $\mathrm{Pb}^{204}$ or $\mathrm{Pb}^{208}$ :

Sample pair $A-B$,

$$
R\left[\frac{{ }^{\prime} R_{5(a-b)}-\left(\frac{\left(\lambda_{2} t\right)^{n}}{n !} \cdots+\frac{\left(\lambda_{2} t\right)^{2}}{2 !}+\lambda_{2} t\right)}{{ }^{\prime} R_{8(a-b)}-\left(\frac{\left(\lambda_{1} t\right)^{n}}{n !} \cdots+\frac{\left(\lambda_{1} t\right)^{2}}{2 !}+\lambda_{1} t\right)}\right]=R^{*}
$$

where the normalized difference ratios

$$
\begin{aligned}
& { }^{\prime} R_{5(a-b)}=\frac{{ }^{t} N_{7 a}-{ }^{t} N_{7 b}}{{ }^{\prime} N_{5 a}-{ }^{\prime} N_{5 b}} \\
& { }^{\prime} R_{8(a-b)}=\frac{{ }^{t} N_{6 a}-{ }^{t} N_{6 b}}{{ }^{\prime} N_{8 a}-{ }^{\prime} N_{8 b}}
\end{aligned}
$$

and sample pair $A-C$,

$$
R\left[\frac{{ }^{\prime} R_{5(a-c)}-\left(\frac{\left(\lambda_{2} t\right)^{n}}{n !} \cdots+\frac{\left(\lambda_{2} t\right)^{2}}{2 !}+\lambda_{2} t\right)}{{ }^{\prime} R_{8(a-c)}-\left(\frac{\left(\lambda_{1} t\right)^{n}}{n !} \cdots+\frac{\left(\lambda_{1} t\right)^{2}}{2 !}+\lambda_{1} t\right)}\right]=R^{*}
$$

where

$$
\begin{aligned}
& { }^{\prime} R_{5(a-c)}=\frac{{ }^{t} N_{7 a}-{ }^{t} N_{7 c}}{{ }^{\prime} N_{5 a}-{ }^{\prime} N_{5 c}} \\
& { }^{\prime} R_{8(a-c)}=\frac{{ }^{t} N_{6 a}-{ }^{t} N_{6 c}}{{ }^{\prime} N_{8 a}-{ }^{\prime} N_{8 c}} .
\end{aligned}
$$

Placing equation 37 equal to equation 38 and collecting terms, one obtains:

$\left[\frac{\lambda_{1}^{n}}{n !}\left({ }^{\prime} R_{5(a-c)}-' R_{5(a-b)}\right)+\frac{\lambda_{2}^{n}}{n !}\left({ }^{\prime} R_{8(a-b)}-{ }^{\prime} R_{8(a-c)}\right)\right] t_{n} \ldots$

$\left[\frac{\lambda_{1}^{2}}{2 !}\left({ }^{\prime} R_{5(a-c)}-' R_{5(a-b)}\right)+\frac{\lambda_{2}^{2}}{2 !}\left({ }^{\prime} R_{8(a-b)}-^{\prime} R_{8(a-c)}\right)\right] t^{2}$

$+\left[\lambda_{1}\left({ }^{\prime} R_{5(a-c)}-{ }^{\prime} R_{5(a-b)}+\lambda_{2}\left({ }^{\prime} R_{8(a-b)}-{ }^{\prime} R_{8(a-c)}\right)\right] t\right.$

$+^{\prime} R_{5(a-b)} R_{8(a-c)}-R_{5(a-c)} R_{8(a-b)}=0$.

If computing facilities are not available, equation 39 may be taken only to the second degree and the terms $f_{1}$ and $f_{2}$ added. Solving for $t$, one obtains:

$$
t=\frac{-b \pm \sqrt{b^{2}-4 a c}}{2 a}
$$

where

$$
\begin{aligned}
2 a= & {\left[\lambda_{1}^{2}\left({ }^{\prime} R_{5(a-c)}-{ }^{\prime} R_{5(a-b)}\right)+\lambda_{2}^{2}\left({ }^{\prime} R_{8(a-b)}-{ }^{\prime} R_{8(a-c)}\right)\right] } \\
b= & {\left[\lambda_{1}\left({ }^{\prime} R_{5(a-c)}-{ }^{\prime} R_{5(a-b)}\right)+\lambda_{2}\left({ }^{\prime} R_{8(a-b)}-{ }^{\prime} R_{8(a-c)}\right)\right] } \\
c= & {\left[{ }^{\prime} R_{5(a-b)}{ }^{\prime} R_{8(a-c)}-{ }^{\prime} R_{5(a-c)}{ }^{\prime} R_{8(a-b)}+f_{1}\left({ }^{\prime} R_{5(a-c)}\right.\right.} \\
& \left.\left.-' R_{5(a-b)}\right)+f_{2}\left({ }^{\prime} R_{8(a-b)}-{ }^{\prime} R_{8(a-c)}\right)\right] .
\end{aligned}
$$

Equation 39 taken to the third degree or higher has two positive roots for values of the ratios, ' $R_{5(a-b)}$,

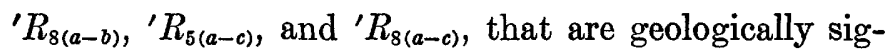
nificant. As in the previous case, with an increase in the degree of the equations, these roots approach the exact concordant age corrected for original radiogenic lead or loss of lead. For most geologically significant values for the ratios, equation 40 will also have two positive roots. For values of $t_{1}$ less than the lowest trial lead-uranium age, the smaller root will approach rapidly the exact concordant age corrected for original radiogenic lead. With the same value for $t_{1}$, the larger root has no geologic meaning. To obtain the "leadloss" age, different values of $t_{1}$ equal to or greater than the largest trial lead-lead age must be substituted. The initial choice of $t_{1}$ may be guided by a rough graphical solution of

$\frac{\left(N_{207} / N_{204}\right) x-\left(N_{207} / N_{204}\right) y}{\left(N_{235} / N_{204}\right) x-\left(N_{235} / N_{204}\right) y}$

$$
\text { versus } \frac{\left(N_{200} / N_{204}\right) x-\left(N_{208} / N_{204}\right) y}{\left(N_{238} / N_{204}\right) x-\left(N_{238} / N_{204}\right) y}
$$

\section{EXAMPLE OF CALCULATION}

If the data for the third sample, $C$, are added to the age data given on page $\mathrm{E} 21$, it is possible to use equations 39 and 40 to calculate a concordant age, $t$, without having any knowledge of the amounts or ratios of the contaminating original radiogenic and common lead.

\begin{tabular}{c|c|c|c|c|c|c}
\hline \multirow{2}{*}{ Sample } & \multicolumn{2}{|c|}{ Isotopic composition (in atom percent) } & \multicolumn{2}{|c}{$\begin{array}{c}\text { Uranium and lead con- } \\
\text { tent (chemical scale) }\end{array}$} \\
\cline { 2 - 7 } & $\mathrm{Pb}^{204}$ & $\mathrm{~Pb}^{206}$ & $\mathrm{~Pb}^{207}$ & $\mathrm{~Pb}^{208}$ & Percent U & $\begin{array}{c}\text { Percent } \\
\mathrm{Pb}\end{array}$ \\
\hline $\mathrm{yb}_{-}$ & $0.226_{3}$ & $80.65_{7}$ & $11.28_{9}$ & $7.82_{7}$ & $46.84_{7}$ & $13.61_{2}$ \\
\hline
\end{tabular}

Assuming a common lead whose isotopic composition is $\quad \mathrm{Pb}^{204}=1.52_{5}, \quad \mathrm{~Pb}^{206}=22.86_{7}, \quad \mathrm{~Pb}^{207}=22.86_{9}, \quad$ and $\mathrm{Pb}^{208}=52.75_{3}$, trial age calculations yield the following discordant results:

$\begin{array}{rrrr} & \mathrm{Pb}^{200} / \mathrm{U}^{238} & \mathrm{~Pb}^{207 / \mathrm{U}^{238}} & \mathrm{~Pb} 2007 / \mathrm{Pb} \mathrm{b}^{208} \\ \text { Sample } C \ldots \ldots & 1,515 \mathrm{~m} . \mathrm{y} . & 1,590 \mathrm{~m} . \mathrm{y} . & 1,690 \mathrm{~m} . \mathrm{y} .\end{array}$

If the data for samples $A$ and $B$ given in the preceding example (p. E21) are combined with the data for sample $C$, equation 39 can now be used for concordant age calculations provided that the assumptions given on page E20 can be fulfilled. Table 8 shows the results of these calculations for equations of the second to the tenth degree. These calculated ages are in close agreement with the ages given for samples $A$ and $B$ in table 7 . 
TABLE 8.-Computed concordant ages obtained from equation 39

\begin{tabular}{c|c|c}
\hline \multirow{2}{*}{ Degree of equation } & \multicolumn{2}{|c}{ Age (millions of years) } \\
\cline { 2 - 3 } & $\begin{array}{c}\text { Corrected for original } \\
\text { radiogenic lead }\end{array}$ & $\begin{array}{c}\text { Corrected for loss or } \\
\text { gain of lead or } \\
\text { uranium }\end{array}$ \\
\hline & $126_{7.0}$ & $647_{05 .}$ \\
\hline 2 & $133_{4.4}$ & $465_{3.5}$ \\
\hline 5 & $138_{3.5}$ & $312_{2.7}$ \\
\hline 5 & $139_{6.4}$ & $276_{3.0}$ \\
\hline 9 & $139_{9.5}$ & $265_{4.6}$ \\
\hline 10 & $140_{0.1}$ & $262_{0.9}$ \\
\hline
\end{tabular}

If the analytical data for the three samples are expressed as multiples of the number of $\mathrm{Pb}^{208}$ atoms in samples $A, B$, and $C$, respectively, one obtains,

Sample A
$N_{5 a}=0.2761_{6}$
$N_{8 a}=38.02_{7}$
$N^{\prime} N_{6 a}=11.07_{1}$
$N^{\prime} N_{7 a}=1.619_{0}$

Sample B
$N_{5 b}=0.9308_{5}$
${ }^{\prime} N_{8 b}=128.1_{8}$
${ }^{i} N_{6 b}=33.15_{4}$
${ }^{i} N_{7 b}=3.627_{7}$

Sample $\mathrm{C}$

$' N_{5 c}=0.2733_{5}$

$' N_{8 c}=37.64_{0}$

${ }^{i} N_{6 c}=10.30_{5}$

${ }^{i} N_{7 c}=1.442_{3}$

then,

$$
\begin{aligned}
{ }^{\prime} R_{5(a-b)} & =3.068_{3} & { }^{\prime} R_{8(a-b)} & =0.2449_{6} \\
{ }^{\prime} R_{5(a-c)} & =62.88_{3} & { }^{\prime} R_{8(a-c)} & =1.979_{3} \\
\text { and for } t_{1} & =1,350, & f_{2} & =0.5415_{0}
\end{aligned}
$$

Solving equation 40 for $t$,

where

$$
t=\frac{-b \pm \sqrt{b^{2}-4 a c}}{2 a}
$$

$$
\begin{aligned}
2 a & =\left[\lambda_{1}^{2}\left(R_{5(a-c)}-R_{5(a-b)}\right)+\lambda_{2}^{2}\left({ }^{\prime} R_{8(a-b)}-{ }^{\prime} R_{8(a-c)}\right)\right] \\
& =-22.62_{3} \times 10^{-20} y^{-1} \\
b= & {\left[\lambda_{1}\left({ }^{\prime} R_{5(a-c)}-{ }^{\prime} R_{5(a-b)}\right)+\lambda_{2}\left({ }^{\prime} R_{8(a-b)}-^{\prime} R_{8(a-c)}\right)\right] } \\
& =75.06_{8} \times 10^{-10} y^{-1} \\
c & =\left[{ }^{\prime} R_{5(a-b)} R_{8(a-c)}-^{\prime} R_{5(a-c)} R_{8(a-b)}+\right. \\
& \left.f_{1}\left({ }^{\prime} R_{5(a-c)}-{ }^{\prime} R_{5(a-b)}\right)+f_{2}\left({ }^{\prime} R_{8(a-b)}-{ }^{\prime} R_{8(a-c)}\right)\right] \\
& =-10.18_{0} \\
t & =\left[\frac{-75.06_{8} \pm \sqrt{\left(75.06_{8}\right)^{2}-2 \times-22.62_{3} \times-10.18_{0}}}{-22.62_{3}}\right] \\
& =\left[\frac{-75.06_{8} \pm \sqrt{5174.6}}{-22.62_{3}}\right] \times 10^{10} y \\
= & \frac{-75.06_{8}+71.93_{4}}{-22.62_{3}} \times 10^{10} y=0.1385 \times 10^{10} y \\
= & 1,385 \mathrm{~m} . \mathrm{y} .
\end{aligned}
$$

The small discrepancy in the calculated age obtained from equations 36 and 40 is due to the fact that samples $A$ and $C$ are quite similar in isotopic composition. As a result, the difference between ' $N_{5 a}-{ }^{\prime} N_{5 c}$ is very small, $-0.0027_{8}$. This small number appears as the denominator of the term $R_{5(a-c)}$ and consequently affects the final age calculation.

The extent of the departure of equation 40 from the concordant age resulting from the use of values $f_{1}$ and $f_{2}$ for $t_{1}=1,350 \mathrm{~m} . \mathrm{y}$. (from table 2 ) can be determined by comparing $R^{*}{ }_{(a-b)}$ and $R^{*}{ }_{(b-c)}$. Using equations 37 and 38 and $t=.1385 \times 10^{10} y, R^{*}{ }_{(a-b)}$ and $R^{*}{ }_{(a-c)}$ are respectively $0.2159_{3}$ and 0.2333 . At $t=1,400$ m.y., $R^{*}{ }_{(a-b)}$ and $R^{*}{ }_{(a-c)}$ are $0.2498_{5}$ and $0.2500_{4}$ as compared with the value $R^{*}=0.2500_{4}$ given on page E21.

For many geological problems the age, $t=1,385 \mathrm{~m} . \mathrm{y}$., would be acceptable. This age could then be reported for the assumption that the trial age discordancies were a result of an incorrect common lead correction and a failure to include a correction for original radiogenic lead. If, however, an additional refinement in the age is required, new values must be chosen for $f_{1}$ and $f_{2}$ from table 2 where $t_{1}$ now lies between the age limits, $1,385<t_{1}<1,480$. Selecting from table 2 values of $f_{1}$ and $f_{2}$ for $t_{1}=1,410$, the recalculated age using equation 40 is $t=1,408$ m.y. As this recalculated age now lies close to but below $t_{1}=1,410$, the concordant age must fall between 1,408 and 1,385 m.y. The relatively close agreement between the recalculated $t$ and the second choice for $t_{1}$ would suggest that for most geological problems an additional age calculation would be unnecessary. The final age would be rounded down from 1,408 m.y. to the nearest $5 \mathrm{~m}$.y. and reported as $t=1,405 \mathrm{~m} . \mathrm{y}$. As has been mentioned, the lead-uranium ratios used in the example on page E21 were chosen for $t=1,400 \mathrm{~m}$.y.

For certain geologic problems however, it may be desirable or necessary to evaluate further the assumption that the discordant trial ages are a consequence of errors in the correction made for the lead originally present in a group of related-age samples. If sufficient isotopic data are available from the area, it may be possible to compare the measured $\mathrm{Pb}^{207} / \mathrm{Pb}^{206}$ ratio of the lead extracted from associated radiogenically enriched nonradioactive minerals with the calculated $R^{*}$. In addition, the measured $\mathrm{Pb}^{206} / \mathrm{Pb}^{204}$ and $\mathrm{Pb}^{207} / \mathrm{Pb}^{204}$ (or $\mathrm{Pb}^{206} / \mathrm{Pb}^{208}$ and $\mathrm{Pb}^{207} / \mathrm{Pb}^{208}$ ) ratios of the lead extracted from the associated nonradioactive minerals and the calculated ' $N_{6 a}^{c *}$, ' $N_{7 a}^{c *}$ ratios (eq. 30, 31) can be plotted on the same graph. If the calculated $R^{*}$ and measured $\mathrm{Pb}^{207} / \mathrm{Pb}^{206}$ ratios are in reasonable agreement, and if the calculated ' $N_{6}^{c *}$ and ' $N_{7}^{c *}$ lie on the same line as the measured $\mathrm{Pb}^{206} / \mathrm{Pb}^{204}$ and $\mathrm{Pb}^{207} /$ $\mathrm{Pb}^{206}$ ratios, these facts may be used as additional 
evidence for the evaluation of the discordant trial ages in terms of original radiogenic lead.

To calculate ' $N_{6}^{c *}$ and ' $N_{7}^{c *}$ it is first necessary to find the value of $t$ such that $t$ approximates very closely $t_{1}$, or $R_{(a-b)}^{*}=R_{(a-c)}^{*}$. If computing facilities are not available, additional recalculations using equation 40 must be made.

Accepting the exact solution of equation 39 or 40 as $t=1,400$ m.y., equation 37 may be used to obtain $R^{*}$ and equation 30 to calculate ' $N_{6}^{c *}$. For sample $A$, the value of ' $N_{6 a}^{c *}$ is $1.941_{8}$. Equation 31 is used to calculate' $N_{7 a}^{c *}$, and the value obtained is $0.8180_{4}$. Similarly, for samples $B$ and $C,{ }^{\prime} N_{6 b}^{c *},{ }^{\prime} N_{7 b}^{c *},{ }^{c *} N_{6 c}^{c *}$, and ' $N_{7 c}^{c *}$ are respectively, $2.381_{6}, 0.9280_{7}, 1.268_{5}$, and $0.6495_{7}$. These values may be used to calculate the isotopic composition of the lead originally present in the samples and may now be plotted on the same graph with the measured $\mathrm{Pb}^{206} /$ $\mathrm{Pb}^{204}$ and $\mathrm{Pb}^{207} / \mathrm{Pb}^{204}$ ratios of the lead extracted from the associated nonradioactive minerals.

If the $\mathrm{Pb}^{207} / \mathrm{Pb}^{206}$ ratio, $R^{c}$, of the common lead is known from independent sources or is assumed, the amounts of common lead in the radioactive sample can be calculated fron the relation,

$$
{ }^{\prime} N_{6 a}^{c}=\frac{{ }^{\prime} N_{7 a}^{c *}-R^{*}{ }^{\prime} N_{6 a}^{c *}}{R^{c}-R^{*}}
$$

Knowing ' $N_{6 a}^{c}$ and $R^{c}$, it is now possible to obtain ' $N_{7 a}^{c}$, as well as ' $N_{6 a}^{*}$ and ' $N_{7 a}^{*}$. Finally, using $\mathrm{Pb}^{208}=1.0000$ and the $\mathrm{Pb}^{204} / \mathrm{Pb}^{208}$ ratio from the original isotopic analyses, the isotopic composition of the common lead may be calculated.

Thus, from the chemical and isotopic data on three closely related but unaltered radioactive samples that yield discordant trial ages, it is possible to calculate a single concordant age, $t$, without knowledge of either the amounts or the ratio of the common and original radiogenic lead assumed to be present in the sample. In addition, the ratio of the original radiogenic lead required to produce such a concordant age may be calculated as well as the isotopic composition of the lead originally present in the samples. These results combined with calculated ages obtained using other assumptions, additional isotopic data, and the field mineralogic relations, can then be used in the final evaluation of the age data.

\section{GRAPHIC SOLUTION}

The graphical concordant ages obtained by using normalized difference plots for not less than three samples, $C, D$, and $E$, formed at the same time, are shown in figure 4. Assuming, in addition, that the samples contain different amounts of lead and uranium and were contaminated by a common lead having a uniform $\mathrm{Pb}^{207} / \mathrm{Pb}^{206}$ ratio, a line passing through the coordinates of the points $(C-D)$ and $(C-E)$ cuts the concordant age curve at $t$ and $t_{1}$. The slope of the line passing through $(C-D)$ and $(C-E)$, divided by 137.7, is equal to $R^{*}$, the $\mathrm{Pb}^{207} / \mathrm{Pb}^{206}$ ratio of the radiogenic lead lost or added at the time, $t$. The concordant age, $t$, is the age that would be obtained after correcting for the addition of an older generation of radiogenic lead formed, perhaps, in the time interval $t-t_{1}$. The concordant age, $t_{1}$, would correspond to the correction of samples $C, D$, and $E$ for loss or gain of lead or uranium at one time in the past, $t$. Thus it is possible to obtain graphically concordant ages for a suite of at least three cogenetic uranium-bearing minerals without knowledge of either the amount or isotopic composition of the contaminating common lead, and either the effects of a single period of alteration or the presence of a yet older generation of radiogenic lead.

\section{GENERAL EQUATIONS}

The preceding discussion has been specifically directed at the problem of evaluating discordant leaduranium ages. Several of the equations that have been developed can be generalized, however, to aid in the evaluation of other types of discordant age pairs such as $\mathrm{Pb}^{206} / \mathrm{U}^{238}-\mathrm{Pb}^{208} / \mathrm{Th}^{232}$ and $\mathrm{Pb}^{207} / \mathrm{U}^{235}-\mathrm{Pb}^{208} /$ $\mathrm{Th}^{232}$. Under certain limited conditions there is the possibility that the general form of the equations can be applied to such discordant age pairs as $\mathrm{Pb}^{206} / \mathrm{U}^{238}$ $\mathrm{Sr}^{87} / \mathrm{Rb}^{87}, \mathrm{~Pb}^{208} / \mathrm{Th}^{232}-\mathrm{Sr}^{87} / \mathrm{Rb}^{87}$, and perhaps others. It is not necessary for these pairs of radioactive parents and their stable daughter products to have been derived from the same radioactive mineral, although it is necessary for the minerals and their geochronologic elements to meet the general conditions enumerated for the lead-uranium systems considered above.

An examination of the equations derived for the lead-uranium system suggests that the most useful general equations are those concerned with the correction for contamination by a common stable isotope which is indistinguishable from the stable daughter product produced by radioactive decay deposited at the time of mineral formation. The assumption for either the $\mathrm{Pb}-\mathrm{U}^{235}, \mathrm{Th}^{232}$ or $\mathrm{Pb}-\mathrm{U}^{238}, \mathrm{Th}^{232}$ systems that the same ratio of common daughters, $R_{a}^{c}=R_{b}^{c}$, is present originally in two or more cogenetic mineral samples is geologically acceptable. The assumption, however, for other discordant age pairs that two or more cogenetic minerals would necessarily be originally contaminated by two radiogenically enriched components whose ratios were the same, that is, $R_{a}^{*}=R_{b}^{*}$, does not appear to be geologically justified. In the $\mathrm{Pb}-\mathrm{U}$ system the ratio of the parents of $\mathrm{Pb}^{206}$ and $\mathrm{Pb}^{207}, \mathrm{U}^{238}$ and $\mathrm{U}^{235}$, are known to be essentially constant. The obvious possibility of local variations in 
the ratios of the concentrations of other radioactive parents such as $U$ and Th, or even $U$ and $R b$ could easily result in small local variations in the ratios of the radiogenic daughter products available to the solutions from which the new minerals were formed.

Equations 11, 12, 16, and 17 can be easily converted to the general form by making, where appropriate, the following changes in notation: $R_{5}=R_{1}, R_{8}=R_{2}, R_{5}=$ $R_{1 t}$, and $R_{8 t}=R_{2 t}$

where $R_{1}=N d_{1} / N p_{1}$, the ratio of the total number of atoms of stable radiogenic daughter product $D_{1}$ after correction (if necessary) for contamination of common $D_{1}^{c}$ originally present to the total number of atoms of radioactive parent, $P_{1}$, now present in the mineral sample, $A_{1}$;

$R_{2}=N d_{2} / N p_{2}$, the ratio of the total number of atoms of a different stable radiogenic daughter product, $D_{2}$, after correction (if necessary) for contamination of common $D_{2}^{c}$ originally present to the total number of atoms of radioactive parent, $P_{2}$, now present in the same mineral sample $A_{1}$ or in a cogenetic mineral sample $A_{2}$;

$R_{1 t}={ }^{t} N d_{1} / N p_{1}$, the ratio of the total number of atoms of stable daughter product, $D_{1}$, to the total number of atoms of radioactive parent, $P_{1}$, now present in the mineral sample $A_{1}$;

$R_{2 t}={ }^{t} N d_{2} / N p_{2}$, the ratio of the total number of atoms of stable daughter product, $D_{2}$, to the total number of atoms of radioactive parent, $P_{2}$, now present in the same mineral sample $A_{1}$ or in a cogenetic mineral sample;

and where $R, R^{*}, R^{c}, \lambda_{1}, \lambda_{2}$, and $t$ are defined as

$R=N p_{1} / N p_{2}$, the ratio of the total number of atoms of the chemically different radioactive parents, $P_{1}$ and $P_{2}$, now present in the same mineral, $A_{1}$, or in a cogenetic pair of minerals, $A_{1}$ and $A_{2}$;

$R^{*}=N^{*} d_{1} / N^{*} d_{2}$, the ratio of the number of atoms of original radiogenic daughter product, $D_{1}^{*}$, present at the time of mineral formation in mineral $A_{1}$ to the number of atoms of original radiogenic daughter product, $D_{2}^{*}$, present at the time of mineral formation in the same mineral $A_{1}$ or a cogenetic mineral, $A_{2}$;

$R^{c}=N^{c} d_{1} / N^{c} d_{2}$, the ratio of the number of atoms of contaminating common daughter product, $D_{1}^{c}$, present at the time of its formation in mineral $A_{1}$ to the number of atoms of contaminating daughter product, $D_{2}^{c}$, present at the time of mineral formation in mineral $A_{1}$ or a cogenetic mineral $A_{2}$;

$\lambda_{1}=$ the decay constant of $P_{1} \times 10^{-10} y^{-1}$;

$\lambda_{2}=$ the decay constant of $P_{2} \times 10^{-10} y^{-1}$;

$\lambda_{1} \neq \lambda_{2}$

$t=$ the age of mineral $A$ and (or) cogenetic mineral $A_{1} \times 10^{10}$ years $\left(t A=t A_{1}\right)$.

The general form of equation 26 cannot be as easily derived because, as has been mentioned, the term $R$ is no longer the same constant for two or more samples, although it is known for each sample. Equation 26 takes the form

$$
\begin{aligned}
& \left(R_{A}-R_{B}\right)\left[\frac{\left(\lambda_{1} \lambda_{2}\right)^{n}}{n ! n !} t^{2 n}+\left(\lambda_{1} \lambda_{2}\right)^{(n-1)}\left(\frac{\lambda_{2}}{(n-1) ! n !}\right.\right. \\
& \left.+\frac{\lambda_{1}}{n !(n-1) !}\right) t^{(2 n-1)}+\left(\lambda_{1} \lambda_{2}\right)^{(n-2)}\left(\frac{\lambda_{2}^{2}}{(n-2) ! n !}\right. \\
& \left.+\frac{\lambda_{1} \lambda_{2}}{(n-1) !(n-1) !}+\frac{\lambda_{1}^{2}}{n !(n-2) !}\right) t^{(2 n-2)}+\ldots \\
& +\left(\lambda_{1} \lambda_{2}\right)\left(\frac{\lambda_{2}{ }^{(n-1)}}{1 ! n !}+\frac{\lambda_{1} \lambda_{2}{ }^{(n-2)}}{2 !(n-1) !}+\cdots+\frac{\lambda_{1}^{(n-2)} \lambda_{2}}{(n-1) ! 2 !}\right. \\
& \left.\left.+\frac{\lambda_{1}^{(n-1)}}{n ! 1 !}\right) t^{(n+1)}\right]+\left[\left(R_{B} R_{2 b}-R_{A} R_{2 a}\right) \lambda_{1}^{n} / n !\right. \\
& +\left(R_{B} R_{1 a}-R_{A} R_{1 b}\right) \lambda_{2}^{n} / n !+\left(R_{A}-R_{B}\right)\left(\lambda_{1} \lambda_{2}\right)\left\{\frac{\lambda_{2}^{(n-2)}}{1 !(n-1) !}\right. \\
& +\frac{\lambda_{1} \lambda_{2}{ }^{(n-3)}}{2 !(n-2) !}+\cdots+\frac{\lambda_{1}{ }^{\left(\frac{n}{2}-3\right)} \lambda_{2}^{\frac{n}{2}}}{(n / 2-1) !(n / 2+1) !} \\
& +\frac{\lambda_{1}^{\left(\frac{n}{2}-1\right)} \lambda_{2}^{\left(\frac{n}{2}-1\right)}}{(n / 2) !(n / 2) !}+\frac{\lambda_{1}^{\frac{n}{2}} \lambda_{2}{ }^{\left(\frac{n}{2}-3\right)}}{(n / 2+1) !(n / 2-1) !}+\ldots \\
& \left.\left.+\frac{\lambda_{1}{ }^{(n-3)} \lambda_{2}}{(n-2) ! 2 !}+\frac{\lambda_{1}{ }^{(n-2)}}{(n-1) ! 1 !}\right\}\right] t^{n}+\ldots \\
& +\left[\left(R_{B} R_{2 b}-R_{A} R_{2 a}\right) \lambda_{1}^{3} / 3 !+\left(R_{B} R_{1 a}-R_{A} R_{1 b}\right) \lambda_{2}^{3} / 3 !\right. \\
& \left.+\left(\lambda_{1} / 2 !+\lambda_{2} / 2 !\right)\left(R_{A}-R_{B}\right)\left(\lambda_{1} \lambda_{2}\right)\right] t^{3} \\
& +\left[\left(R_{B} R_{2 b}-R_{A} R_{2 a}\right) \lambda_{1}^{2} / 2 !+\left(R_{B} R_{1 a}-R_{A} R_{1 b}\right) \lambda_{2}^{2} / 2 !\right. \\
& \left.+\left(R_{A}-R_{B}\right) \lambda_{1} \lambda_{2}\right] t^{2}+\left[\left(R_{B} R_{2 b}-R_{A} R_{2 a}\right) \lambda_{1}\right. \\
& \left.+\left(R_{B} R_{1 a}-R_{A} R_{1 b}\right) \lambda_{2}\right] t+R_{A} R_{1 b} R_{2 a}-R_{B} R_{1 a} R_{2 b}=0 .
\end{aligned}
$$

where $R_{A}=N p_{1 a} / N p_{2 a}$, the ratio of the total number of the chemically different radioactive parents, $P_{1 a}$ and $P_{2 a}$, now present in the same mineral $A$ or in a cogenetic pair of minerals $A_{1}$ and $A_{2}$; 
$R_{B}=N p_{1 b} / N p_{2 b}$, the ratio of the total number of atoms of the chemically different radioactive parents, $P_{1 b}$ and $P_{2 b}$ now present in the same mineral $B$ or in a cogenetic pair of minerals $B_{1}$ and $B_{2}$;

$R_{1 a}=N d_{1 a} / N p_{1 a}$, the ratio of the total number of atoms of stable daughter product, $D_{1 a}$, to the total number of atoms of radioactive parent, $P_{1 a}$, now present in mineral sample $A_{1}$

$R_{2 a}=N d_{2 a} / N p_{2 a}$, the ratio of the total number of atoms of stable daughter product, $D_{2 a}$, to the total number of atoms of radioactive parent, $P_{2 a}$, now present in mineral sample $A_{1}$ or in a cogenetic mineral sample $A_{2}$;

$R_{1 b}=N d_{1 b} / N p_{1 b}$, the ratio of the total number of atoms of stable daughter product, $D_{1 b}$, to the total number of atoms of radioactive parent, $P_{1 b}$, now present in mineral sample $B_{1}$;

$R_{2 b}=N d_{2 b} / N p_{2 b}$, the ratio of the total number of atoms of stable daughter product, $D_{2 b}$, to the total number of atoms of radioactive parent, $P_{2 b}$, now present in mineral sample $B_{1}$ or in a cogenetic mineral sample $B_{2}$;

$\lambda_{1}=$ decay constant of $P_{1 a}$ and $P_{1 b} \times 10^{-10} y^{-1}$;

$\lambda_{2}=$ decay constant of $P_{2 a}$ and $P_{2 b} \times 10^{-10} y^{-1}$;

$t=$ the age of the mineral pair $A_{1}$ and $B_{1}$ or the pairs of cogenetic minerals $A_{1}, A_{2}$, and $B_{1}$, $B_{2}\left(t A_{1}=t B_{1}\right)$.

\section{REFERENCES CITED}

Ahrens, L. H., 1955a, The convergent lead ages of the oldest monazites and uraninites (Rhodesia, Manitoba, Madagascar, and Transvaal): Geochim. et Cosmochim. Acta, v. 7, p. 294-300.

1955b, Implications of the Rhodesia age pattern: Geochim. et Cosmochim. Acta, v. 8, p. 1-15.

Aldrich, L. T., and Wetherill, G. W., 1958, Geochronology by radioactive decay: Ann. Rev. Nuclear Sci., v. 8, p. 257-298.

Collins, C. B., Farquhar, R. M., and Russell, R. D., 1954, Isotopic constitution of radiogenic leads and the measurement of geologic time: Geol. Soc. America Bull., v. 65, p. 1-21.

Eckelmann, W. R., and Kulp, J. L., 1956, Uranium-lead method of age determination, Part 1: Lake Athabasca problem: Geol. Soc. America Bull., v. 67, p. 35-54.

Gerling, E. K., 1958, Effect of metamorphism on geologic age as determined by the lead method: Geokhimya (Translation) No. 4, p. 363-373.

Giletti, B. J., and Kulp, J. L., 1955, Radon leakage from radioactive minerals: Am. Mineralogist, v. 40 , p. 481-496.

Greenhalgh, D., and Jeffery, P. M., 1959, A contribution to the pre-Cambrian chronology of Australia: Geochim. et Cosmochim. Acta, v. 16, p. 39-57.

Horne, J. E. T., 1957a, Age of a later uraninite from the Witwatersrand: Great Britain Geol. Survey Age Determination Rept. 2, p. 1-4.
Horne, J. E. T. $1957 \mathrm{~b}$, Ages of uraninites from Nkana, Northern Rhodesia and from Shinkolobwe, Belgian Congo: Great Britain Geol. Survey Age Determination Rept. 3, p. 1-3.

Horne, J. E. T., and Davidson, C. F., 1955, The age of the mineralization of the Witwatersrand: Great Britain Geol. Survey Bull. 10, p. 58-73.

Houtermans, F. G., 1946, Die Isotopenhäufigkeiten im natürlichen Blei und das Alter des Urans: Naturwissenschaften, v. 33, p. $185-186$.

-1947, Das Alter des Urans: Zeitschr. Naturforschung, v. $2 \mathrm{a}$, p. $322-328$.

Keevil, N. B., 1939, The calculation of geological age: Am. Jour. Sci., v. 237, p. 195-214.

Kulp, J. L., Bate, G. L., and Broecker, W. S., 1954, Present status of the lead method of age determination: Am. Jour. Sci., v. 252, p. 345-365.

Kulp, J. L., and Eckelmann, R. W., 1957, Diseordant U-Pb ages and mineral type: Am. Mineralogist, v. 42, p. 154-164.

Louw, J. D., and Strelow, F. W. E., 1955, Geological age determinations on Witwatersrand uraninites using the lead-isotope method: South Africa Geol. Soc. Trans., v. 57, p. 209-230.

Robinson, S. C., 1955, Mineralogy of uranium deposits, Goldfields, Saskatchewan: Canada Geol. Survey Bull. 31, n. $1-128$.

Russell, R. D., and Ahrens, L. H., 1957, Additional regularities among discordant lead-uranium ages: Geochim. et Cosmochim. Acta, v. 11, p. 213-218.

Stieff, L. R., and Stern, T. W., 1956, Interpretation of the discordant age sequence of uranium ores, in Page, L. R., and others, compilers, Contributions to the geology of uranium and thorium by the U.S. Geological Survey and Atomic Energy Commission for the United Nations International Conference on Peaceful Uses of Atomic Energy, Geneva, Switzerland, 1955: U.S. Geol. Survey Prof. Paper 300, p. 549-555.

- 1961, Graphic and algebraic solutions of the discordant lead-uranium age problem: Geochim. et Cosmochim. Acta, v. 22 , p. $176-199$.

Stieff, L. R., Stern, T. W., and Milkey, R. G., 1953, A preliminary determination of the age of some uranium ores of the Colorado Plateau by the lead-uranium method: U.S. Geol. Survey Circ. 271, p. 1-19.

Stieff, L. R., Stern, T. W., Oshiro, Seiki, and Senftle, F. E., 1959, Tables for the calculation of lead isotope ages: U.S. Geol. Survey Prof. Paper 334-A, p. 1-40.

Tilton, G. R., 1960, Volume diffusion as a mechanism for discordant lead ages: Jour. Geophys. Research, v. 65, p. 2933-2945.

Tugarinov, A. I., 1954, Reliability of the absolute age of uranium minerals from the ratio of lead isotopes: Akad. Nauk SSSR Doklady, v. 99, p. 1061-1063.

Wetherill, G. W., 1956, Discordant uranium-lead ages, I: Am. Geophys. Union Trans., v. 37, p. 320-326.

Wickman, F. E., 1939, Some graphs on the calculation of geological age: Sveriges Geol. Undersökning Årsbok, v. 33, no. 7, p. 1-8.

- 1942, On the emanating power and the measurement of geological time: Geol. Fören. Stockholm Förh., v. 64, p. 465-476.

1955, Leakage of uranium and lead and the measurement of geologic time, in Nuclear Processes in Geologic Setting: Natl. Acad. Sci.-Natl. Research Council Publ. 400, p. 62. 
